\title{
$1 \quad$ Martensite-to-austenite reversion and recrystallization in cryogenically-rolled type 321 metastable austenitic steel
}

3

4 A. Aletdinov ${ }^{1}$, S. Mironov ${ }^{2 *}$, G.F. Korznikova ${ }^{1}$, T. Konkova ${ }^{1,3}$, R.G. Zaripova ${ }^{4}$, 5 M.M. Myshlyaev ${ }^{5,6}$, and S.L. Semiatin ${ }^{7}$

6

$7^{1}$ Institute for Metals Superplasticity Problems, Russian Academy of Science, 39 Khalturin Str., Ufa, 450001, Russia $8^{2}$ Belgorod National Research University, Pobeda 85, Belgorod 308015, Russia

$9^{3}$ University of Strathclyde, 75 Montrose Street, Glasgow, G1 1XJ, United Kingdom

$10^{4}$ Ufa State Aviation Technical University, 12 K. Marx St., Ufa 450000, Russia

$11^{5}$ Baikov Institute of Metallurgy and Material Science, Russian Academy of Science, 49 Lenin-av., Moscow 119991, Russia $12^{6}$ Institute of Solid State Physics, Russian Academy of Sciences, 2 Academic Osypian Str., Chernogolovka, Moscow Oblast 13 142432, Russia

$14^{7}$ Air Force Research Laboratory, Materials and Manufacturing Directorate, AFRL/RXCM, Wright-Patterson AFB, OH 15 45433-7817, USA

16

The annealing behavior of cryogenically-rolled type 321 metastable austenitic steel was established. Cryogenic deformation gave rise to martensitic transformation which developed preferentially within deformation bands. Subsequent annealing in the range of $600-700^{\circ} \mathrm{C}$ resulted in reversion of the strain-induced martensite to austenite. At $800^{\circ} \mathrm{C}$, the reversion was followed by static recrystallization. At relatively-low temperatures, the reversion was characterized by a very strong variant selection, which led to the restoration of the crystallographic orientation of the coarse parent austenite grains. An increase in the annealing temperature relaxed the variant-selection tendency and provided subsequent recrystallization thus leading to significant grain refinement. Nevertheless, a significant portion of the original coarse grains was found to be untransformed and therefore the fine-grain structure was fairly heterogeneous.

Keywords: Ultrafine-grain materials; Metastable austenitic steel; Cryogenic deformation; Martensite-to-austenite reversion; Recrystallization; Microstructure; Electron backscatter diffraction (EBSD)

\section{Introduction}

The possibility of significant improvement in mechanical properties has prompted considerable interest in the development of ultrafine-grain materials. Typically, this is achieved by the application of severe-plastic-deformation techniques [1], but such methods are often laborious and difficult to apply for the fabrication of commercial-scale products. For metastable austenitic steels, however, the ultrafine-grain structure may be produced by conventional cold rolling followed by annealing. This approach is based on a strain-induced martensitic transformation during cold 
deformation and subsequent martensite-to-austenite reversion during heat treatment and is sometimes referred to as an "advanced" thermomechanical process [2].

Extensive research over a 25 -year period has demonstrated the remarkable complexity of microstructural changes involved in this processing route. During the deformation step, the nucleation of strain-induced martensite has been reported to occur at dislocation pile-ups [3-6], mechanical twins [7-12], or deformation bands [3, 5, 7, 12-14]. The austenitic and martensitic phases are typically found to be related through a Kurdjumov-Sachs (K-S) orientation relationship, viz., $\{111\}_{\gamma} \|\{110\}_{\alpha^{\prime}}$ and $\left\langle 110>_{\gamma} \|<111\right\rangle_{\alpha^{\prime}}[3,5,7,12,14-16]$, although substantial deviations are sometimes observed [11]. The phase transformation may also involve the formation of a transient $\varepsilon$-martensite phase, i.e., it may develop via a $\gamma \rightarrow \varepsilon \rightarrow \alpha^{\prime}$ transformation sequence $[3,5,7,8,13,14$, 17]. The size of the strain-induced martensitic particles is usually reported to be in the nanoscale range [7-12, 14, 17-22].

During subsequent annealing, reversion back to austenite may be governed by two different mechanisms, i.e., athermal (martensitic) shear or thermally-activated diffusion [23]. The activation of a particular mechanism is believed to be dependent on the specific chemical composition of the material and temperature [24] as well as the heating rate [25]. Sometimes, both mechanisms may operate concurrently $[11,26]$. In the case of the shear mechanism, the reverse transformation typically follows the K-S relation [11, 23, 27-32]. Moreover, the crystallographic orientation of the newly-formed austenite may be nearly identical to that of the parent (prior-austenite) grain [23, 27, 28, 31-36]. This austenite "memory" effect is sometimes attributed to strong variant selection during the phase transformation [27, 32], as well as to a relief of residual stress [32]. The shear reversion mechanism is also characterized by a high dislocation density [23, 24, 28, 33, 34, 37] which arises from the retention of dislocation substructure within the martensitic phase as well as that generated during reversion [34]. In the case of the diffusional mechanism, no clear orientation relationship between the new austenite and the martensite is found [23]. However, multiple new orientations produced by reversion can result in grain refinement [11, 23, 27, 32-36]. At high annealing temperatures, reversion may also be followed by static recrystallization [23, 26, 35, 38].

It is also sometimes believed that lower deformation temperatures may enhance the grain-refinement efficiency of advanced thermomechanical processing. Specifically, lower temperatures should increase the driving force for both martensitic transformation during the deformation step as well as that for reversion and recrystallization during subsequent annealing. In view of potential property benefits with regard to microstructure refinement for commercial scale sheet products, the processing of metastable austenitic steels at cryogenic temperatures has attracted significant interest recently [8, 19, 20, 31, 39, 40].

The work reported herein is part of wide-ranging research project whose overall aim has been to evaluate the efficiency of advanced thermomechanical processing utilizing cryogenic deformation for refinement of the grain structure in type 321 metastable austenitic steel. The microstructural response of this material to conventional thermal mechanical processing has been described in a number of recent reports [41-43]. It has been shown that rolling to a 90 pct. thickness reduction at ambient temperature results in the formation of a microstructure with 50 pct. martensite 
[41]. Subsequent reversion during annealing gave rise to a bimodal structure consisting of fine-grain reverted austenite and relatively coarse-grain remnants of untransformed austenite [41]. Such a bimodal microstructure provided an excellent combination of strength and ductility [41]. Furthermore, a lowering of the rolling temperature to $-20^{\circ} \mathrm{C}$ has been shown to significantly enhance strain-induced martensitic transformation and thus promote a finer austenite grain size in the final reverted microstructure [42].

In a previous investigation of type 321 metastable austenitic steel [44], the specific effect of cryogenic rolling on microstructure and texture evolution was examined. The current paper is focused on the post-rolling annealing behavior of cryogenically-rolled material.

\section{Material and Experimental Procedures}

The program material comprised type 321 metastable austenitic stainless steel with nominal $^{\dagger}$ chemical composition shown in Table 1 . The initial material was rolled to $85 \%$ thickness reduction at $950^{\circ} \mathrm{C}$ and then annealed at $1200^{\circ} \mathrm{C}$ for 1 hour, thereby producing a fully-recrystallized austenitic grain structure with a mean grain size of $\sim 100 \mu \mathrm{m}$. The preprocessed material was then cryogenically rolled to $30 \%$ overall thickness reduction (true strain $=-0.36$ ). The reduction was performed in a single pass using a rolling speed of $160 \mathrm{~mm} / \mathrm{s}$ in a cluster mill with $65-\mathrm{mm}$-diameter work rolls. Higher reductions were found to lead to significant (undesirable) deformation heating and roll-separating forces which exceeded the capacity of the laboratory equipment. To provide cryogenic deformation conditions, the rolling preform was soaked in liquid nitrogen and held for 15 minutes prior to rolling. The typical flat-rolling convention was adopted in this work; i.e., the rolling, long-transverse, and thickness/normal directions were denoted as RD, TD, and ND, respectively.

To evaluate the temperature range for the martensite-to-austenite reversion and recrystallization, microhardness measurements were performed. Vickers microhardness values were determined by applying a load of $1 \mathrm{~kg}$ for $10 \mathrm{~s}$. For each material condition studied, 50 measurements were made to obtain an average value.

Based on the results of these preliminary experiments, nine temperatures were selected for detailed microstructural examinations: $400^{\circ} \mathrm{C}\left(0.34 \mathrm{~T}_{\mathrm{m}}\right.$, where $\mathrm{T}_{\mathrm{m}}$ is the melting point), $500^{\circ} \mathrm{C}$ $\left(0.39 \mathrm{~T}_{\mathrm{m}}\right), 550^{\circ} \mathrm{C}\left(0.42 \mathrm{~T}_{\mathrm{m}}\right), 600^{\circ} \mathrm{C}\left(0.44 \mathrm{~T}_{\mathrm{m}}\right), 620^{\circ} \mathrm{C}\left(0.45 \mathrm{~T}_{\mathrm{m}}\right), 650^{\circ} \mathrm{C}\left(0.47 \mathrm{~T}_{\mathrm{m}}\right), 670^{\circ} \mathrm{C}\left(0.48 \mathrm{~T}_{\mathrm{m}}\right)$, $700^{\circ} \mathrm{C}\left(0.49 \mathrm{~T}_{\mathrm{m}}\right)$, and $800^{\circ} \mathrm{C}(0.54 \mathrm{~T} \mathrm{~m})$. In all cases, cryo-rolled specimens were heated to the particular temperature at a rate of $\sim 10 \mathrm{~K} / \mathrm{s}$, held for $1 \mathrm{~h}$, and then water quenched.

Microstructural characterization was performed on the mid-thickness rolling plane (i.e., RD-TD plane) via electron backscatter diffraction (EBSD). For this purpose, samples were prepared using conventional metallographic techniques followed by electropolishing in a solution comprising $95 \%$ acetic acid and $5 \%$ perchloric acid using an applied potential of $60 \mathrm{~V}$. For EBSD, a JSM-7800F field-emission-gun scanning-electron microscope (FEG-SEM) operating at an accelerating voltage of $25 \mathrm{kV}$ and a TSL OIM ${ }^{\mathrm{TM}}$ system were employed.

To examine the microstructure at different length scales, several EBSD maps were acquired for each material condition. Low-resolution (overview) maps were obtained using a scan step size

\footnotetext{
${ }^{\dagger}$ According to Russian industrial standard
} 
of ether 1 or $2 \mu \mathrm{m}$; higher-resolution maps were acquired using a scan step size of either 50 or 100 $\mathrm{nm}$. The statistics of EBSD measurements are summarized in supplementary Table $\mathrm{S}-1^{\ddagger}$. For each diffraction pattern, seven Kikuchi bands were used to minimize indexing error. The $\alpha^{\prime}$-martensite was indexed as a body-centered-cubic phase; this approach is believed to be feasible for EBSD of steels [45]. To ensure reliability of the data, all grains comprising two or fewer pixels were automatically "cleaned" from the maps using the grain-dilation option in the OIM ${ }^{\mathrm{TM}}$ software. Furthermore, to eliminate spurious boundaries caused by orientation noise, a lower-limit boundary-misorientation cut-off of $2^{\circ}$ was employed. A $15^{\circ}$ criterion was applied to differentiate low-angle boundaries (LABs) from high-angle boundaries (HABs).

Interpretation of microstructural changes was assisted by thermodynamic calculations derived using ThermoCalc software with the TCFe9 database.

\section{Results and Discussion}

\subsection{Preliminary analysis}

\subsubsection{Microhardness measurements}

The effect of annealing temperature on the room-temperature microhardness (Fig. 1) showed a noticeable amount $(\sim 15 \%)$ of hardening at $400^{\circ} \mathrm{C}$. ThermoCalc calculations predicted the nucleation of $\mathrm{CrC}$ and $\mathrm{Ni}_{3} \mathrm{Ti}$ phases at this temperature (Figs. 2a and b, respectively), which perhaps explains this surprising effect. At present, however, the precipitation of the particles has not been confirmed experimentally and therefore requires further study.

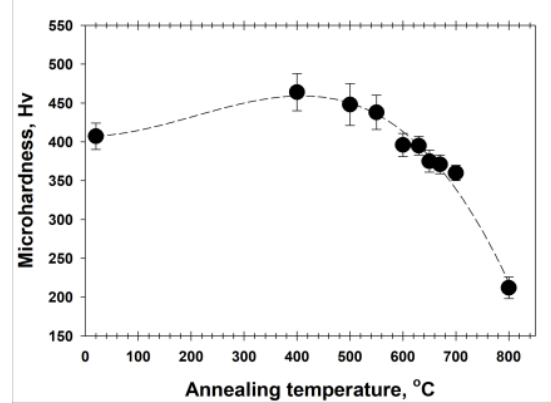

Figure 1. Effect of annealing temperature on microhardness. In all cases, annealing time was $1 \mathrm{~h}$. Note: Error bars show standard deviation.
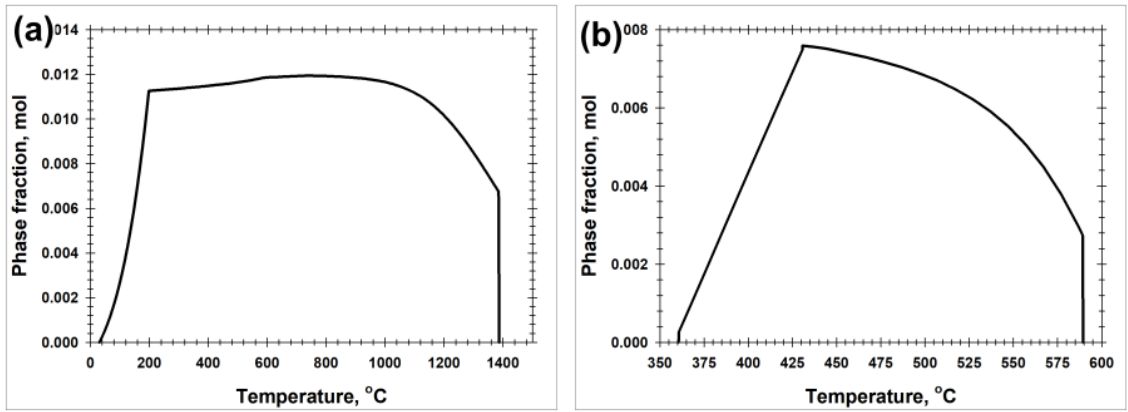

Figure 2. ThermoCalc predictions of the temperature dependence of the volume fraction of (a) $\mathrm{CrC}$ and (b) $\mathrm{Ni}_{3} \mathrm{Ti}$ particles.

‡ Refer to electronic supplementary material 
At temperatures in excess of $550^{\circ} \mathrm{C}$, rapid material softening was found, which likely indicates the martensite-to-austenite reversion.

\subsubsection{EBSD examination}

Representative examples of low-resolution (overview) phase maps of the cryo-rolled and annealed materials are summarized in Fig. 3. The material in the as-rolled condition (Fig. 3a) contained a significant fraction of martensitic phases. The measured content of $\alpha^{\prime}$ - and $\varepsilon$-martensite was $\sim 35$ pct. and $\sim 3$ pct., respectively. However, considering the relatively-coarse scan step size $(1 \mu \mathrm{m})$ as well as the very fine nature of the martensitic phases, the measured fractions were presumably underestimated.
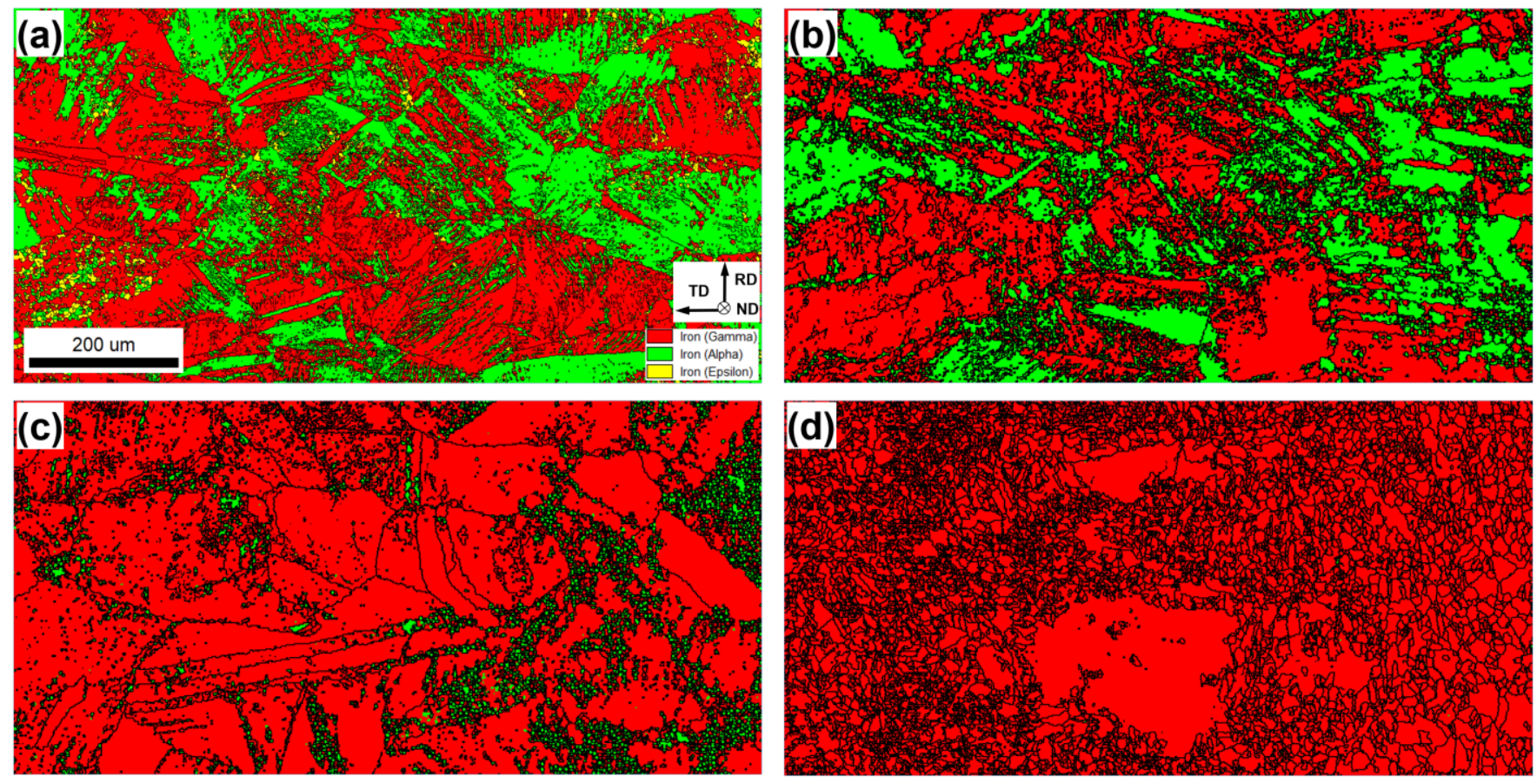

Figure 3. Selected portions of low-resolution EBSD phase maps showing microstructure (a) after cryogenic rolling, and after subsequent annealing at (b) $400^{\circ} \mathrm{C}$, (c) $600^{\circ} \mathrm{C}$, and (d) $800^{\circ} \mathrm{C}$; in all cases, annealing time was $1 \mathrm{~h}$. The phase color code is shown in the bottom right corner of (a); black lines depict HABs. RD, ND and TD denote the rolling direction, normal direction and transverse direction, respectively.

Subsequent annealing of the cryo-rolled material at $400^{\circ} \mathrm{C}$ resulted in dissolution of $\varepsilon$-martensite (Fig. 3b). This was consistent with the well-known low thermal stability of this phase, which transforms into austenite at relatively-low annealing temperatures [38, 46]. Moreover, the $\varepsilon$ $\rightarrow \gamma$ transformation is believed to be governed by a shear mechanism [38], which should generate dislocations [46], and thus contributed to the strengthening observed at $400^{\circ} \mathrm{C}$ (Fig. 1b). On the other hand, the fraction of $\alpha^{\prime}$ martensite did not change noticeably (compare Figs. $3 a \& b$ ).

At $600^{\circ} \mathrm{C}$, the fraction of $\alpha^{\prime}$ martensite was reduced to $\sim 10$ pct. (Fig. 3c) thus providing evidence of reversion to austenite; this observation was in line with material softening at this temperature (Fig. 1). Equally important, austenite reversion did not result in significant grain refinement in the austenitic phase but provided rather a reconstruction of the parent austenite grains (Fig. 3c); this behavior is discussed in more detail in Section 3.2. 
Surprisingly, the reversion process led to a marked refinement of the remaining $\alpha^{\prime}$ martensite (Figs. 3b vs 3c); moreover, EBSD measurements revealed considerable reduction of orientation spread in this phase (supplementary Fig. S-1). These observations indicated that the martensitic phase may have experienced substantial change prior to the reversion into austenite. However, the limited statistics of the measurements in the $\alpha^{\prime}$ martensite at this annealing temperature prevented a convincing conclusion to be drawn.

A further increase in annealing temperature to $800^{\circ} \mathrm{C}$ led to almost complete disappearance of the $\alpha^{\prime}$ martensite and significantly reduced the austenite grain size (Fig. $3 d$ ). The latter observation suggested a recrystallization process.

Based on the broad analysis in this section, therefore, two temperature ranges were selected for detailed microstructural examination: $600-700^{\circ} \mathrm{C}$ (i.e., martensite-to-austenite reversion) and $800^{\circ} \mathrm{C}$ (i.e., the suggested recrystallization).

\subsection{Martensite-to-austenite reversion}

\subsubsection{Broad aspects of the process}

To investigate the martensite-to-austenite-reversion process, the microstructures of specimens annealed in the range of $600-700^{\circ} \mathrm{C}$ were examined in greater detail. In EBSD inverse-pole-figure (orientation) maps from as-rolled and annealed materials (e.g., Fig. 4), austenite grains were colored according to their crystallographic orientations relative to the ND, and HABs were depicted as black lines. Black clusters represented martensitic phases.
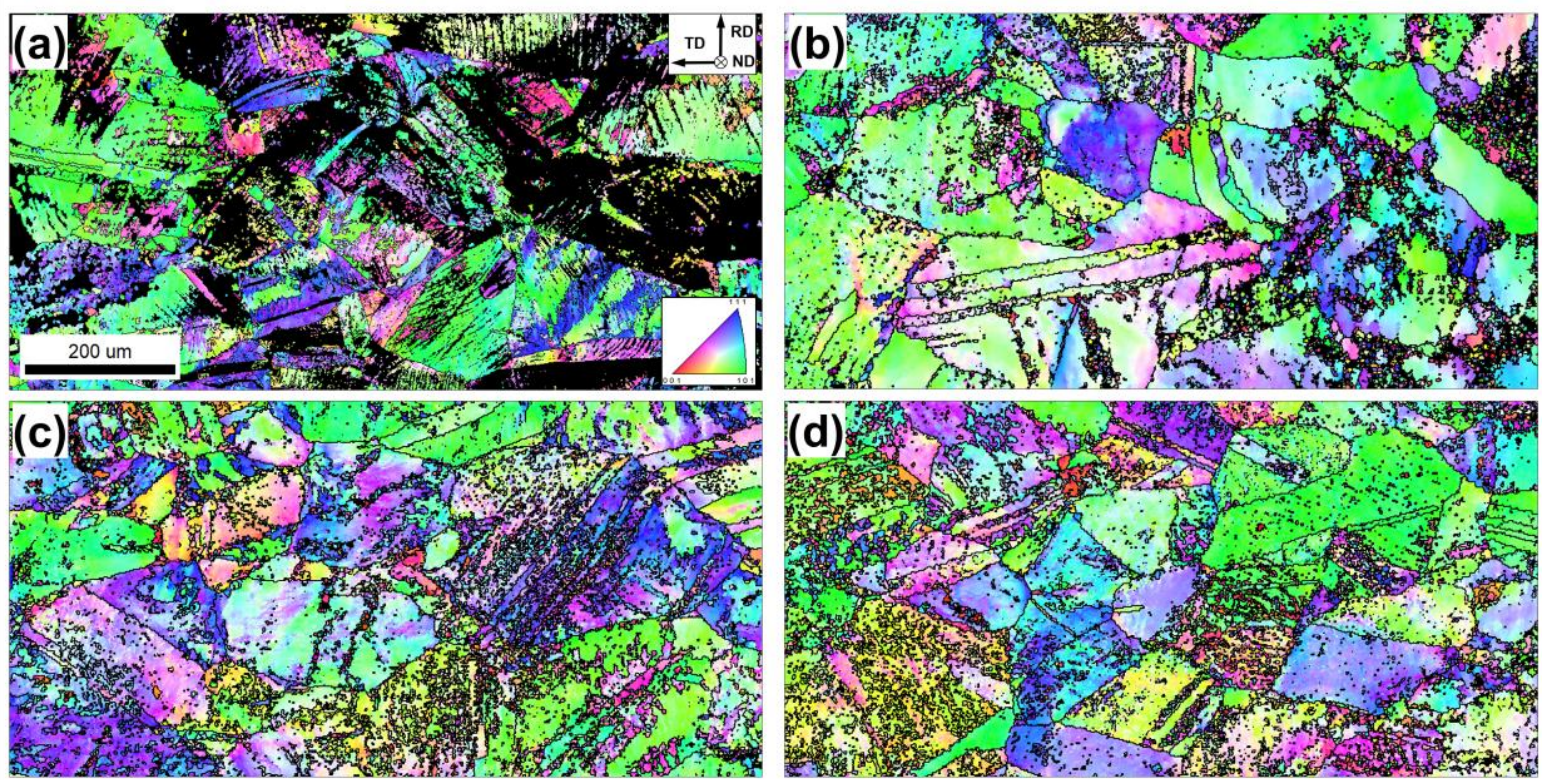

Figure 4. Selected portions of low-resolution EBSD orientation maps showing austenite microstructure (a) after cryogenic rolling and after subsequent annealing at (b) $600^{\circ} \mathrm{C}$, (c) $650^{\circ} \mathrm{C}$, and (d) $700^{\circ} \mathrm{C}$; in all cases, annealing time was $1 \mathrm{~h}$. In the maps, individual grains are colored according to their crystallographic orientation relative to ND; the color code triangle is shown in the bottom right corner of (a). HABs are depicted as black lines. Note: black clusters show the martensitic phase. 
In the cryogenically-rolled condition (Fig. 4a), the remnants of the original coarse-grain austenite structure were clearly seen. In the authors' previous work [44], the relatively-slow kinetics of grain refinement in austenite was attributed to a martensitic transformation occurring in the most-heavily-strained areas; this suppressed the normal development of deformation-induced boundaries in the austenitic phase.

Martensite-to-austenite reversion at relatively-low temperatures also provided only limited grain refinement (Fig. 4b). The orientation map clearly demonstrated that reversion resulted by and large in essentially a reconstruction of the original coarse austenite grains, as suggested in the previous section. On the other hand, an increase of the reversion temperature enhanced grain refinement (see Figs. 4b vs $4 c-d$ ).
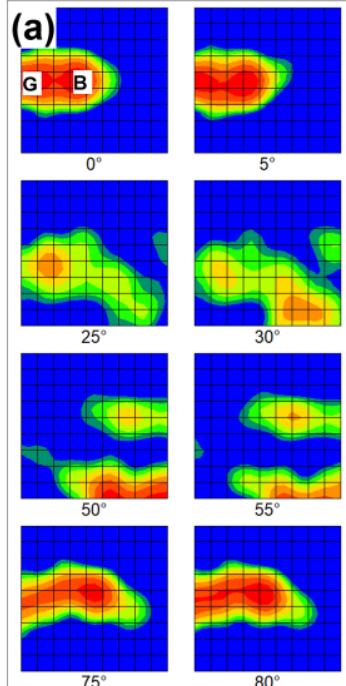

Texture Name: Harmonic: $L=16, \mathrm{HW}=5.0$ Calculation Method. Harmonic Series Expansion Series Rank (1): 16 Gaussian Smoothing: $5.0^{\circ}$ Sample Symmetry. Orthotropic
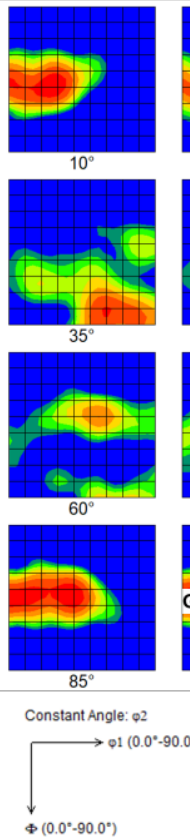
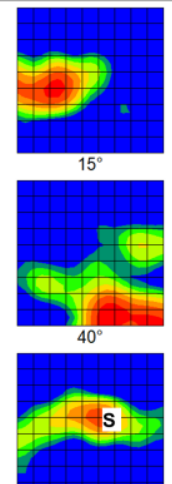

$65^{\circ}$
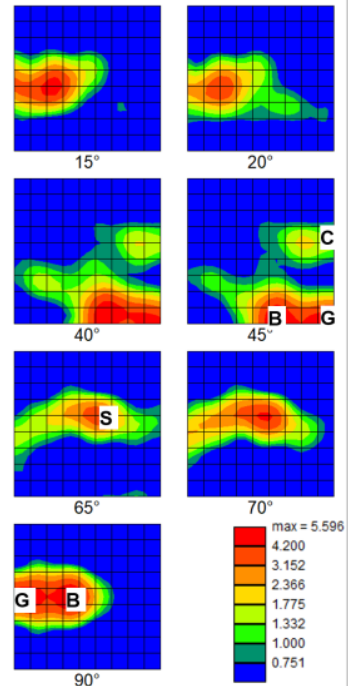

$B=\{110\}<112>$ Brass
$G=\{110\}<100>$ Goss
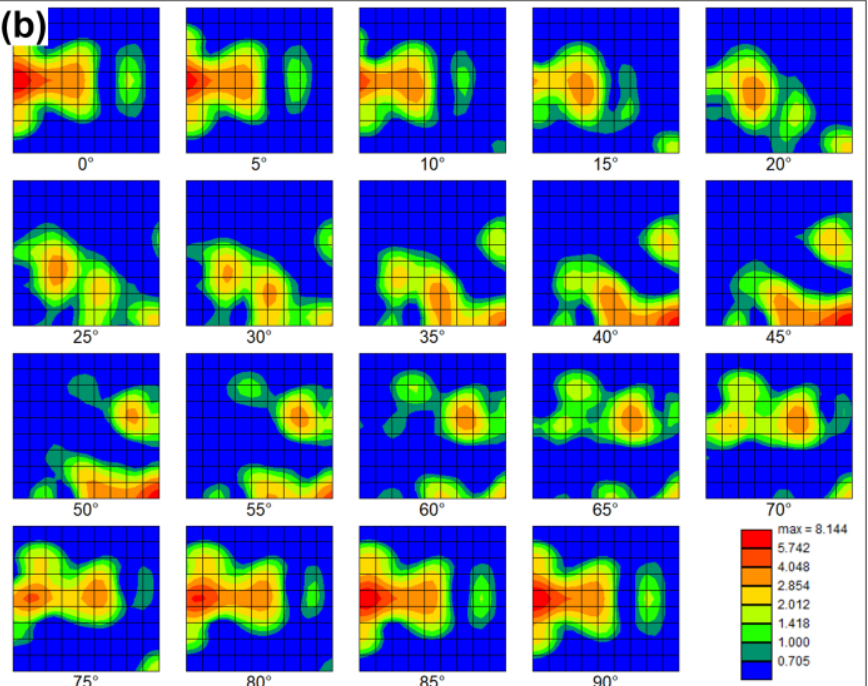

$C=\{112\}<111>$ Copper

$S=\{123\}<634>S$

Figure 5. Orientation distribution functions showing texture in austenitic phase after (a) cryogenic rolling or (b) subsequent annealing at $600^{\circ} \mathrm{C}$ for $1 \mathrm{~h}$. For simplicity, the approximate positions of several ideal rolling orientations are indicated in (a)

Texture analysis (Fig. 5) confirmed the restoration of crystallographic orientations of the parent austenite grains during low-temperature reversion. In particular, the cryogenically-rolled austenite was characterized by a typical rolling texture comprising Brass $\{110\}<112>$, Goss $\{110\}<100>$, $S\{123\}<634>$, and Copper $\{112\}<111>$ orientations (Fig. 5a). Martensite reversion back to austenite increased the orientation spread around these components somewhat but provided no fundamental changes in the principal texture components (Fig. 5b).

\subsubsection{The reversion mechanism}

To examine the detailed mechanism of martensite reversion back to austenite, various types of high-resolution EBSD maps were taken from both cryo-rolled and annealed samples; typical examples are shown in Figs. 6 to 8. These included Kikuchi-band-contrast maps (Figs. 6a, 7a, and 8a), phase maps (Fig. 6b), and orientation (inverse-pole-figure) maps (Figs. 6c, 7b, and 8b). The Kikuchi-band-contrast maps were based on measurement of the sharpness of Kikuchi patterns; the 
sharpness decreases in regions with crystal defects and thus provides images similar to that obtained by conventional optical microscopy.
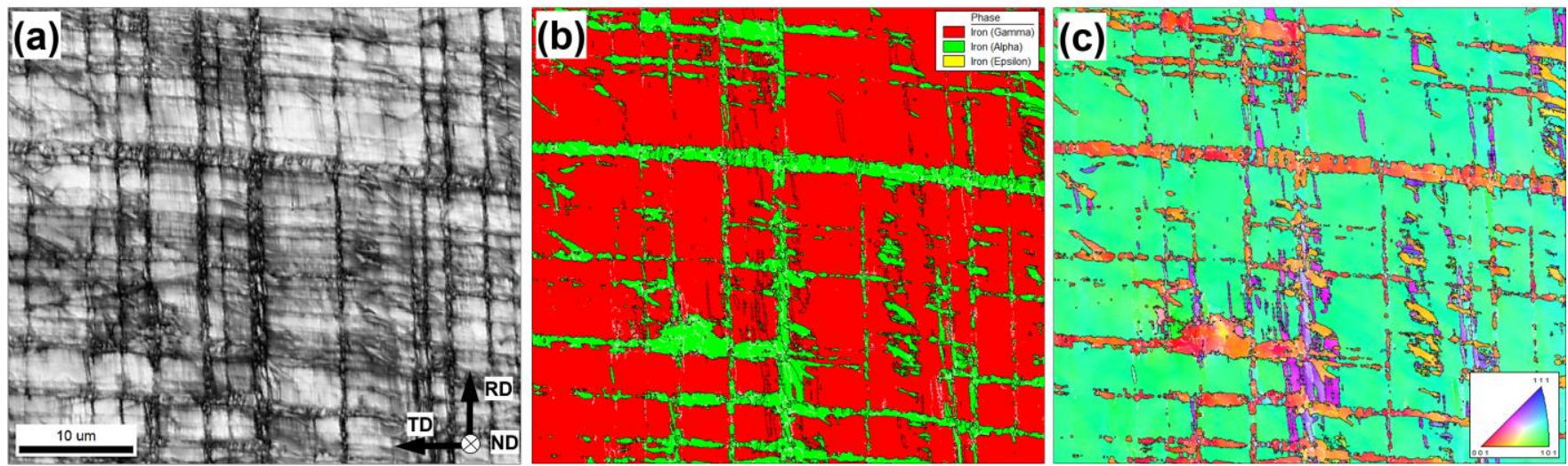

Figure 6. High-resolution EBSD maps taken from the as-cryogenically-rolled material: (a) Kikuchi-band-contrast map, (b) phase map, and (c) orientation map. In (b) and (c), LABs and HABs are depicted as bright and dark lines, respectively. In (c), individual grains are colored according to their crystallographic orientation relative to the ND (color code triangle is shown in the bottom right corner).
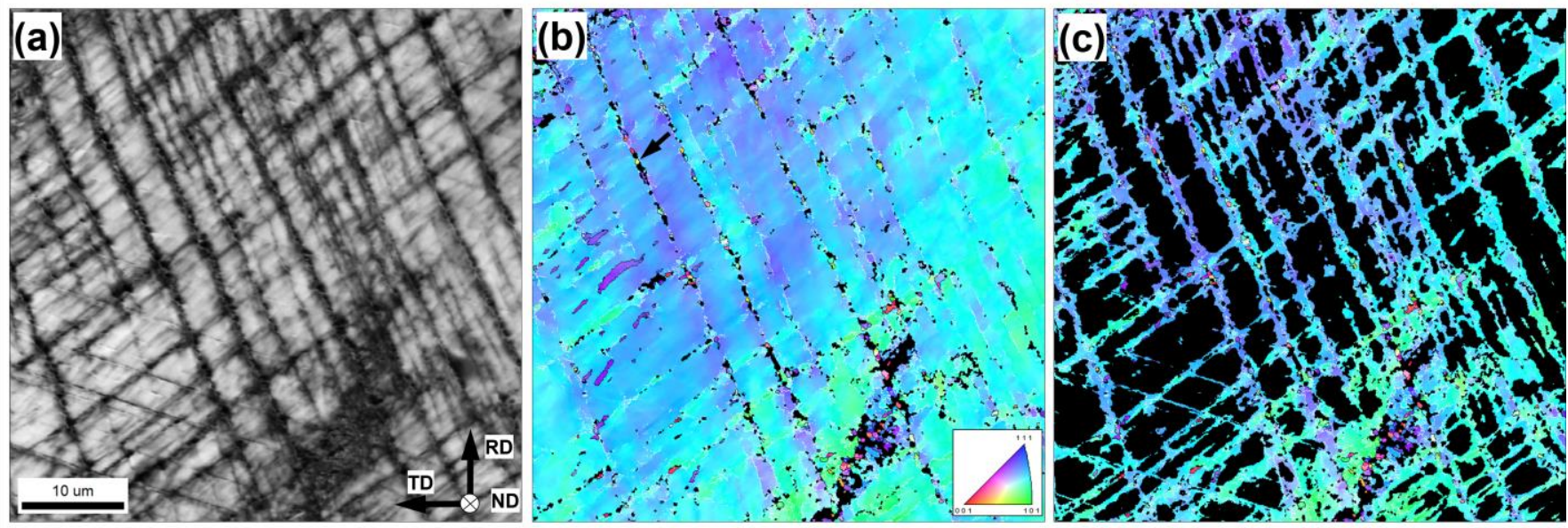

Figure 7. High-resolution EBSD maps taken from material annealed at $600^{\circ} \mathrm{C}$ for $1 \mathrm{~h}$ : (a) Kikuchi-band-contrast map, (b) austenite orientation map, and (c) orientation map of the reverted austenite (see Section 3.2.3 for details). In (b) and (c), the austenite grains are colored according to their crystallographic orientation relative to the ND; LABs and HABs are depicted as bright and dark lines, respectively. In (b), black areas represent martensitic phase and the arrow indicates a new orientation produced during martensite-to austenite reversion.

In the cryogenically-deformed material, strain-induced martensite was preferentially located in deformation bands (Figs. $6 a$ \& b). This agrees well with numerous reports in the literature [3, 5, 7, 12-14]. The almost exclusive concentration of strain-induced martensitic transformation within deformation bands may thus limit the volume fraction of martensite developed during deformation. As expected, the crystallographic orientations of the austenite and martensite were related through a nearly-perfect K-S orientation relationship, as exemplified in Fig. 9a. Moreover, the martensite particles nucleated within a particular austenite grain were characterized by broadly-similar crystallographic orientations (compare Figs. $6 b$ \& $c$ ); this evidenced a strong variant selection 

in the authors' companion paper [44].
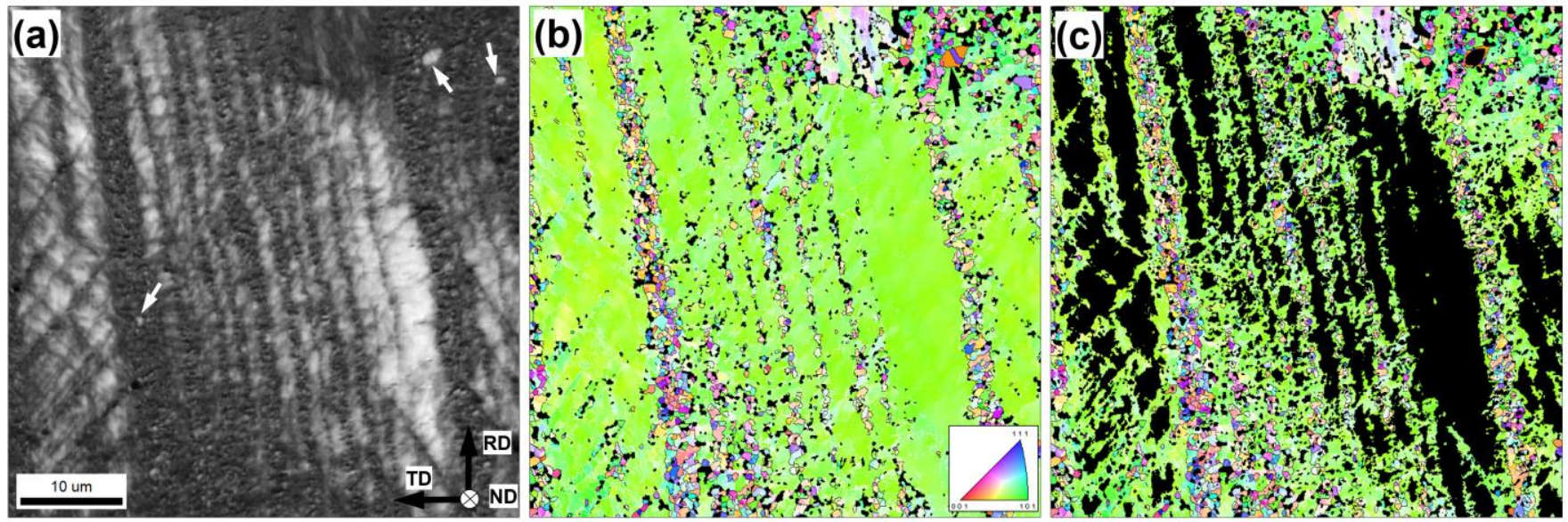

Figure 8. High-resolution EBSD maps taken from material annealed at $700^{\circ} \mathrm{C}$ for $1 \mathrm{~h}$ : (a) Kikuchi-band-contrast map, (b) austenite orientation map, and (c) orientation map of the reverted austenite (see Section 3.2.3 for details). In (a) and (b), arrows indicate recrystallization nuclei. In (b), black clusters show the martensitic phase. In (b) and (c), grains are colored according to their crystallographic orientation relative to the ND; LABs and HABs are depicted as bright and dark lines, respectively.
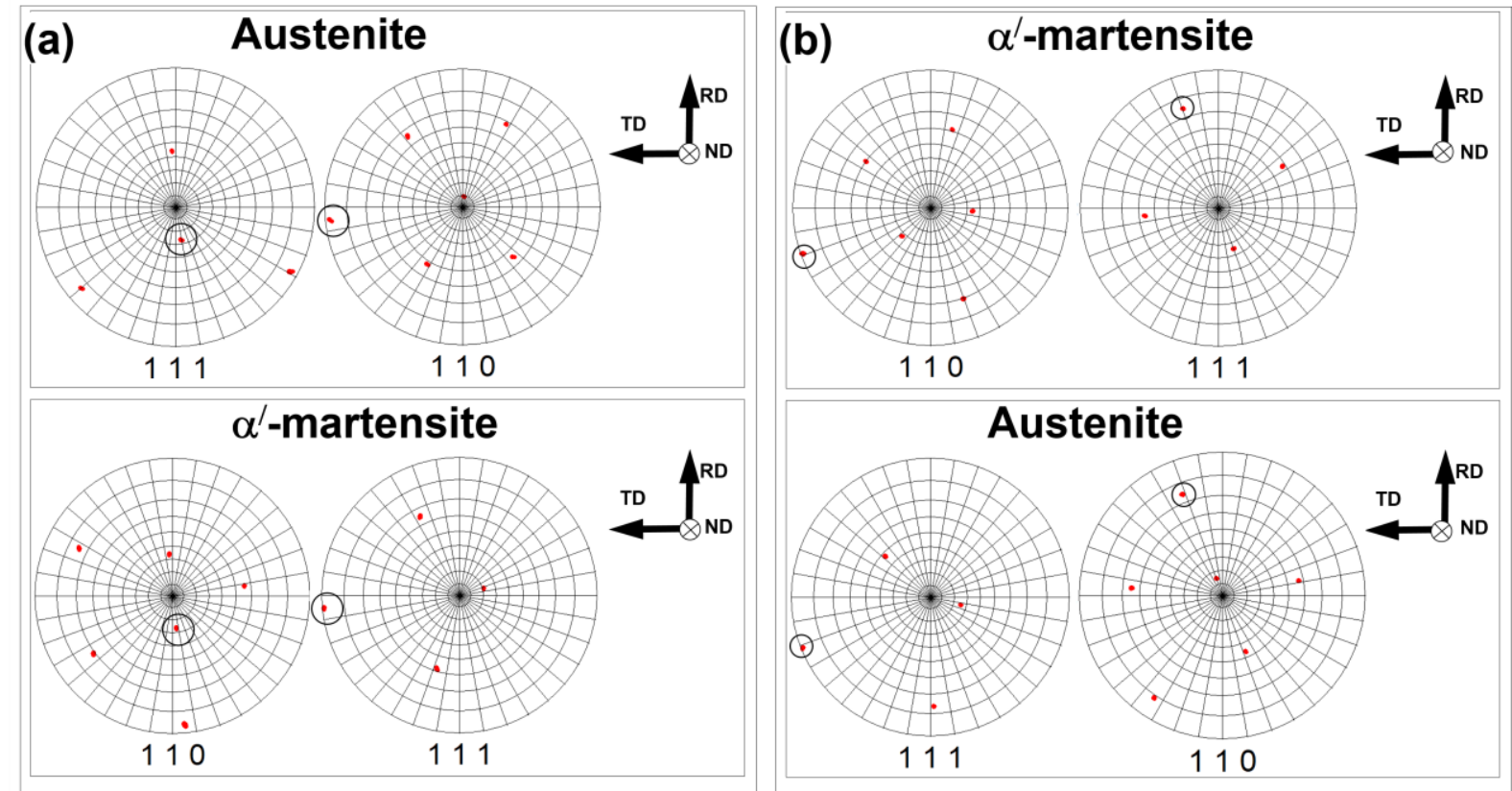

Figure 9. Typical crystallographic relationship between (a) austenite and strain-induced a' martensite in cryo-rolled material, and (b) the retained $a^{\prime}$ martensite and the reverted austenite in annealed material. The closest related directions in the martensitic and the austenitic phases are circled. In (b), the pole figures were obtained from the material annealed at $700^{\circ} \mathrm{C}$ for $1 \mathrm{~h}$.

During the reversion process on heating, the strain-induced martensite transformed back almost completely to austenite (Figs. 7 and 8). However, the resulting austenite tended to appear dark in the Kikuchi-band-contrast maps (Figs. 7a and 8a), thus suggesting a relatively-high dislocation density in this austenite. 
The most striking feature of the austenite formed by the reversion of martensite at relatively-low temperature was the similarity of its crystallographic orientations relative to those of the parent austenite (Fig. 7b). This restoration of the original crystallographic orientation during the reversion process thus provided strong evidence for an austenite memory effect [23, 27, 28, 31-36], and explained the relatively-limited degree of grain-refinement during reversion (Fig. $4 \mathrm{~b}$ ) as well as the restoration of the original rolling texture (Fig. 5b). Nevertheless, the martensite-to-austenite reversion at low temperatures did produce new crystallographic orientations in some cases; an example is indicated by the arrow in Fig. 7b. At relatively high reversion temperatures, the latter phenomenon became much more pronounced, thus leading to significant grain refinement (Fig. $8 b)$. Local crystallographic measurements revealed a nearly-perfect K-S orientation relationship between the retained martensite and such new orientations produced by reversion (Fig. 9b) at both low and high reversion temperatures.

Considering the relatively-high concentration of crystal defects in the austenite generated by martensite reversion, the K-S orientation relationship between the phases, and especially the memory effect, martensite reversion to austenite was deduced to be governed by a shear mechanism. The activation of this mechanism was probably attributable to the relatively low annealing temperatures (i.e., $\sim 0.51-0.57 \mathrm{~T}_{\mathrm{m}}$ ), but may also have been affected by the relatively-high heating rate employed in this work $(\sim 10 \mathrm{~K} / \mathrm{s})$. As shown by Leem, et al. [25], heating rates of $10 \mathrm{~K} / \mathrm{s}$ and above may promote martensitic transformation.

Considering the shear character of the reversion process, the observed austenite memory effect presumably arose from some sort of very strong variant selection during the $\gamma \rightarrow \alpha^{\prime} \rightarrow \gamma$ transformation sequence. Assuming an important sensitivity of this phenomenon to micro-scale residual stresses [32], it may be hypothesized that recovery at high reversion temperatures might relax the variant-selection effect, leading to additional variants, and thus promote grain refinement (Fig. 8b).

It is also worth noting that the martensite which reverted back to austenite at relatively-high temperatures was characterized by a small fraction of sporadic defect-free grains (examples indicated by arrows in Fig. 8a) which sometimes contained annealing twins (example shown by an arrow in Fig. 8b). Perhaps, this indicates the activation of a diffusional mechanism which contributed only slightly to the high-temperature reversion process.

\subsubsection{Grain refinement efficiency}

Measurements of the grain-boundary area in the austenite formed by reversion of martensite served to quantify the efficiency of grain-refinement by this mechanism. To this end, this austenite was extracted from EBSD data (Figs. 7c and 8c). The extraction procedure was based on the fact that such austenite was characterized by a relatively-high dislocation density and thus appeared dark in the Kikuchi-band-contrast maps. Therefore, a contrast threshold in these maps was selected manually to extract the dark band regions (compare Figs. 7a \& c and 8a \&c).

Misorientation data derived from the extracted regions were plotted in terms of misorientation-angle and misorientation-axis distributions (e.g., Fig. 10a); more specifically, the misorientation-angle data were expressed in terms of grain-boundary density, corresponding to the 
total grain-boundary length for a given range of misorientation angles divided by the area of the extracted EBSD map. This metric provides a more direct comparison of grain-boundary characteristics for different material conditions, thus facilitating the evaluation of the grain-refinement effect. The influence of the reversion temperature on total density of HABs is presented in Fig. 10b.
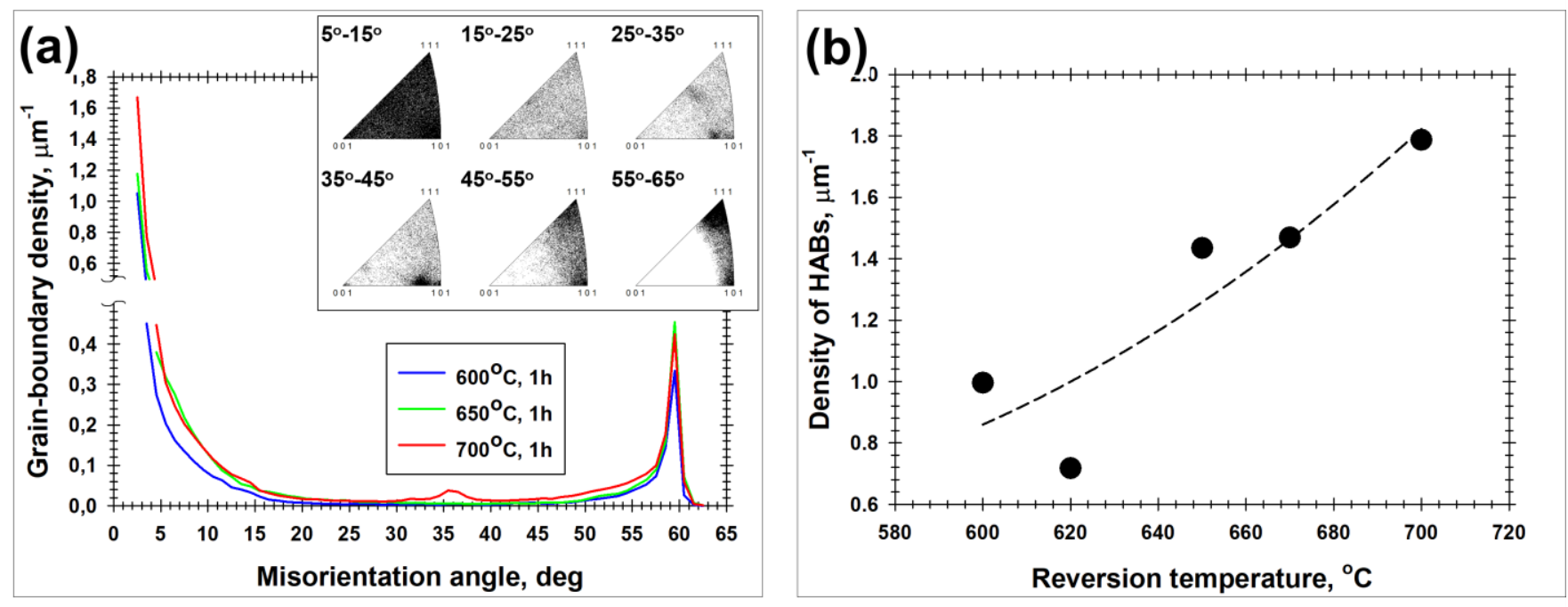

Figure 10. Effect of reversion temperature on (a) misorientation distribution in the reverted austenite, and (b) density of HABs in the reverted austenite. Note: The typical misorientation-axis distribution in the reverted austenite is shown in the top right corner of (a).

The misorientation distributions of the reverted austenite were characterized by a pronounced low-angle maximum, a sharp peak near $60^{\circ}$ as well as clustering of misorientation axes near <110> and <111> poles (Fig. 10a). The measured misorientations were broadly similar to those between the crystallographic variants expected from the $\gamma-\alpha^{\prime}-\gamma$ phase transformation sequence governed by the K-S orientation relationship (supplementary Table S-2). This perhaps also corroborates the shear mechanism of martensite-to-austenite reversion, as mentioned in the previous section.

An increase in the reversion temperature doubled the HAB area in the reverted austenite (Fig. 10b). This reflected an enhancement of grain-refinement as is readily seen by comparing Figs. $7 \mathrm{~b}$ and $8 \mathrm{~b}$. As discussed in the previous section, microstructural changes in this temperature range were affected only slightly by recrystallization. Therefore, the observed increase in $\mathrm{HAB}$ area presumably originated from a reduction in preferential variant selection during the $\alpha^{\prime} \rightarrow \gamma$ transformation.

At $650^{\circ} \mathrm{C}$, the increase in $\mathrm{HAB}$ area was primarily contributed by 60 -degree misorientations (Fig. 10a), thus suggesting the nucleation of twin-related variants. This effect has also been described in the literature [27-29, 32, 34, 36, 47]. At $700^{\circ} \mathrm{C}$, the $\mathrm{HAB}$ area increased for a wide range of misorientation angles (Fig. 10a), providing evidence for the formation of multiple variants. It may thus be concluded that reversion at higher temperatures is more useful for grain refinement. The LAB density was also found to increase with annealing temperature (Fig. 10a), thus perhaps 
reflecting a nucleation of crystallographic variants with relatively-low orientation difference (supplementary Table S-2).

Even at the high temperatures, however, the refinement occurred only in prior-martensitic areas, and regions with retained austenite remained nearly unchanged with regard to microstructural scale (Fig. 8b).

\subsection{Recrystallization}

Typical EBSD maps taken from material annealed at $800^{\circ} \mathrm{C}$ are shown in Fig. 11. In these maps, austenite grains are colored according to their crystallographic orientations relative to the ND whereas the $\alpha^{\prime}$ martensite is black. It is clear from the EBSD data that austenite had undergone recrystallization. However, recrystallization was not complete, and the resulting microstructure thus retained a substantial fraction of coarse unrecrystallized grains (Fig. 11a). Such microstructures are often observed during recrystallization of metastable austenitic steels [26, 48-51].
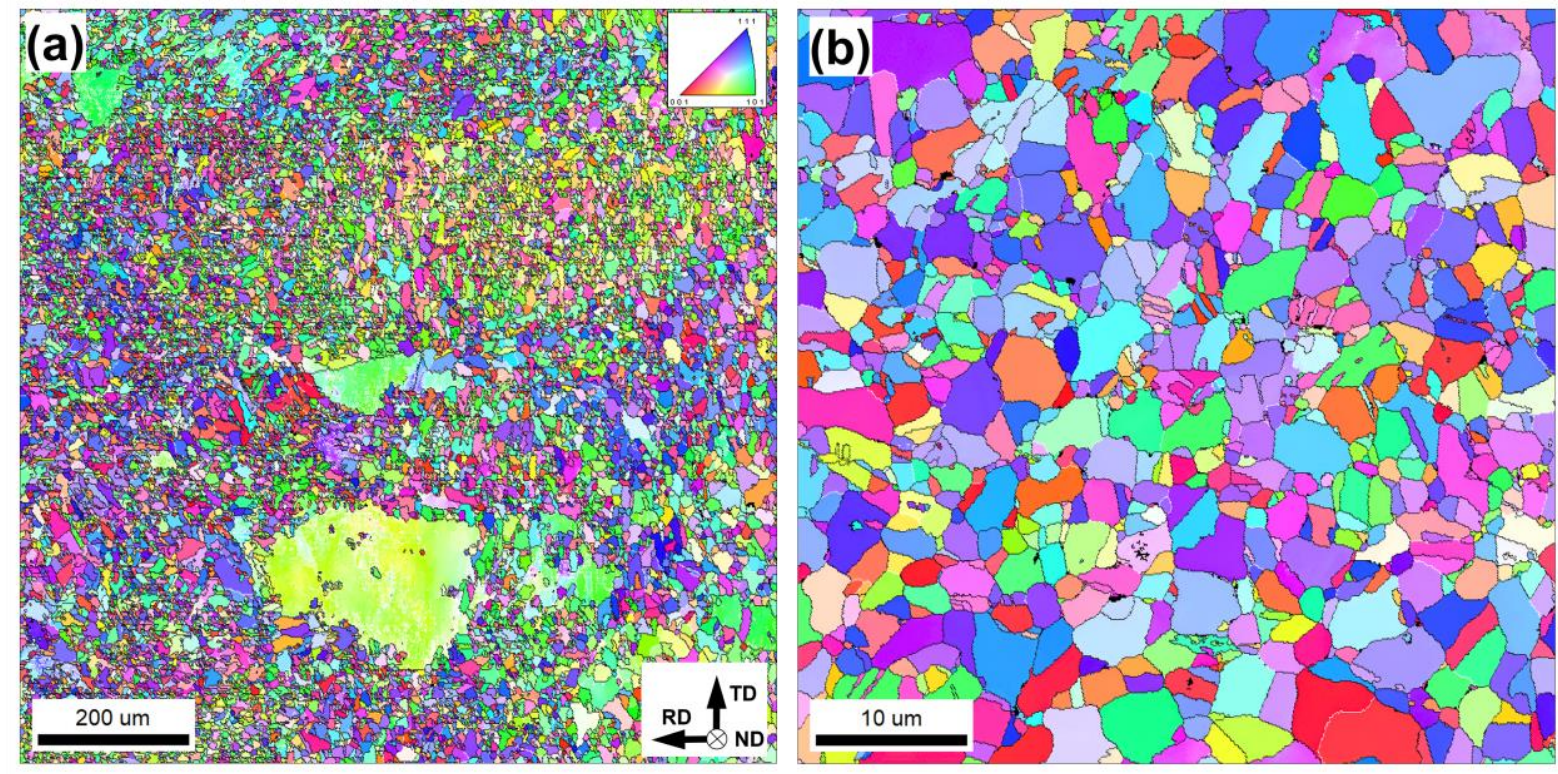

Figure 11. EBSD austenite orientation maps taken from material annealed at $800^{\circ} \mathrm{C}$ for $1 \mathrm{~h}$ : (a) low-magnification (overview) map, and (b) high-resolution map taken from a recrystallized area. In the maps, individual grains are colored according to their crystallographic orientations relative to the ND. LABs and HABs are depicted as bright and black lines, respectively. The retained a' martensite appears black.

To obtain insight into the recrystallization process, the textures of the recrystallized and unrecrystallized regions were extracted from the global EBSD maps using an approach developed by Konkova, et al. [52]. Specifically, recrystallized grains were defined as those having an orientation spread below the limit detectable by EBSD (i.e., $2^{\circ}$ ), and the remaining grains (with higher orientation spread) were taken to be unrecrystallized. An example of the partitioned microstructure is given in supplementary Fig. S-2, and the resulting texture data are shown in Fig. 12. The fraction of recrystallized material measured by this approach was $58 \%$. 


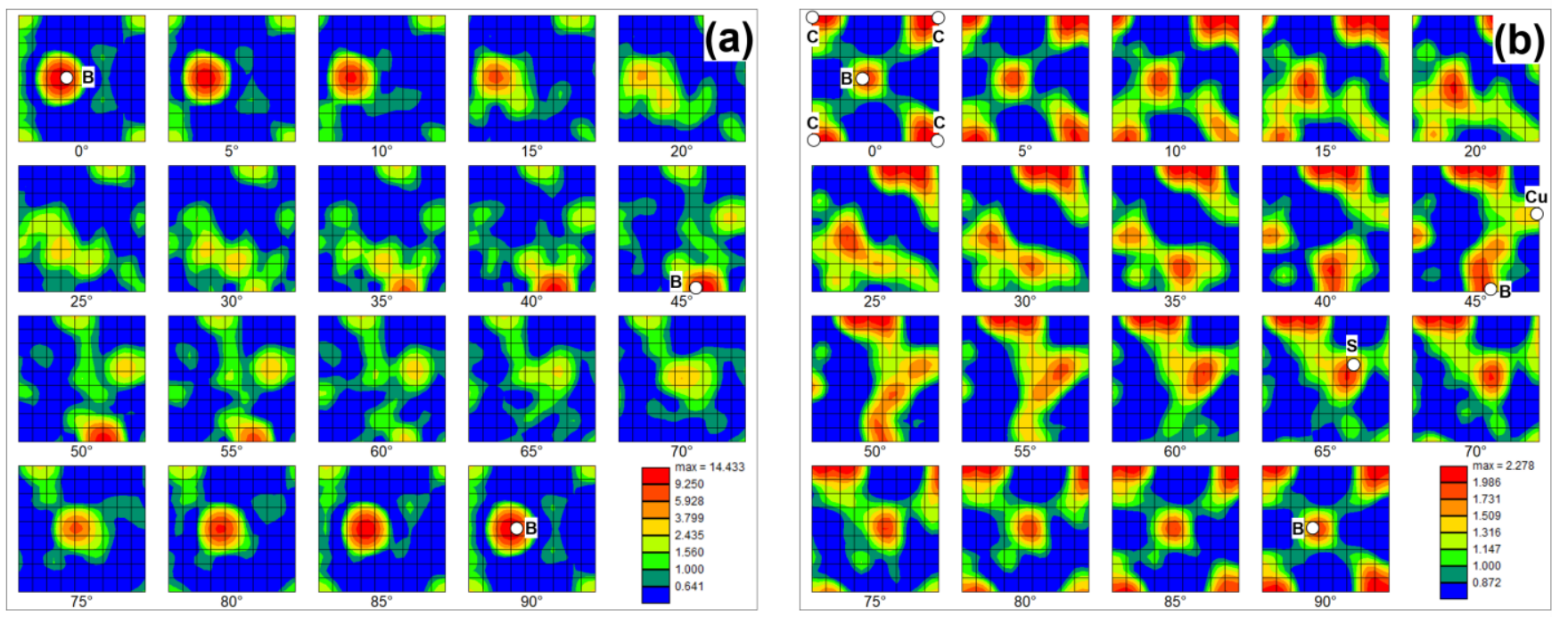

B - Brass $\{110\}<112>$ orientation, $\mathrm{Cu}$ - Copper $\{112\}<111>$ orientation, C - Cube $\{100\}<001>$ orientation, $\mathbf{S}-\mathrm{S}\{123\}<634>$ orientation

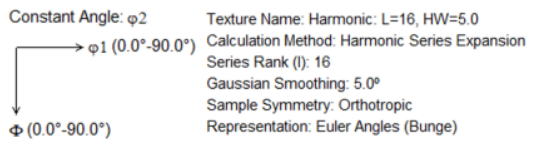

Figure 12. Orientation distribution functions (ODFs) showing the crystallographic texture in austenite in the material annealed at $800^{\circ} \mathrm{C}$ for $1 \mathrm{~h}$ : (a) unrecrystallized material and (b) recrystallized material. For simplicity, several ideal rolling orientations are superimposed on the ODFs

Similar to recent findings by Sun, et al. [48], the main crystallographic orientation of the unrecrystallized grains was found to be close to the Brass $\{110\}<112>$ component (Fig. 12a). The Brass orientation is predicted to be stable during cold rolling [53], and therefore it should accumulate relatively-low orientation gradients during straining and hence a limited driving force for subsequent recrystallization [54]. By contrast, the texture of the recrystallized material was dominated by the Cube $\{001\}<100>$ as well as Brass $\{110\}<112>$, Copper $\{112\}<111>$, and $S$ $\{123\}<634>$ orientations (Fig. 12b). The presence of the three latter components in the recrystallization texture suggested that the recrystallization nuclei inherited the crystallographic orientations of cryogenically-rolled grains (compare Fig. 5a and 12b).
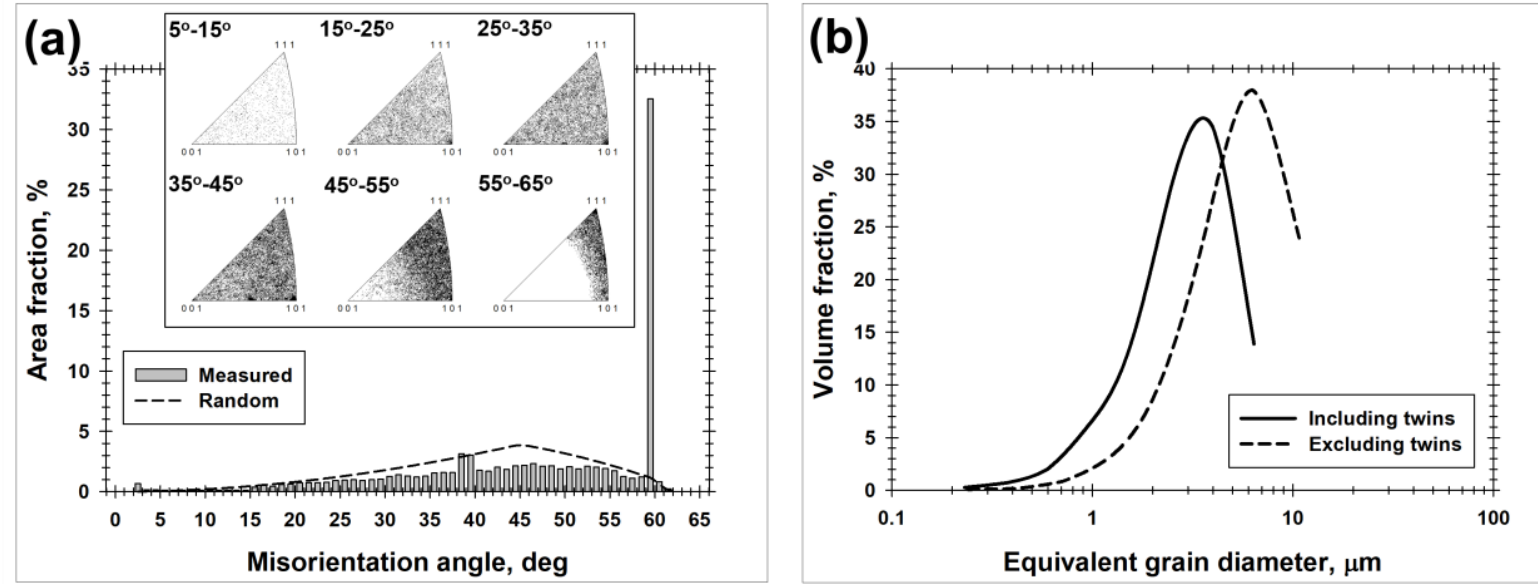

Figure 13. (a) Misorientation distribution and (b) grain-size distributions in the recrystallized austenite developed in material annealed at $800^{\circ} \mathrm{C}$ for $1 \mathrm{~h}$. In (a), misorientation-axis distribution is shown in the upper portion of the figure. 


\section{Conclusions}

The objective of this work was to evaluate the efficiency of advanced thermomechanical processing based on cryogenic deformation for the refinement of grain structure in type 321 metastable austenitic steel. To this end, the material was rolled at liquid-nitrogen temperature and then annealed in the temperature range of $400-800^{\circ} \mathrm{C}(0.34-0.54 \mathrm{~T})$. The main conclusions from this work are as follows.

As expected, the nucleation of strain-induced martensite during rolling as well as its subsequent reversion to austenite during annealing was governed by the K-S orientation relationship $\{111\}_{\gamma} \|\{110\}_{\alpha^{\prime}}$ and $<110>_{\gamma} \|<111>_{\alpha^{\prime}}$. Importantly, however, both processes were characterized by very-strong variant selection. This resulted in a restoration of the crystallographic orientation of the coarse parent austenite grains during the $\gamma \rightarrow \alpha^{\prime} \rightarrow \gamma$ transformation sequence. This effect was most pronounced during relatively low-temperature reversion (i.e. $600-650^{\circ} \mathrm{C}$ ), and therefore the present approach is not feasible for grain refinement.

A very important characteristic of the strain-induced martensite was its almost exclusive activation within deformation bands. This naturally restricted the volume fraction of the martensitic phase developed during rolling. Accordingly, even relaxation of variant selection during reversion at high temperature (i.e. $700^{\circ} \mathrm{C}$ ) resulted only in a bimodal grain structure consisting of transformed ultrafine-grain domains and untransformed coarse-grain remnants of the original grains. 
The refinement of untransformed coarse grains was achieved by recrystallization which follows reversion at $800^{\circ} \mathrm{C}$. However, grains with crystallographic orientations close to Brass $\{110\}<112>$ do not readily recrystallized, and thus the resulting microstructure was noticeably heterogeneous.

At present, therefore, thermomechanical processing utilizing cryogenic deformation is not totally suitable for the formation of an ultrafine-grain microstructure in type 321 metastable austenitic steel. Annealing of the cryorolled material between $700^{\circ} \mathrm{C}$ and $800^{\circ} \mathrm{C}$ was suggested to be a possible pathway for the technology optimization. Such treatment may promote extensive variant selection during the martensite reversion but avoid an excessive growth of recrystallized grains and thus produce the desirable ultrafine-grained structure. To eliminate the recrystallization-resistant grains with nearly-Brass orientation (and thereby provide microstructure uniformity), a relatively long-term anneal may be required, however.

\section{Acknowledgements}

The present work was partially supported by the Russian Fund for Fundamental Research (project No.17-42-020426). The authors would also like to thank P. Klassman for technical assistance during cryogenic rolling.

\section{References}

[1] R. Valiev: Nature Mater., 2004, vol. 8, pp. 511-516, doi:10.1038/nmat1180

[2] R. Song, D. Ponge, D. Raabe, J.G. Speer, D.K. Matlock: Mater. Sci. Eng. A, 2006, vol. 441, pp. 1-17, https://doi.org/10.1016/j.msea.2006.08.095

[3] K.H. Lo, C.H. Shek, J.K.L. Lai: Mater. Sci. Eng. R, 2009, vol. 65, pp. 39-104, https://doi.org/10.1016/j.mser.2009.03.001

[4] J.W. Brooks, M.H. Loretto, R.E. Smallman: Acta Metall., 1979, vol. 27, pp. 1839-1847, https://doi.org/10.1016/0001-6160(79)90074-9

[5] A.K. De, D.C. Murdock, M.C. Mataya, J.G. Speer, D.K. Matlock: Scripta Mater., 2004, vol. 50, pp. 1445-1449, https://doi.org/10.1016/j.scriptamat.2004.03.011

[6] T. Suzuki, J. Kojima, K. Suzuki, T. Hashimito, M. Ichihara: Acta Metall., 1977, vol. 25, pp. 1151-1162, https://doi.org/10.1016/0001-6160 (77)90202-4

[7] Y.F. Shen, X.X. Li, X. Sun, Y.D. Wang, L. Zuo: Mater. Sci. Eng. A, 2012, vol. 552, pp. 514-522, https://doi.org/10.1016/j.msea.2012.05.080

[8] P. Mallick, N.K. Tewary, S.K. Ghosh, P.P. Chattopadhyay: Mater. Character., in press, https://doi.org/10.1016/j.matchar.2017.09.027

[9] T. Suzuki, J. Kojima, K. Suzuki, T. Hashimito, M. Ichihara: Acta Metall., 1977, vol. 25, pp. 1151-1162, https://doi.org/10.1016/0001-6160(77)90202-4

[10] N. Nakada, H. Ito, Y. Matsuoka, T. Tsuchiyama, S. Takaki: Acta Materialia, 2010, vol. 58, pp. 895-903, https://doi.org/10.1016/j.actamat.2009.10.004

[11] I. Shakhova, V. Dudko, A. Belyakov, K. Tsuzaki, R. Kaibyshev: Mater. Sci. Eng. A, 2012, vol. 545, pp. 176-186, https://doi.org/10.1016/j.msea.2012.02.101 
[12] S. Sabooni, F. Karimzadeh, M.H. Enayati, A.H.W. Ngan: Mater. Sci. Eng. A, 2015, vol. 636, pp. 221-230, https://doi.org/10.1016/j.msea.2015.03.101

[13] G.B. Olson, M. Cohen: Metall. Trans. A, 1975, vol. 6, pp. 791-795, https://doi.org/10.1007/BF02672301

[14] A. Das, S. Sivaprasad, P.C. Chakraborti, S. Tarafder: Mater. Sci. Eng. A, 2011, vol. 528, pp. 7909-7914, https://doi.org/10.1016/j.msea.2011.07.011

[15] K. Tomimura, S. Takaki, S. Tanimoto, Y. Tokunaga: ISIJ International, 1991, vol. 31, pp. 721-727

[16] B. Ravi Kumar, A.K. Singh, B. Mahato, P.K. De, N.R. Bandyopadhyay, D.K. Bhattacharya: Mater. Sci. Eng. A, 2006, vol. 429, pp. 205-211, dx.doi.org/10.1016/j.msea.2006.05.107

[17] T.-H. Lee, E. Shin, C.-S. Oh, H.-Y. Ha, S.-J. Kim: Acta Mater., 2010, vol. 58, pp. 3173-3186, https://doi.org/10.1016/j.actamat.2010.01.056

[18] L. Bracke, K. Verbeken, L. Kestens, J. Penning: Acta Mater., 2009, vol. 57, pp. 1512-1524, https://doi.org/10.1016/j.actamat.2008.11.036

[19] B. Roy, R. Kumar, J. Das: Mater. Sci. Eng. A, 2015, vol. 631, pp. 241-247, https://doi.org/10.1016/j.msea.2015.02.050

[20] T.S. Wang, J.P. Peng, Y.W. Gao, F.C. Zhang, T.F. Jing: Mater. Sci. Eng. A, 2005, vol. 407, pp. 84-88, https://doi.org/10.1016/j.msea.2005.06.022

[21] M. Eskandari, A. Kermanpur, and A. Najafizadeh: Metall. Mater. Trans. A, 2009, vol. 40, pp. 2241-2249, https://doi.org/10.1007/s11661-009-9916-Z

[22] T.-H. Lee, C.-S. Oh, S.J. Kim, S. Takaki: Acta Mater., 2007, vol. 55, pp. 3649-3662, https://doi.org/10.1016/j.actamat.2007.02.023

[23] H. Shirazi, G. Miyamoto, S. Hossein Nedjad, T. Chiba, M. Nili Ahmadabadi, T. Furuhara: Acta Mater., 2018, vol. 144, pp. 269-280, https://doi.org/10.1016/j.actamat.2017.10.068

[24] K. Tomimura, S. Takaki, Y. Tokunaga: ISIJ International, 1991, vol. 31, pp. 1431-1437

[25] D-S. Leem, Y-D. Lee, J-H. Jun, C-S. Choi: Scripta Mater., 2001, vol. 45, pp. 767-472, https://doi.org/10.1016/S1359-6462(01)01093-4

[26] A. Kisko, A.S. Hamada, J. Talonen, D. Porter, L.P. Karjalainen: Mater. Sci. Eng. A, 2016, vol. 657, pp. 359-370, http://dx.doi.org/10.1016/j.msea.2016.01.093

[27] X. Zhang, G. Miyamoto, Y. Toji, S. Nambu, T. Koseki, T. Furuhara: Acta Mater., 2018, vol. 144, pp. 601-612, https://doi.org/10.1016/j.actamat.2017.11.003

[28] N. Nakada, Mater. Letter., 2017, vol. 187, pp. 166-169, http://dx.doi.org/10.1016/j.matlet.2016.10.056

[29] J. Jelenkowski: J. Mater. Proc. Technol., 1997, vol. 64, pp. 207-217

[30] A. Wirth: Micron, 1973, vol. 4, pp. 230-242

[31] A.A. Tiamiyu, A.G. Odeshi, J.A. Szpunar: JMEPEG, 2018, vol. 27, pp. 889-904, https://doi.org/10.1007/s11665-018-3180-6

[32] N. Nakada, T. Tsuchiyama, S. Takaki, S. Hashizume: ISIJ International, 2007, vol. 47, pp. 1527-1532

[33] R.D.K. Misra, Z. Zhang, P.K.C. Venkatasurya, M.C. Somani, L.P. Karjalainen: Mater. Sci. Eng. A, 2010, vol. 527, pp. 7779-7792, dx.doi.org/10.1016/j.msea.2010.08.051

[34] V.V. Sagaradze, V.E. Danilchenko, Ph. L'Heritier, V.A. Shabashov: Mater. Sci. Eng. A, 2002, vol. 337, pp. 146-159

[35] M.C. Somani, P. Juntunen, L.P. Karjalainen, R.D.K. Misra, A. Kyrolainen: Metall. Mater. Trans. A, 2009, vol. 40, pp. $729-744$ 
[36] V.V. Sagaradze: NanoStructured Mater., 1997, vol. 9, pp. 201-204

[37] S. Rajasekhara, L.P. Karjalainen, A. Kyröläinen, P.J. Ferreira: Mater. Sci. Eng. A, 2010, vol. 527, pp. 1986-1996, dx.doi.org/10.1016/j.msea.2009.11.037

[38] Y. Lu, B. Hutchinson, D.A. Molodov, G. Gottstein: Acta Mater., 2010, vol. 58, pp. 3079-3090, https://doi.org/10.1016/j.actamat.2010.01.045

[39] M. Klimova, S. Zherebtsov, N. Stepanov, G. Salishchev, D.A. Molodov: Mater. Character., 2017, vol. 132, pp. 20-30, https://doi.org/10.1016/j.matchar.2017.07.043

[40] A.A. Tiamiyu, J.A. Szpunar, A.G. Odeshi, I. Oguocha, M. Eskandari: Metall. Mater. Trans. A, 2017, vol. 48, pp. 5990-6012, https://doi.org/10.1007/s11661-017-4361-x

[41] H.A. Rezzei, M.S. Ghazani, B. Eghbali, Effect of post deformation annealing on the microstructure and mechanical properties of cold rolled AISI 321 austenitic stainless steel, Mater. Sci. Eng. A, 2018, vol. 736, pp. 364-374, https://doi.org/10.1016/j.msea.2018.09.012

[42] M.G. Shahri, S.R. Hosseini, M. Salehi, Formation of nano/ultrafine grains in AlSI 321 stainless steel using advanced thermo-mechanical process, Acta Metall. Sin. (Engl. Lett.), 2015, vol. 28, pp. 499-504, https://doi.org/10.1007/s40195-015-0225-9

[43] V.M.A. Silva, C.G. Camerini, J.M. Pardal, J.C.G. de Blas, G.R. Perera, Eddy current characterization of cold-worked AISI 321 stainless steel, J. Mater. Res. Technol., 2018, vol. 7, pp. 395-401, https://doi.org/10.1016/j.jmrt.2018.07.002

[44] G. Korznikova, S. Mironov, T. Konkova, A. Aletdinov, R. Zaripova, M. Myshlyaev, S.L. Semiatin: Metall. Mater. Trans. A, 2018, vol. 49, pp. 6325-6336, https://doi.org/10.1007/s11661-018-4919-2

[45] A. Stormvinter, G. Miyamoto, T. Furuhara, P. Hedstrom, A. Borgenstam: Acta Mater., 2012, vol. 60, pp. 7265-7274, http://dx.doi.org/10.1016/j.actamat.2012.09.046

[46] Y. Tomota, Y. Morioka, W. Nakagawara: Acta Mater., 1998, vol. 46, pp. 1419-1426

[47] K.B. Guy, E.P. Butler, D.R.F. West: Met. Sci., 1983, vol. 17, pp. 167-176, dpi: 10.1179/030634583790420961

[48] G.S. Sun, L.X. Du, J. Hu, R.D.K. Misra: Mater. Sci. Eng. A, 2018, vol. 709, pp. 254-264, http://dx.doi.org/10.1016/j.msea.2017.10.054

[49] M. Odnobokova, A. Belyakov, N. Enikeev, D.A. Molodov, R. Kaibyshev: Mater. Sci. Eng. A, 2017, vol. 689, pp. 370-383, http://dx.doi.org/10.1016/j.msea.2017.02.073

[50] M. Nezakat, H. Akhiani, S.M. Sabet, J. Szpunar: Mater. Character., 2017, vol. 123, pp. 115-127, http://dx.doi.org/10.1016/j.matchar.2016.11.019

[51] M. Nezakat, H. Akhiani, M. Hoseini, J. Szpunar: Mater. Character., 2014, vol. 98, pp. 10-17, http://dx.doi.org/10.1016/j.matchar.2014.10.006

[52] T. Konkova, S. Mironov, A. Korznikov, S.L. Semiatin: Mater. Sci. Eng. A, 2011, vol. 528, pp. 7432- 7443, https://doi.org/10.1016/j.msea.2011.06.047

[53] J. Hirsch, K. Lucke: Acta Metall., 1988, vol. 36, pp. 2863-2882, https://doi.org/10.1016/0001-6160(88)90172-1

[54] F.J. Humphreys, M. Hatherly: Recrystallization and related phenomena, 2nd ed., Elsevier, Oxford, 2000

[55] D.P. Field: Ultramicroscopy, 1997, vol. 67, pp. 1-9, https://doi.org/10.1016/S0304-3991(96)00104-0 
Figure 1. Effect of annealing temperature on microhardness. In all cases, the annealing time was 1 h. Note: Error bars show the standard deviation.

Figure 2. ThermoCalc predictions of the temperature dependence of the volume fraction of (a) $\mathrm{CrC}$ and (b) $\mathrm{Ni}_{3}$ Ti particles

Figure 3. Selected portions of low-resolution EBSD phase maps showing microstructure (a) after cryogenic rolling, and after subsequent annealing at (b) $400^{\circ} \mathrm{C}$, (c) $600^{\circ} \mathrm{C}$, and (d) $800^{\circ} \mathrm{C}$; in all cases, the annealing time was $1 \mathrm{~h}$. The phase color code is shown in the bottom right corner of (a); black lines depict HABs. RD, ND, and TD denote the rolling direction, normal direction, and transverse direction, respectively.

Figure 4. Selected portions of low-resolution EBSD orientation maps showing austenite microstructure (a) after cryogenic rolling and after subsequent annealing at (b) $600^{\circ} \mathrm{C}$, (c) $650^{\circ} \mathrm{C}$, and (d) $700^{\circ} \mathrm{C}$; in all cases, the annealing time was $1 \mathrm{~h}$. In the maps, individual grains are colored according to their crystallographic orientation relative to the ND; the color code triangle is shown in the bottom right corner of (a). HABs are depicted as black lines. Note: black clusters show the martensitic phase.

Figure 5. Orientation distribution functions showing texture in the austenitic phase after (a) cryogenic rolling or (b) subsequent annealing at $600^{\circ} \mathrm{C}$ for $1 \mathrm{~h}$. For simplicity, the approximate positions of several ideal rolling orientations are indicated in (a).

Figure 6. High-resolution EBSD maps taken from the as-cryogenically-rolled material: (a) Kikuchi-band contrast map, (b) phase map, and (c) orientation map. In (b) and (c), LABs and HABs are depicted as bright and dark lines, respectively. In (c), individual grains are colored according to their crystallographic orientation relative to the ND.

Figure 7. High-resolution EBSD maps taken from material annealed at $600^{\circ} \mathrm{C}$ for $1 \mathrm{~h}$ : (a) Kikuchi-band-contrast map, (b) austenite orientation map, and (c) orientation map of the reverted austenite. In (b) and (c), the austenite grains are colored according to their crystallographic orientation relative to the ND. LABs and HABs are depicted as bright and dark lines, respectively. In (b), black areas represent martensitic phase, and the arrow indicates a new orientation produced during martensite-to austenite reversion.

Figure 8. High-resolution EBSD maps taken from material annealed at $700^{\circ} \mathrm{C}$ for $1 \mathrm{~h}$ : (a) Kikuchi-band-contrast map, (b) austenite orientation map, and (c) orientation map of the reverted austenite. In (a) and (b), arrows indicate recrystallization nuclei. In (b), black clusters show the martensitic phase. In (b) and (c), grains are colored according to their crystallographic orientation relative to the ND. LABs and HABs are depicted as bright and dark lines, respectively.

Figure 9. Typical crystallographic relationship between (a) austenite and strain-induced $\alpha^{\prime}$ martensite in the cryo-rolled material, and (b) the retained $\alpha^{\prime}$ martensite and the reverted 
austenite in the annealed material. The closest related directions in the martensitic and the austenitic phases are circled. In (b), the pole figures were obtained from the material annealed at $700^{\circ} \mathrm{C}$ for $1 \mathrm{~h}$.

Figure 10. Effect of reversion temperature on (a) misorientation distribution in the reverted austenite, and (b) the density of HABs in the reverted austenite. The typical misorientation-axis distribution in the reverted austenite is shown in the top right corner of (a).

Figure 11. EBSD austenite orientation maps taken from material annealed at $800^{\circ} \mathrm{C}$ for $1 \mathrm{~h}$ : (a) low-magnification (overview) map, and (b) high-resolution map taken from a recrystallized area. In the maps, individual grains are colored according to their crystallographic orientations relative to the ND. LABs and HABs are depicted as bright and black lines, respectively. The retained $\alpha^{\prime}$ martensite appears black.

Figure 12. Orientation distribution functions (ODFs) showing the crystallographic texture in austenite in the material annealed at $800^{\circ} \mathrm{C}$ for $1 \mathrm{~h}$ : (a) unrecrystallized material and (b) recrystallized material. For simplicity, several ideal rolling orientations are superimposed on the ODFs.

Figure 13. (a) Misorientation distribution and (b) grain-size distributions in the recrystallized austenite developed in material annealed at $800^{\circ} \mathrm{C}$ for $1 \mathrm{~h}$. In (a), the misorientation-axis distribution is shown in the upper portion of the figure.

\section{Supplementary Figure Captions}

Fig. S-1. Effect of annealing at $600^{\circ} \mathrm{C}$ for $1 \mathrm{~h}$ on grain orientation spread in $\alpha^{\prime}$ martensite

Fig. S-2. Partitioning of the austenite microstructure in the material annealed at $800^{\circ} \mathrm{C}$ for $1 \mathrm{~h}$ : (a) Unrecrystallized material and (b) recrystallized material. In the maps, individual grains are colored according to their crystallographic orientations relative to the ND. LABs and HABs are depicted as bright and black lines, respectively. 


\section{$1 \quad$ Martensite-to-austenite reversion and recrystallization in cryogenically-rolled type 321 metastable austenitic steel}

3

4 A. Aletdinov ${ }^{1}$, S. Mironov ${ }^{2 *}$, G.F. Korznikova ${ }^{1}$, T. Konkova ${ }^{1,3}$, R.G. Zaripova ${ }^{4}$, 5 M.M. Myshlyaev ${ }^{5,6}$, and S.L. Semiatin ${ }^{7}$

6

$7^{1}$ Institute for Metals Superplasticity Problems, Russian Academy of Science, 39 Khalturin Str., Ufa, 450001, Russia $8^{2}$ Belgorod National Research University, Pobeda 85, Belgorod 308015, Russia

$9^{3}$ University of Strathclyde, 75 Montrose Street, Glasgow, G1 1XJ, United Kingdom

$10^{4}$ Ufa State Aviation Technical University, 12 K. Marx St., Ufa 450000, Russia

$11^{5}$ Baikov Institute of Metallurgy and Material Science, Russian Academy of Science, 49 Lenin-av., Moscow 119991, Russia $12^{6}$ Institute of Solid State Physics, Russian Academy of Sciences, 2 Academic Osypian Str., Chernogolovka, Moscow Oblast 13 142432, Russia

$14^{7}$ Air Force Research Laboratory, Materials and Manufacturing Directorate, AFRL/RXCM, Wright-Patterson AFB, OH 15 45433-7817, USA

16

The annealing behavior of cryogenically-rolled type 321 metastable austenitic steel was established. Cryogenic deformation gave rise to martensitic transformation which developed preferentially within deformation bands. Subsequent annealing in the range of $600-700^{\circ} \mathrm{C}$ resulted in reversion of the strain-induced martensite to austenite. At $800^{\circ} \mathrm{C}$, the reversion was followed by static recrystallization. At relatively-low temperatures, the reversion was characterized by a very strong variant selection, which led to the restoration of the crystallographic orientation of the coarse parent austenite grains. An increase in the annealing temperature relaxed the variant-selection tendency and provided subsequent recrystallization thus leading to significant grain refinement. Nevertheless, a significant portion of the original coarse grains was found to be untransformed and therefore the fine-grain structure was fairly heterogeneous.

Keywords: Ultrafine-grain materials; Metastable austenitic steel; Cryogenic deformation; Martensite-to-austenite reversion; Recrystallization; Microstructure; Electron backscatter diffraction (EBSD)

\section{Introduction}

The possibility of significant improvement in mechanical properties has prompted considerable interest in the development of ultrafine-grain materials. Typically, this is achieved by the application of severe-plastic-deformation techniques [1], but such methods are often laborious and difficult to apply for the fabrication of commercial-scale products. For metastable austenitic steels, however, the ultrafine-grain structure may be produced by conventional cold rolling followed by annealing. This approach is based on a strain-induced martensitic transformation during cold 
deformation and subsequent martensite-to-austenite reversion during heat treatment and is sometimes referred to as an "advanced" thermomechanical process [2].

Extensive research over a 25 -year period has demonstrated the remarkable complexity of microstructural changes involved in this processing route. During the deformation step, the nucleation of strain-induced martensite has been reported to occur at dislocation pile-ups [3-6], mechanical twins [7-12], or deformation bands [3, 5, 7, 12-14]. The austenitic and martensitic phases are typically found to be related through a Kurdjumov-Sachs (K-S) orientation relationship, viz., $\{111\}_{\gamma} \|\{110\}_{\alpha^{\prime}}$ and $\left\langle 110>_{\gamma} \|<111\right\rangle_{\alpha^{\prime}}[3,5,7,12,14-16]$, although substantial deviations are sometimes observed [11]. The phase transformation may also involve the formation of a transient $\varepsilon$-martensite phase, i.e., it may develop via a $\gamma \rightarrow \varepsilon \rightarrow \alpha^{\prime}$ transformation sequence $[3,5,7,8,13,14$, 17]. The size of the strain-induced martensitic particles is usually reported to be in the nanoscale range [7-12, 14, 17-22].

During subsequent annealing, reversion back to austenite may be governed by two different mechanisms, i.e., athermal (martensitic) shear or thermally-activated diffusion [23]. The activation of a particular mechanism is believed to be dependent on the specific chemical composition of the material and temperature [24] as well as the heating rate [25]. Sometimes, both mechanisms may operate concurrently $[11,26]$. In the case of the shear mechanism, the reverse transformation typically follows the K-S relation [11, 23, 27-32]. Moreover, the crystallographic orientation of the newly-formed austenite may be nearly identical to that of the parent (prior-austenite) grain [23, 27, 28, 31-36]. This austenite "memory" effect is sometimes attributed to strong variant selection during the phase transformation [27, 32], as well as to a relief of residual stress [32]. The shear reversion mechanism is also characterized by a high dislocation density [23, 24, 28, 33, 34, 37] which arises from the retention of dislocation substructure within the martensitic phase as well as that generated during reversion [34]. In the case of the diffusional mechanism, no clear orientation relationship between the new austenite and the martensite is found [23]. However, multiple new orientations produced by reversion can result in grain refinement [11, 23, 27, 32-36]. At high annealing temperatures, reversion may also be followed by static recrystallization [23, 26, 35, 38].

It is also sometimes believed that lower deformation temperatures may enhance the grain-refinement efficiency of advanced thermomechanical processing. Specifically, lower temperatures should increase the driving force for both martensitic transformation during the deformation step as well as that for reversion and recrystallization during subsequent annealing. In view of potential property benefits with regard to microstructure refinement for commercial scale sheet products, the processing of metastable austenitic steels at cryogenic temperatures has attracted significant interest recently [8, 19, 20, 31, 39, 40].

The work reported herein is part of wide-ranging research project whose overall aim has been to evaluate the efficiency of advanced thermomechanical processing utilizing cryogenic deformation for refinement of the grain structure in type 321 metastable austenitic steel. The microstructural response of this material to conventional thermal mechanical processing has been described in a number of recent reports [41-43]. It has been shown that rolling to a 90 pct. thickness reduction at ambient temperature results in the formation of a microstructure with 50 pct. martensite 
[41]. Subsequent reversion during annealing gave rise to a bimodal structure consisting of fine-grain reverted austenite and relatively coarse-grain remnants of untransformed austenite [41]. Such a bimodal microstructure provided an excellent combination of strength and ductility [41]. Furthermore, a lowering of the rolling temperature to $-20^{\circ} \mathrm{C}$ has been shown to significantly enhance strain-induced martensitic transformation and thus promote a finer austenite grain size in the final reverted microstructure [42].

In a previous investigation of type 321 metastable austenitic steel [44], the specific effect of cryogenic rolling on microstructure and texture evolution was examined. The current paper is focused on the post-rolling annealing behavior of cryogenically-rolled material.

\section{Material and Experimental Procedures}

The program material comprised type 321 metastable austenitic stainless steel with nominal $^{\dagger}$ chemical composition shown in Table 1 . The initial material was rolled to $85 \%$ thickness reduction at $950^{\circ} \mathrm{C}$ and then annealed at $1200^{\circ} \mathrm{C}$ for 1 hour, thereby producing a fully-recrystallized austenitic grain structure with a mean grain size of $\sim 100 \mu \mathrm{m}$. The preprocessed material was then cryogenically rolled to $30 \%$ overall thickness reduction (true strain $=-0.36$ ). The reduction was performed in a single pass using a rolling speed of $160 \mathrm{~mm} / \mathrm{s}$ in a cluster mill with 65-mm-diameter work rolls. Higher reductions were found to lead to significant (undesirable) deformation heating and roll-separating forces which exceeded the capacity of the laboratory equipment. To provide cryogenic deformation conditions, the rolling preform was soaked in liquid nitrogen and held for 15 minutes prior to rolling. The typical flat-rolling convention was adopted in this work; i.e., the rolling, long-transverse, and thickness/normal directions were denoted as RD, TD, and ND, respectively.

To evaluate the temperature range for the martensite-to-austenite reversion and recrystallization, microhardness measurements were performed. Vickers microhardness values were determined by applying a load of $1 \mathrm{~kg}$ for $10 \mathrm{~s}$. For each material condition studied, 50 measurements were made to obtain an average value.

Based on the results of these preliminary experiments, nine temperatures were selected for detailed microstructural examinations: $400^{\circ} \mathrm{C}\left(0.34 \mathrm{~T}_{\mathrm{m}}\right.$, where $\mathrm{T}_{\mathrm{m}}$ is the melting point $), 500^{\circ} \mathrm{C}$ $\left(0.39 \mathrm{~T}_{\mathrm{m}}\right), 550^{\circ} \mathrm{C}\left(0.42 \mathrm{~T}_{\mathrm{m}}\right), 600^{\circ} \mathrm{C}\left(0.44 \mathrm{~T}_{\mathrm{m}}\right), 620^{\circ} \mathrm{C}\left(0.45 \mathrm{~T}_{\mathrm{m}}\right), 650^{\circ} \mathrm{C}\left(0.47 \mathrm{~T}_{\mathrm{m}}\right), 670^{\circ} \mathrm{C}\left(0.48 \mathrm{~T}_{\mathrm{m}}\right)$, $700^{\circ} \mathrm{C}\left(0.49 \mathrm{~T}_{\mathrm{m}}\right)$, and $800^{\circ} \mathrm{C}\left(0.54 \mathrm{~T}_{\mathrm{m}}\right)$. In all cases, cryo-rolled specimens were heated to the particular temperature at a rate of $\sim 10 \mathrm{~K} / \mathrm{s}$, held for $1 \mathrm{~h}$, and then water quenched.

Microstructural characterization was performed on the mid-thickness rolling plane (i.e., RD-TD plane) via electron backscatter diffraction (EBSD). For this purpose, samples were prepared using conventional metallographic techniques followed by electropolishing in a solution comprising $95 \%$ acetic acid and $5 \%$ perchloric acid using an applied potential of $60 \mathrm{~V}$. For EBSD, a JSM-7800F field-emission-gun scanning-electron microscope (FEG-SEM) operating at an accelerating voltage of $25 \mathrm{kV}$ and a TSL OIM ${ }^{\mathrm{TM}}$ system were employed.

To examine the microstructure at different length scales, several EBSD maps were acquired for each material condition. Low-resolution (overview) maps were obtained using a scan step size

\footnotetext{
${ }^{\dagger}$ According to Russian industrial standard
} 
of ether 1 or $2 \mu \mathrm{m}$; higher-resolution maps were acquired using a scan step size of either 50 or 100 $\mathrm{nm}$. The statistics of EBSD measurements are summarized in supplementary Table $\mathrm{S}-1^{\ddagger}$. For each diffraction pattern, seven Kikuchi bands were used to minimize indexing error. The $\alpha^{\prime}$-martensite was indexed as a body-centered-cubic phase; this approach is believed to be feasible for EBSD of steels [45]. To ensure reliability of the data, all grains comprising two or fewer pixels were automatically "cleaned" from the maps using the grain-dilation option in the OIM ${ }^{\mathrm{TM}}$ software. Furthermore, to eliminate spurious boundaries caused by orientation noise, a lower-limit boundary-misorientation cut-off of $2^{\circ}$ was employed. A $15^{\circ}$ criterion was applied to differentiate low-angle boundaries (LABs) from high-angle boundaries (HABs).

Interpretation of microstructural changes was assisted by thermodynamic calculations derived using ThermoCalc software with the TCFe9 database.

\section{Results and Discussion}

\subsection{Preliminary analysis}

\subsubsection{Microhardness measurements}

The effect of annealing temperature on the room-temperature microhardness (Fig. 1) showed a noticeable amount $(\sim 15 \%)$ of hardening at $400^{\circ} \mathrm{C}$. ThermoCalc calculations predicted the nucleation of $\mathrm{CrC}$ and $\mathrm{Ni}_{3} \mathrm{Ti}$ phases at this temperature (Figs. 2a and b, respectively), which perhaps explains this surprising effect. At present, however, the precipitation of the particles has not been confirmed experimentally and therefore requires further study.

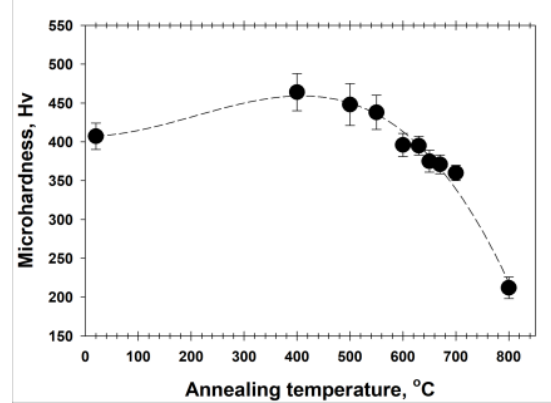

Figure 1. Effect of annealing temperature on microhardness. In all cases, annealing time was $1 \mathrm{~h}$. Note: Error bars show standard deviation.
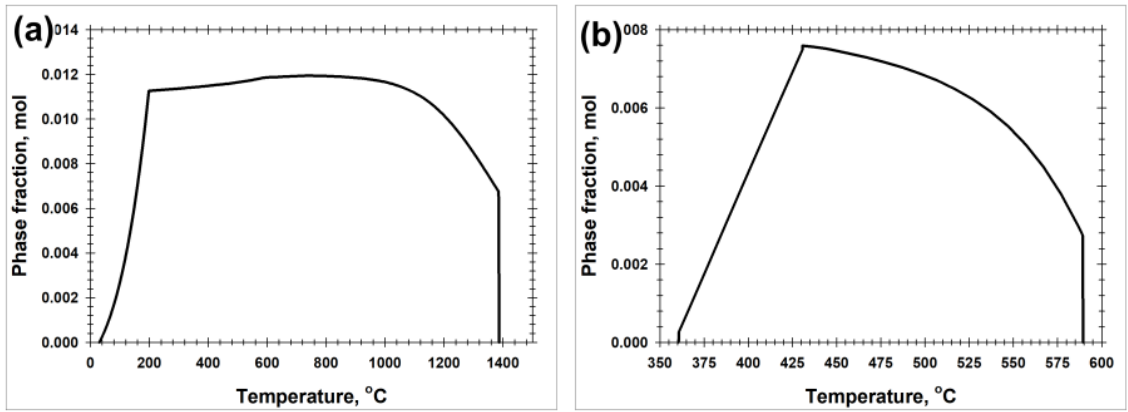

Figure 2. ThermoCalc predictions of the temperature dependence of the volume fraction of (a) $\mathrm{CrC}$ and (b) $\mathrm{Ni}_{3} \mathrm{Ti}$ particles.

‡ Refer to electronic supplementary material 
At temperatures in excess of $550^{\circ} \mathrm{C}$, rapid material softening was found, which likely indicates the martensite-to-austenite reversion.

\subsubsection{EBSD examination}

Representative examples of low-resolution (overview) phase maps of the cryo-rolled and annealed materials are summarized in Fig. 3. The material in the as-rolled condition (Fig. 3a) contained a significant fraction of martensitic phases. The measured content of $\alpha^{\prime}$ - and $\varepsilon$-martensite was $\sim 35$ pct. and $\sim 3$ pct., respectively. However, considering the relatively-coarse scan step size $(1 \mu \mathrm{m})$ as well as the very fine nature of the martensitic phases, the measured fractions were presumably underestimated.
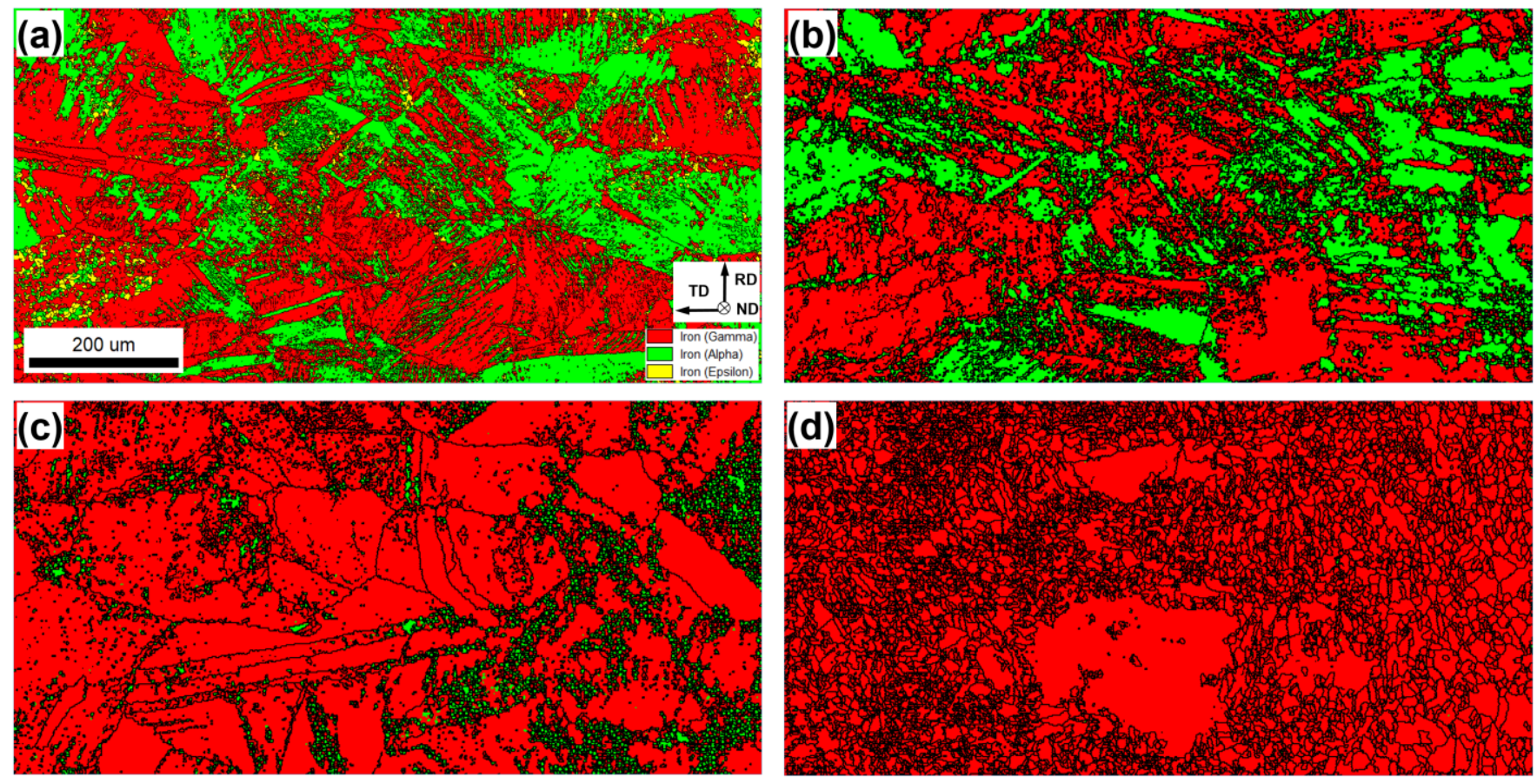

Figure 3. Selected portions of low-resolution EBSD phase maps showing microstructure (a) after cryogenic rolling, and after subsequent annealing at (b) $400^{\circ} \mathrm{C}$, (c) $600^{\circ} \mathrm{C}$, and (d) $800^{\circ} \mathrm{C}$; in all cases, annealing time was $1 \mathrm{~h}$. The phase color code is shown in the bottom right corner of (a); black lines depict HABs. RD, ND and TD denote the rolling direction, normal direction and transverse direction, respectively.

Subsequent annealing of the cryo-rolled material at $400^{\circ} \mathrm{C}$ resulted in dissolution of $\varepsilon$-martensite (Fig. 3b). This was consistent with the well-known low thermal stability of this phase, which transforms into austenite at relatively-low annealing temperatures $[38,46]$. Moreover, the $\varepsilon$ $\rightarrow \gamma$ transformation is believed to be governed by a shear mechanism [38], which should generate dislocations [46], and thus contributed to the strengthening observed at $400^{\circ} \mathrm{C}$ (Fig. 1b). On the other hand, the fraction of $\alpha^{\prime}$ martensite did not change noticeably (compare Figs. $3 a \& b$ ).

At $600^{\circ} \mathrm{C}$, the fraction of $\alpha^{\prime}$ martensite was reduced to $\sim 10$ pct. (Fig. 3c) thus providing evidence of reversion to austenite; this observation was in line with material softening at this temperature (Fig. 1). Equally important, austenite reversion did not result in significant grain refinement in the austenitic phase but provided rather a reconstruction of the parent austenite grains (Fig. 3c); this behavior is discussed in more detail in Section 3.2. 
Surprisingly, the reversion process led to a marked refinement of the remaining $\alpha^{\prime}$ martensite (Figs. 3b vs 3c); moreover, EBSD measurements revealed considerable reduction of orientation spread in this phase (supplementary Fig. S-1). These observations indicated that the martensitic phase may have experienced substantial change prior to the reversion into austenite. However, the limited statistics of the measurements in the $\alpha^{\prime}$ martensite at this annealing temperature prevented a convincing conclusion to be drawn.

A further increase in annealing temperature to $800^{\circ} \mathrm{C}$ led to almost complete disappearance of the $\alpha^{\prime}$ martensite and significantly reduced the austenite grain size (Fig. $3 d$ ). The latter observation suggested a recrystallization process.

Based on the broad analysis in this section, therefore, two temperature ranges were selected for detailed microstructural examination: $600-700^{\circ} \mathrm{C}$ (i.e., martensite-to-austenite reversion) and $800^{\circ} \mathrm{C}$ (i.e., the suggested recrystallization).

\subsection{Martensite-to-austenite reversion}

\subsubsection{Broad aspects of the process}

To investigate the martensite-to-austenite-reversion process, the microstructures of specimens annealed in the range of $600-700^{\circ} \mathrm{C}$ were examined in greater detail. In EBSD inverse-pole-figure (orientation) maps from as-rolled and annealed materials (e.g., Fig. 4), austenite grains were colored according to their crystallographic orientations relative to the ND, and HABs were depicted as black lines. Black clusters represented martensitic phases.
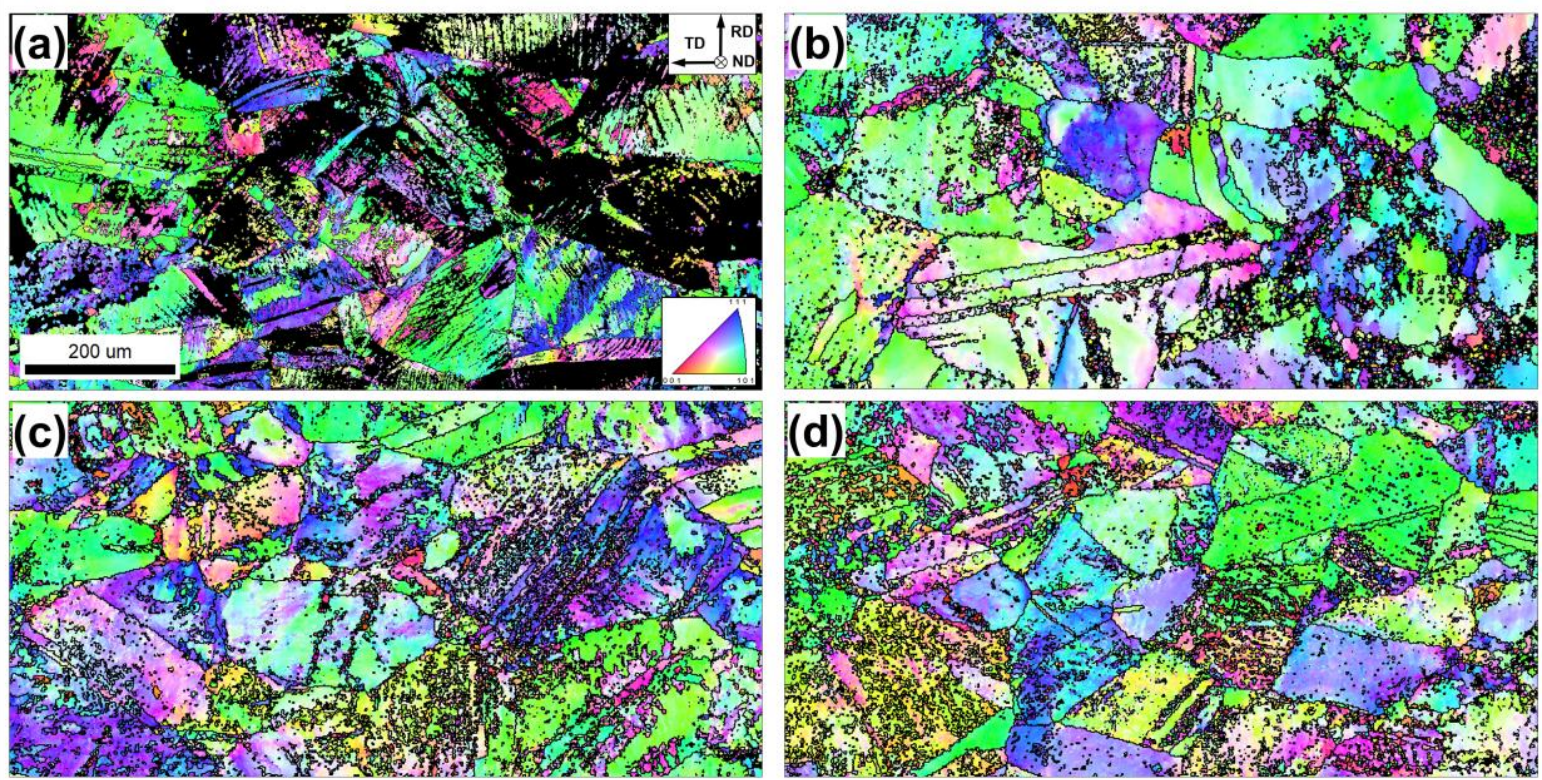

Figure 4. Selected portions of low-resolution EBSD orientation maps showing austenite microstructure (a) after cryogenic rolling and after subsequent annealing at (b) $600^{\circ} \mathrm{C}$, (c) $650^{\circ} \mathrm{C}$, and (d) $700^{\circ} \mathrm{C}$; in all cases, annealing time was $1 \mathrm{~h}$. In the maps, individual grains are colored according to their crystallographic orientation relative to ND; the color code triangle is shown in the bottom right corner of (a). HABs are depicted as black lines. Note: black clusters show the martensitic phase. 
In the cryogenically-rolled condition (Fig. 4a), the remnants of the original coarse-grain austenite structure were clearly seen. In the authors' previous work [44], the relatively-slow kinetics of grain refinement in austenite was attributed to a martensitic transformation occurring in the most-heavily-strained areas; this suppressed the normal development of deformation-induced boundaries in the austenitic phase.

Martensite-to-austenite reversion at relatively-low temperatures also provided only limited grain refinement (Fig. 4b). The orientation map clearly demonstrated that reversion resulted by and large in essentially a reconstruction of the original coarse austenite grains, as suggested in the previous section. On the other hand, an increase of the reversion temperature enhanced grain refinement (see Figs. 4b vs $4 c-d$ ).
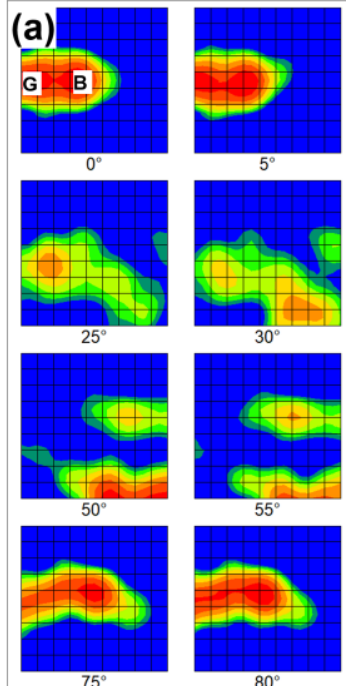

Texture Name: Harmonic: $L=16, \mathrm{HW}=5.0$ Calculation Method. Harmonic Series Expansion Series Rank (1): 16 Gaussian Smoothing: $5.0^{\circ}$ Sample Symmetry. Orthotropic
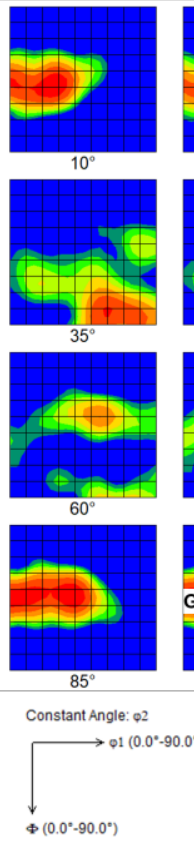
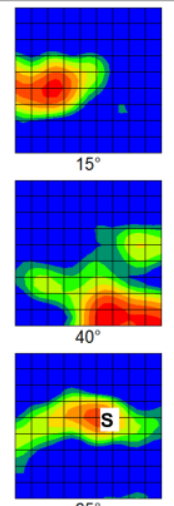

$65^{\circ}$

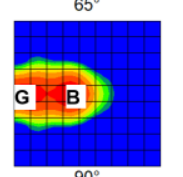

$B=\{110\}<112>$ Brass

$G=\{110\}<100>$ Goss
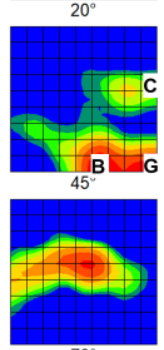
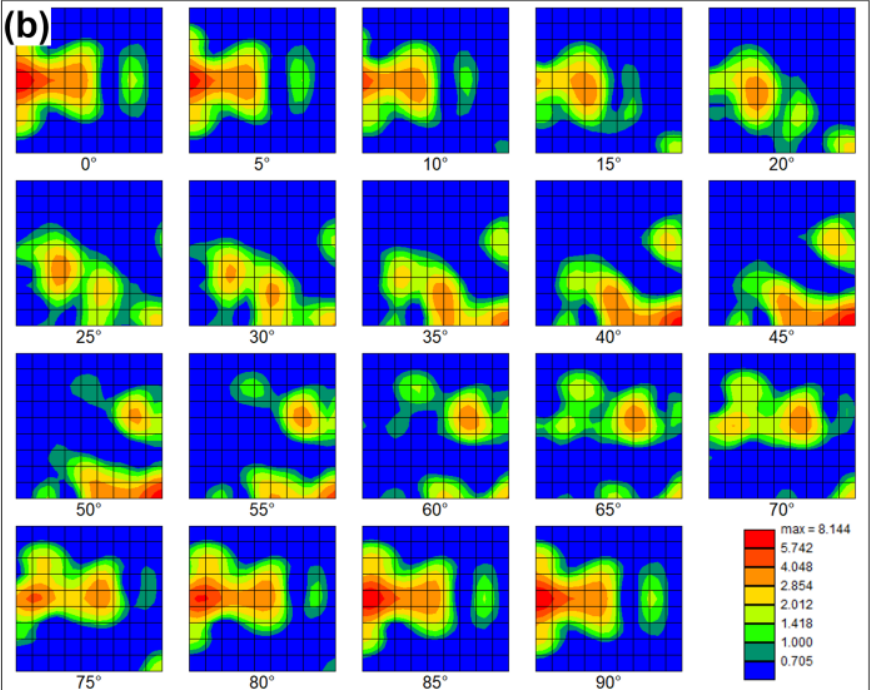

$C=\{112\}<111>$ Copper

$S=\{123\}<634>S$

Figure 5. Orientation distribution functions showing texture in austenitic phase after (a) cryogenic rolling or (b) subsequent annealing at $600^{\circ} \mathrm{C}$ for $1 \mathrm{~h}$. For simplicity, the approximate positions of several ideal rolling orientations are indicated in (a)

Texture analysis (Fig. 5) confirmed the restoration of crystallographic orientations of the parent austenite grains during low-temperature reversion. In particular, the cryogenically-rolled austenite was characterized by a typical rolling texture comprising Brass $\{110\}<112>$, Goss $\{110\}<100>$, $S\{123\}<634>$, and Copper $\{112\}<111>$ orientations (Fig. 5a). Martensite reversion back to austenite increased the orientation spread around these components somewhat but provided no fundamental changes in the principal texture components (Fig. 5b).

\subsubsection{The reversion mechanism}

To examine the detailed mechanism of martensite reversion back to austenite, various types of high-resolution EBSD maps were taken from both cryo-rolled and annealed samples; typical examples are shown in Figs. 6 to 8. These included Kikuchi-band-contrast maps (Figs. 6a, 7a, and 8a), phase maps (Fig. 6b), and orientation (inverse-pole-figure) maps (Figs. 6c, 7b, and 8b). The Kikuchi-band-contrast maps were based on measurement of the sharpness of Kikuchi patterns; the 
sharpness decreases in regions with crystal defects and thus provides images similar to that obtained by conventional optical microscopy.
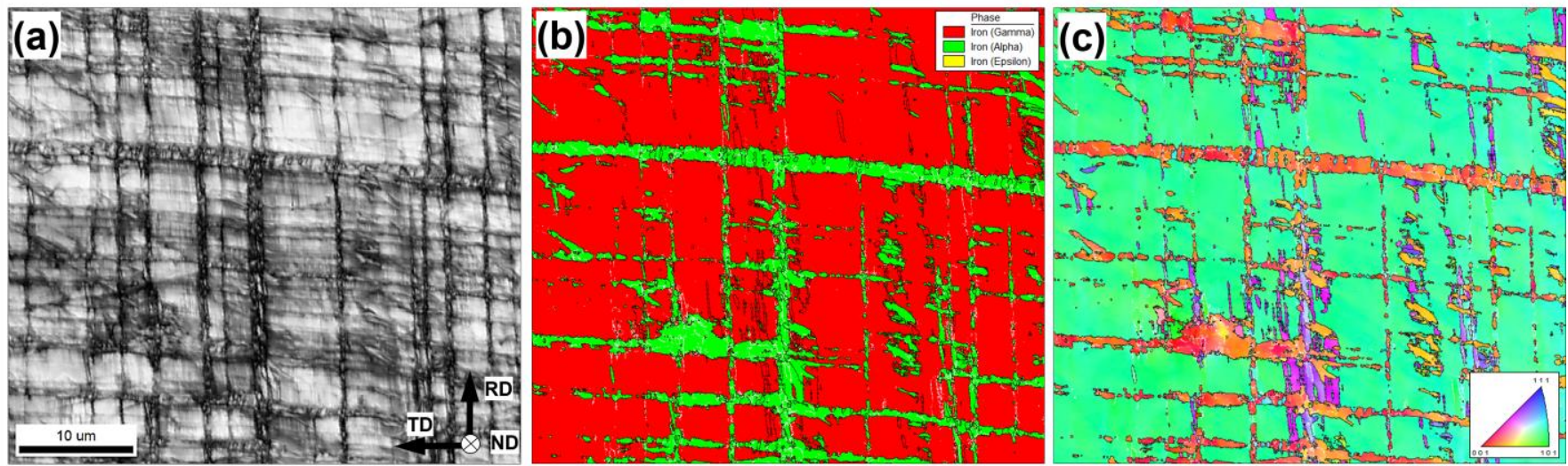

Figure 6. High-resolution EBSD maps taken from the as-cryogenically-rolled material: (a) Kikuchi-band-contrast map, (b) phase map, and (c) orientation map. In (b) and (c), LABs and HABs are depicted as bright and dark lines, respectively. In (c), individual grains are colored according to their crystallographic orientation relative to the ND (color code triangle is shown in the bottom right corner).
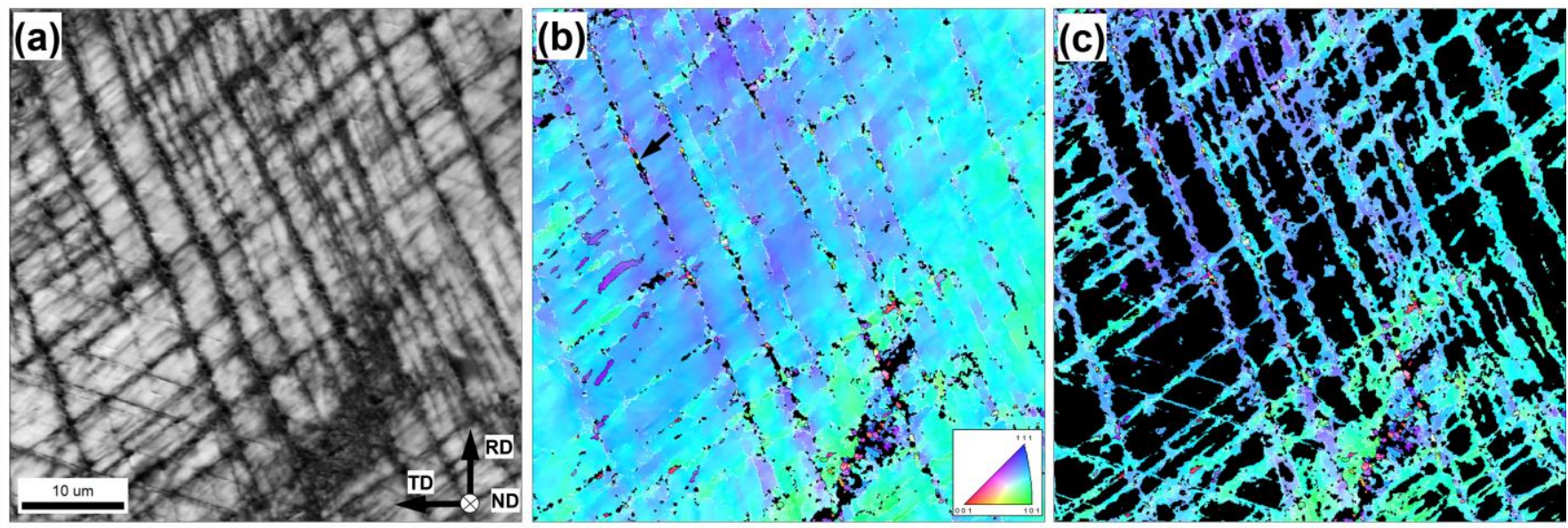

Figure 7. High-resolution EBSD maps taken from material annealed at $600^{\circ} \mathrm{C}$ for $1 \mathrm{~h}$ : (a) Kikuchi-band-contrast map, (b) austenite orientation map, and (c) orientation map of the reverted austenite (see Section 3.2.3 for details). In (b) and (c), the austenite grains are colored according to their crystallographic orientation relative to the ND; LABs and HABs are depicted as bright and dark lines, respectively. In (b), black areas represent martensitic phase and the arrow indicates a new orientation produced during martensite-to austenite reversion.

In the cryogenically-deformed material, strain-induced martensite was preferentially located in deformation bands (Figs. $6 a$ \& b). This agrees well with numerous reports in the literature [3, 5, 7, 12-14]. The almost exclusive concentration of strain-induced martensitic transformation within deformation bands may thus limit the volume fraction of martensite developed during deformation. As expected, the crystallographic orientations of the austenite and martensite were related through a nearly-perfect K-S orientation relationship, as exemplified in Fig. 9a. Moreover, the martensite particles nucleated within a particular austenite grain were characterized by broadly-similar crystallographic orientations (compare Figs. $6 b$ \& $c$ ); this evidenced a strong variant selection 

in the authors' companion paper [44].
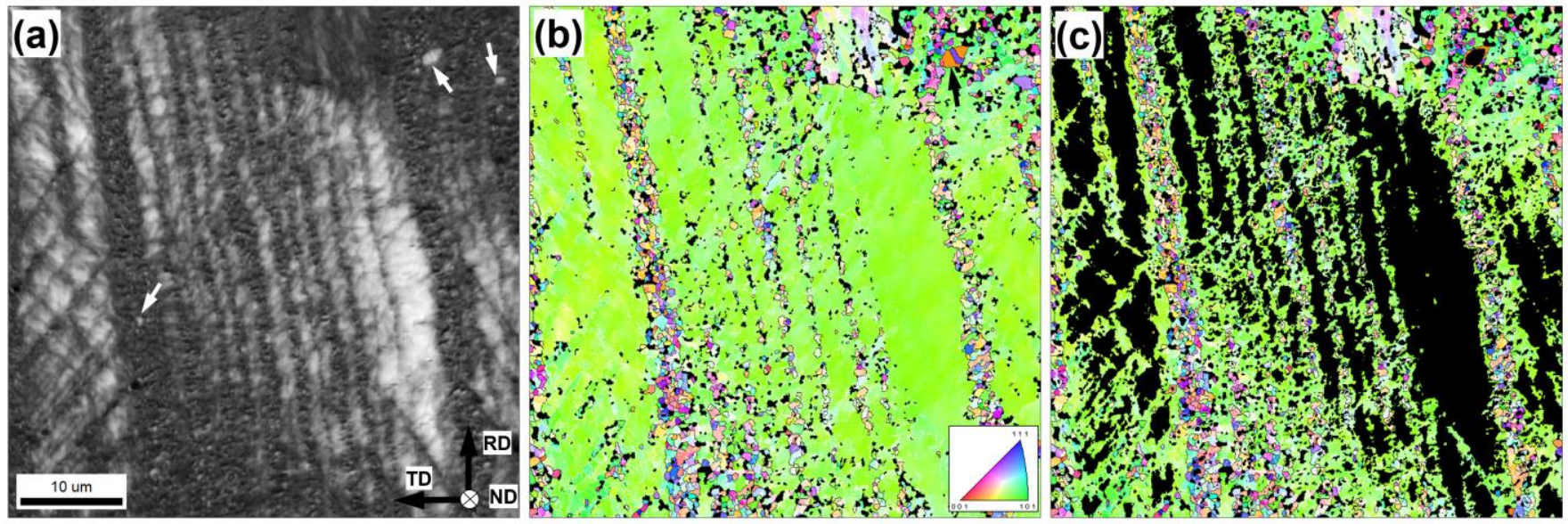

Figure 8. High-resolution EBSD maps taken from material annealed at $700^{\circ} \mathrm{C}$ for $1 \mathrm{~h}$ : (a) Kikuchi-band-contrast map, (b) austenite orientation map, and (c) orientation map of the reverted austenite (see Section 3.2.3 for details). In (a) and (b), arrows indicate recrystallization nuclei. In (b), black clusters show the martensitic phase. In (b) and (c), grains are colored according to their crystallographic orientation relative to the ND; LABs and HABs are depicted as bright and dark lines, respectively.
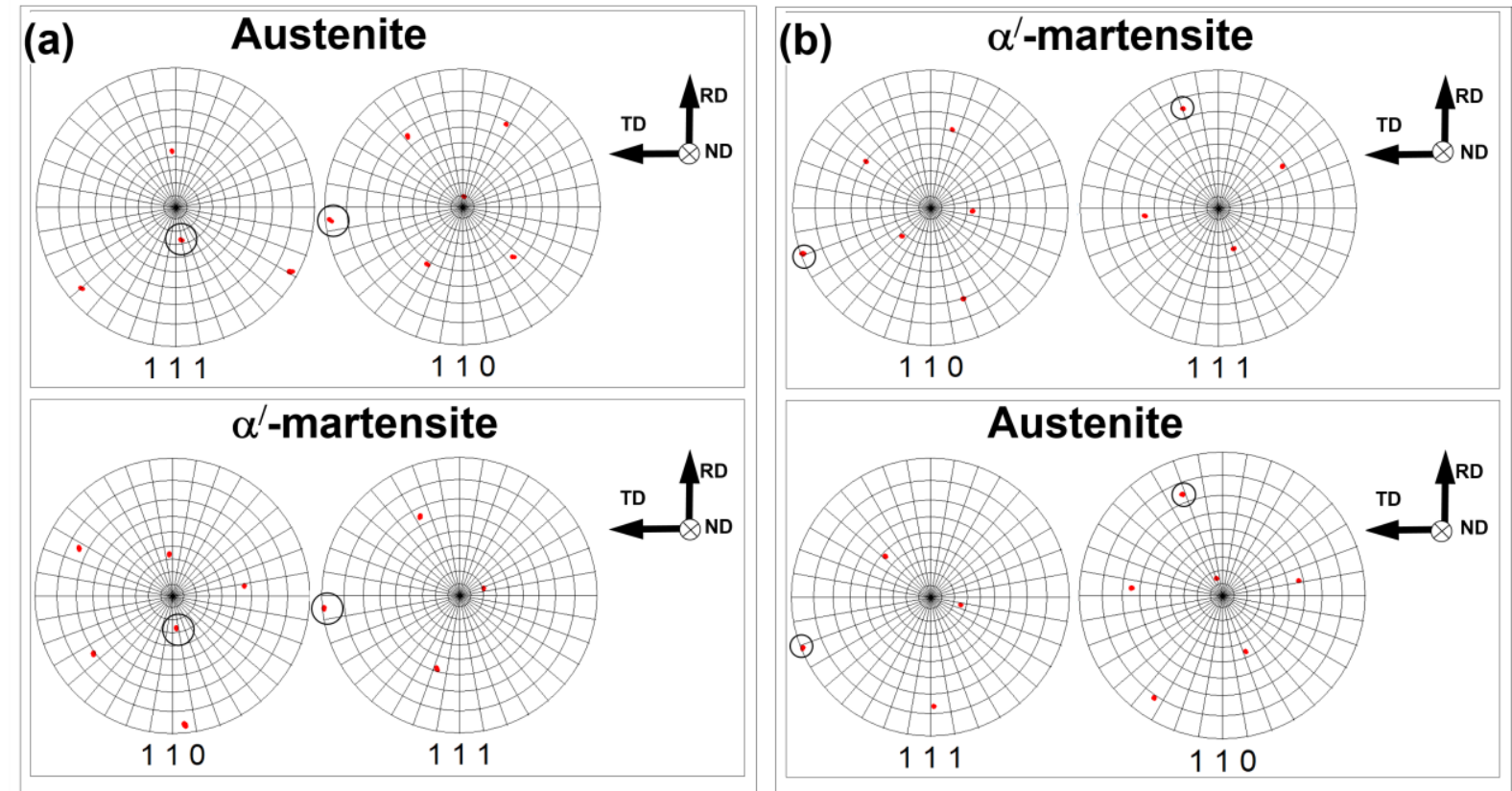

Figure 9. Typical crystallographic relationship between (a) austenite and strain-induced a' martensite in cryo-rolled material, and (b) the retained $a^{\prime}$ martensite and the reverted austenite in annealed material. The closest related directions in the martensitic and the austenitic phases are circled. In (b), the pole figures were obtained from the material annealed at $700^{\circ} \mathrm{C}$ for $1 \mathrm{~h}$.

During the reversion process on heating, the strain-induced martensite transformed back almost completely to austenite (Figs. 7 and 8). However, the resulting austenite tended to appear dark in the Kikuchi-band-contrast maps (Figs. 7a and 8a), thus suggesting a relatively-high dislocation density in this austenite. 
The most striking feature of the austenite formed by the reversion of martensite at relatively-low temperature was the similarity of its crystallographic orientations relative to those of the parent austenite (Fig. 7b). This restoration of the original crystallographic orientation during the reversion process thus provided strong evidence for an austenite memory effect [23, 27, 28, 31-36], and explained the relatively-limited degree of grain-refinement during reversion (Fig. $4 \mathrm{~b}$ ) as well as the restoration of the original rolling texture (Fig. 5b). Nevertheless, the martensite-to-austenite reversion at low temperatures did produce new crystallographic orientations in some cases; an example is indicated by the arrow in Fig. 7b. At relatively high reversion temperatures, the latter phenomenon became much more pronounced, thus leading to significant grain refinement (Fig. $8 b)$. Local crystallographic measurements revealed a nearly-perfect K-S orientation relationship between the retained martensite and such new orientations produced by reversion (Fig. 9b) at both low and high reversion temperatures.

Considering the relatively-high concentration of crystal defects in the austenite generated by martensite reversion, the K-S orientation relationship between the phases, and especially the memory effect, martensite reversion to austenite was deduced to be governed by a shear mechanism. The activation of this mechanism was probably attributable to the relatively low annealing temperatures (i.e., $\sim 0.51-0.57 \mathrm{~T}_{\mathrm{m}}$ ), but may also have been affected by the relatively-high heating rate employed in this work $(\sim 10 \mathrm{~K} / \mathrm{s})$. As shown by Leem, et al. [25], heating rates of $10 \mathrm{~K} / \mathrm{s}$ and above may promote martensitic transformation.

Considering the shear character of the reversion process, the observed austenite memory effect presumably arose from some sort of very strong variant selection during the $\gamma \rightarrow \alpha^{\prime} \rightarrow \gamma$ transformation sequence. Assuming an important sensitivity of this phenomenon to micro-scale residual stresses [32], it may be hypothesized that recovery at high reversion temperatures might relax the variant-selection effect, leading to additional variants, and thus promote grain refinement (Fig. 8b).

It is also worth noting that the martensite which reverted back to austenite at relatively-high temperatures was characterized by a small fraction of sporadic defect-free grains (examples indicated by arrows in Fig. 8a) which sometimes contained annealing twins (example shown by an arrow in Fig. 8b). Perhaps, this indicates the activation of a diffusional mechanism which contributed only slightly to the high-temperature reversion process.

\subsubsection{Grain refinement efficiency}

Measurements of the grain-boundary area in the austenite formed by reversion of martensite served to quantify the efficiency of grain-refinement by this mechanism. To this end, this austenite was extracted from EBSD data (Figs. 7c and 8c). The extraction procedure was based on the fact that such austenite was characterized by a relatively-high dislocation density and thus appeared dark in the Kikuchi-band-contrast maps. Therefore, a contrast threshold in these maps was selected manually to extract the dark band regions (compare Figs. 7a \& c and 8a \&c).

Misorientation data derived from the extracted regions were plotted in terms of misorientation-angle and misorientation-axis distributions (e.g., Fig. 10a); more specifically, the misorientation-angle data were expressed in terms of grain-boundary density, corresponding to the 
total grain-boundary length for a given range of misorientation angles divided by the area of the extracted EBSD map. This metric provides a more direct comparison of grain-boundary characteristics for different material conditions, thus facilitating the evaluation of the grain-refinement effect. The influence of the reversion temperature on total density of HABs is presented in Fig. 10b.
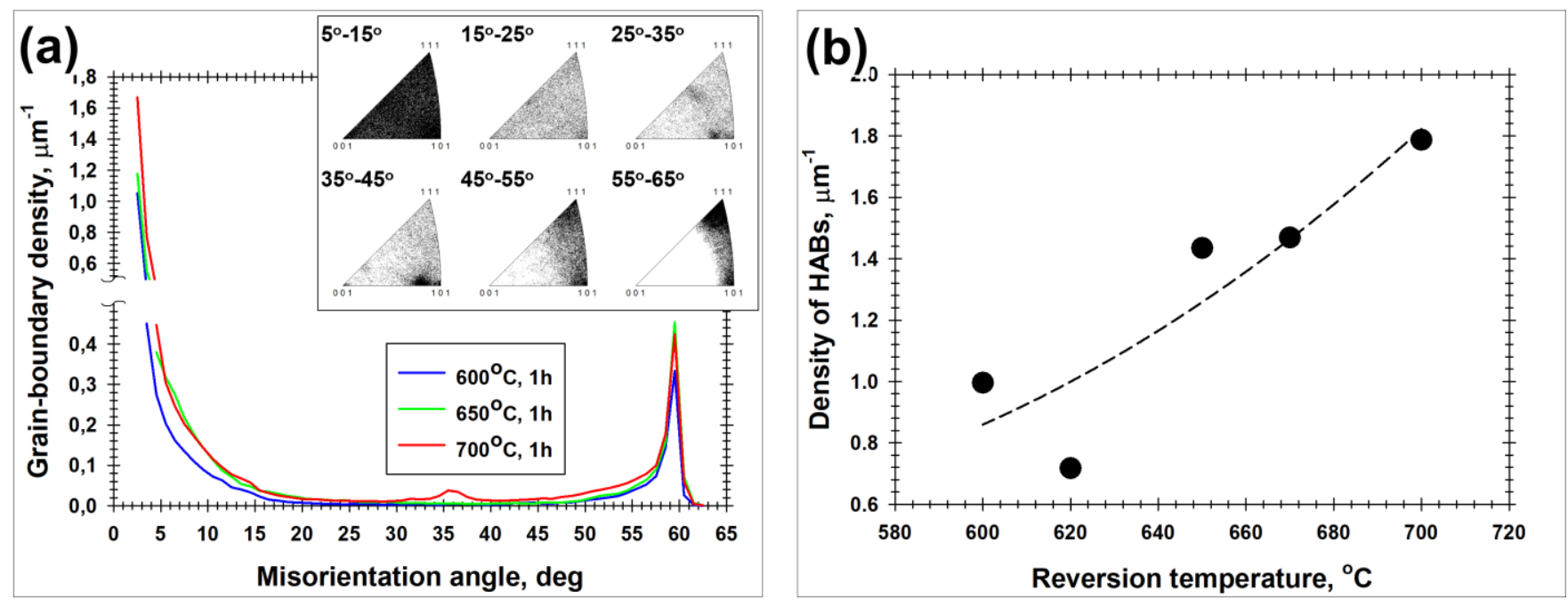

Figure 10. Effect of reversion temperature on (a) misorientation distribution in the reverted austenite, and (b) density of HABs in the reverted austenite. Note: The typical misorientation-axis distribution in the reverted austenite is shown in the top right corner of (a).

The misorientation distributions of the reverted austenite were characterized by a pronounced low-angle maximum, a sharp peak near $60^{\circ}$ as well as clustering of misorientation axes near <110> and <111> poles (Fig. 10a). The measured misorientations were broadly similar to those between the crystallographic variants expected from the $\gamma-\alpha^{\prime}-\gamma$ phase transformation sequence governed by the K-S orientation relationship (supplementary Table S-2). This perhaps also corroborates the shear mechanism of martensite-to-austenite reversion, as mentioned in the previous section.

An increase in the reversion temperature doubled the HAB area in the reverted austenite (Fig. 10b). This reflected an enhancement of grain-refinement as is readily seen by comparing Figs. $7 \mathrm{~b}$ and $8 \mathrm{~b}$. As discussed in the previous section, microstructural changes in this temperature range were affected only slightly by recrystallization. Therefore, the observed increase in $\mathrm{HAB}$ area presumably originated from a reduction in preferential variant selection during the $\alpha^{\prime} \rightarrow \gamma$ transformation.

At $650^{\circ} \mathrm{C}$, the increase in $\mathrm{HAB}$ area was primarily contributed by 60 -degree misorientations (Fig. 10a), thus suggesting the nucleation of twin-related variants. This effect has also been described in the literature $[27-29,32,34,36,47]$. At $700^{\circ} \mathrm{C}$, the $\mathrm{HAB}$ area increased for a wide range of misorientation angles (Fig. 10a), providing evidence for the formation of multiple variants. It may thus be concluded that reversion at higher temperatures is more useful for grain refinement. The LAB density was also found to increase with annealing temperature (Fig. 10a), thus perhaps 
reflecting a nucleation of crystallographic variants with relatively-low orientation difference (supplementary Table S-2).

Even at the high temperatures, however, the refinement occurred only in prior-martensitic areas, and regions with retained austenite remained nearly unchanged with regard to microstructural scale (Fig. 8b).

\subsection{Recrystallization}

Typical EBSD maps taken from material annealed at $800^{\circ} \mathrm{C}$ are shown in Fig. 11. In these maps, austenite grains are colored according to their crystallographic orientations relative to the ND whereas the $\alpha^{\prime}$ martensite is black. It is clear from the EBSD data that austenite had undergone recrystallization. However, recrystallization was not complete, and the resulting microstructure thus retained a substantial fraction of coarse unrecrystallized grains (Fig. 11a). Such microstructures are often observed during recrystallization of metastable austenitic steels [26, 48-51].
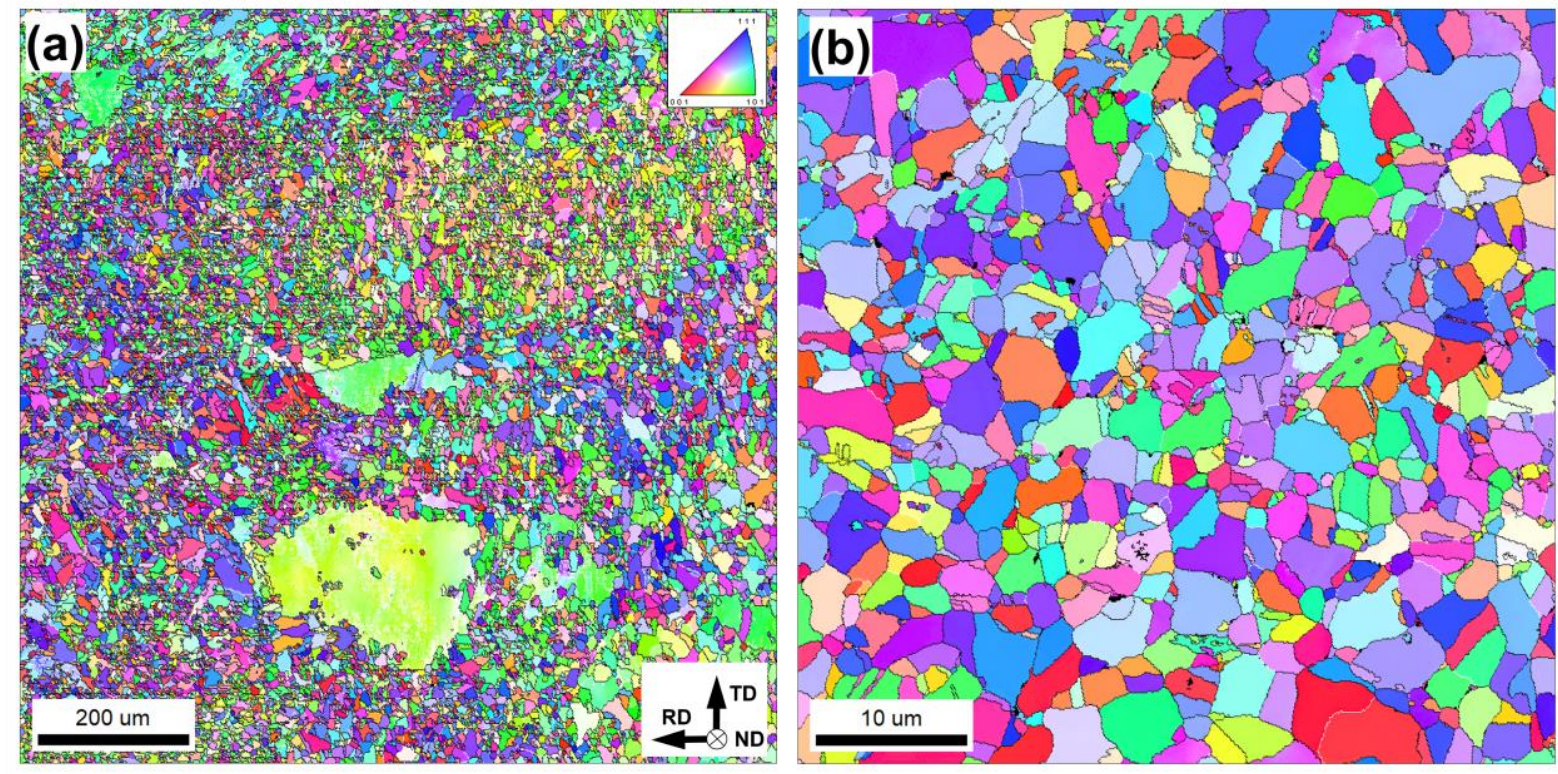

Figure 11. EBSD austenite orientation maps taken from material annealed at $800^{\circ} \mathrm{C}$ for $1 \mathrm{~h}$ : (a) low-magnification (overview) map, and (b) high-resolution map taken from a recrystallized area. In the maps, individual grains are colored according to their crystallographic orientations relative to the ND. LABs and HABs are depicted as bright and black lines, respectively. The retained a' martensite appears black.

To obtain insight into the recrystallization process, the textures of the recrystallized and unrecrystallized regions were extracted from the global EBSD maps using an approach developed by Konkova, et al. [52]. Specifically, recrystallized grains were defined as those having an orientation spread below the limit detectable by EBSD (i.e., $2^{\circ}$ ), and the remaining grains (with higher orientation spread) were taken to be unrecrystallized. An example of the partitioned microstructure is given in supplementary Fig. S-2, and the resulting texture data are shown in Fig. 12. The fraction of recrystallized material measured by this approach was $58 \%$. 


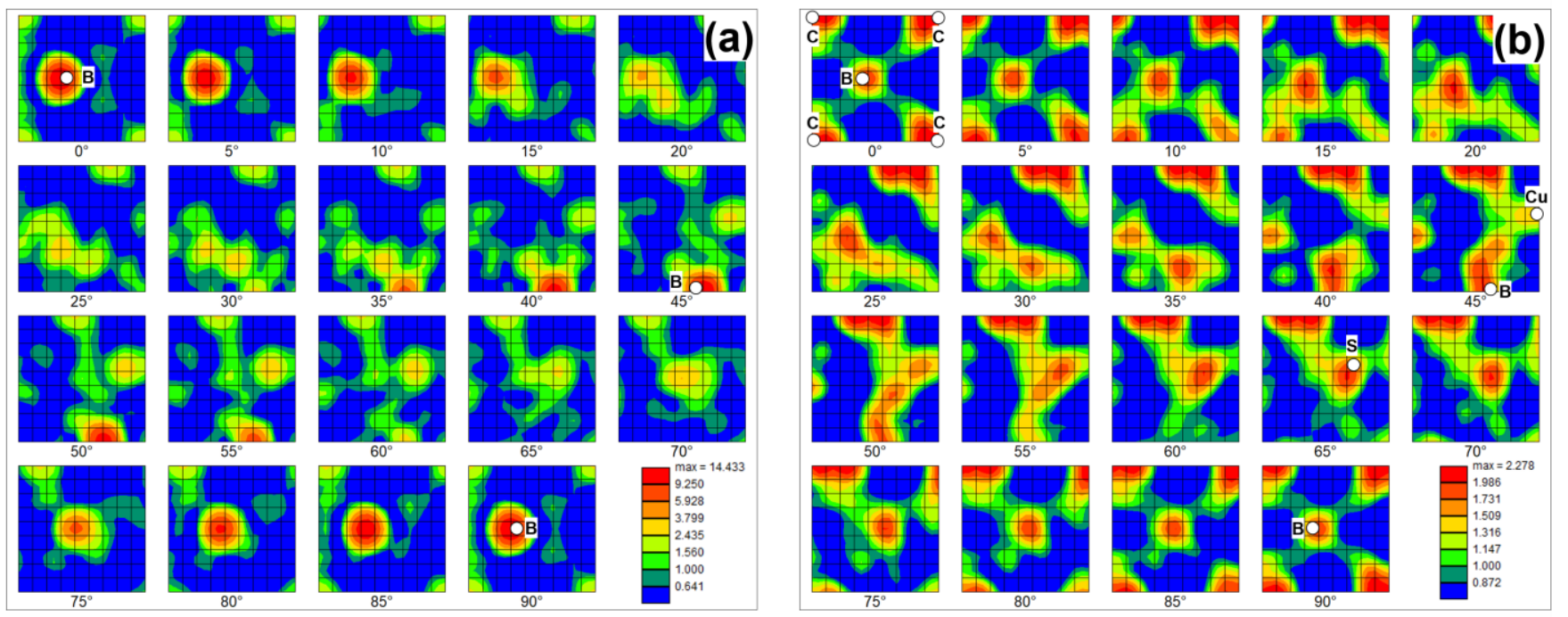

B - Brass $\{110\}<112>$ orientation, $\mathrm{Cu}$ - Copper $\{112\}<111>$ orientation, C - Cube $\{100\}<001>$ orientation, $\mathbf{S}-\mathrm{S}\{123\}<634>$ orientation

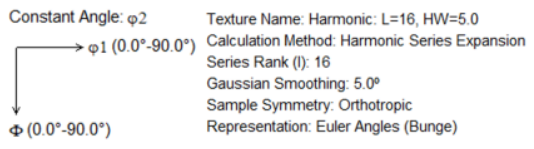

Figure 12. Orientation distribution functions (ODFs) showing the crystallographic texture in austenite in the material annealed at $800^{\circ} \mathrm{C}$ for $1 \mathrm{~h}$ : (a) unrecrystallized material and (b) recrystallized material. For simplicity, several ideal rolling orientations are superimposed on the ODFs

Similar to recent findings by Sun, et al. [48], the main crystallographic orientation of the unrecrystallized grains was found to be close to the Brass $\{110\}<112>$ component (Fig. 12a). The Brass orientation is predicted to be stable during cold rolling [53], and therefore it should accumulate relatively-low orientation gradients during straining and hence a limited driving force for subsequent recrystallization [54]. By contrast, the texture of the recrystallized material was dominated by the Cube $\{001\}<100>$ as well as Brass $\{110\}<112>$, Copper $\{112\}<111>$, and $S$ $\{123\}<634>$ orientations (Fig. 12b). The presence of the three latter components in the recrystallization texture suggested that the recrystallization nuclei inherited the crystallographic orientations of cryogenically-rolled grains (compare Fig. 5a and 12b).
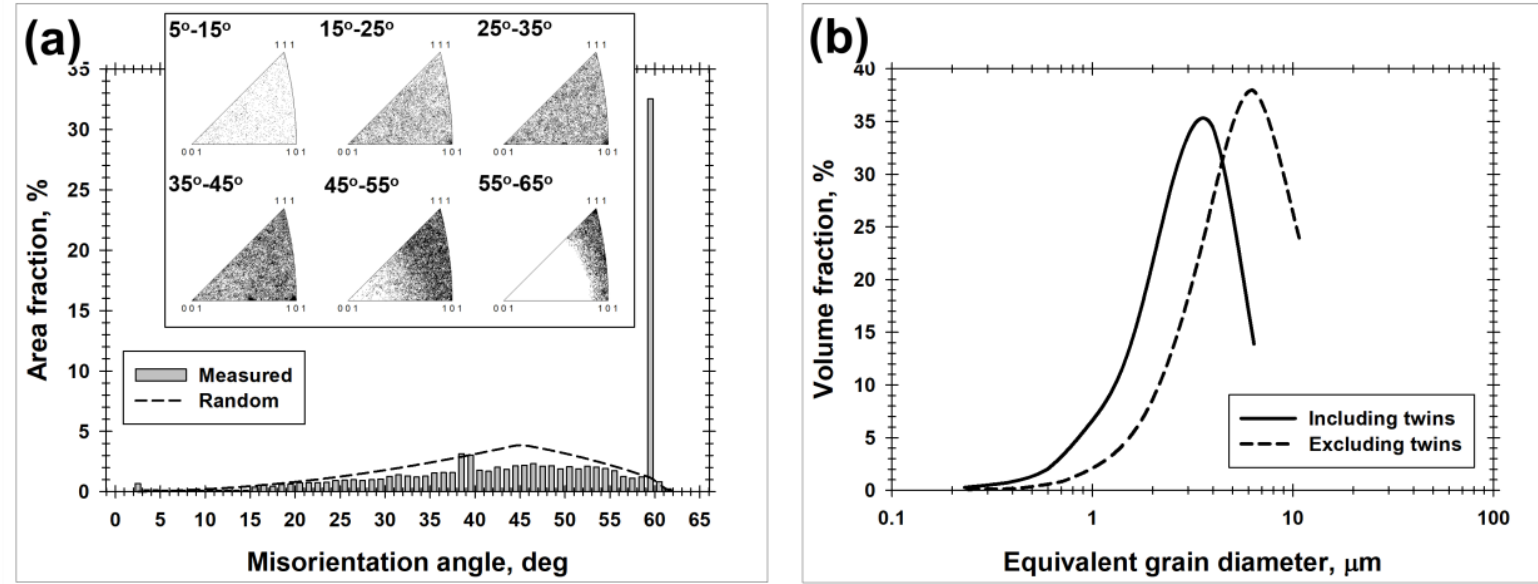

Figure 13. (a) Misorientation distribution and (b) grain-size distributions in the recrystallized austenite developed in material annealed at $800^{\circ} \mathrm{C}$ for $1 \mathrm{~h}$. In (a), misorientation-axis distribution is shown in the upper portion of the figure. 
Somewhat surprisingly, it was found that the recrystallized material also contained a small fraction of retained martensite (small, black regions in Fig. 11b). The confidence index of these EBSD data typically exceeded 0.1 , thus suggesting relatively-reliable measurements [55]. Local crystallographic measurements revealed no clear orientation relationship between adjacent martensite and austenite grains in such instances, thus suggesting a diffusional mechanism for martensite reversion. This finding is consistent with misorientation distribution in the recrystallized austenite (Fig. 13a), which was distinctly different from that in the austenite formed by martensite reversion shown in Fig. 10a. Nevertheless, the martensite reversion mechanism at this temperature is not completely clear and warrants further study.

Although recrystallization resulted in grain refinement, the mean grain size was well above the desirable ultrafine-grain range (Fig. 13b). Specifically, the mean grain diameter of the recrystallized grains (including annealing twins) was measured to be $\sim 1.2 \mu \mathrm{m}$. The scale of such features as well as the pronounced heterogeneity of the overall microstructure (Fig. 11a) thus indicates that modifications to the processing route are necessary to obtain an optimal material. In this regard, annealing of the cryo-rolled material between $700^{\circ} \mathrm{C}$ and $800^{\circ} \mathrm{C}$ may be of particular interest. Such a treatment may promote extensive variant selection during martensite reversion but avoid excessive growth of recrystallized grains, thus producing a desirable ultrafine-grain structure. To eliminate recrystallization-resistant grains with near-Brass orientations (and thereby provide microstructure uniformity), a relatively long-term anneal may be required, however.

\section{Conclusions}

The objective of this work was to evaluate the efficiency of advanced thermomechanical processing based on cryogenic deformation for the refinement of grain structure in type 321 metastable austenitic steel. To this end, the material was rolled at liquid-nitrogen temperature and then annealed in the temperature range of $400-800^{\circ} \mathrm{C}(0.34-0.54 \mathrm{~T})$. The main conclusions from this work are as follows.

As expected, the nucleation of strain-induced martensite during rolling as well as its subsequent reversion to austenite during annealing was governed by the K-S orientation relationship $\{111\}_{\gamma} \|\{110\}_{\alpha^{\prime}}$ and $<110>_{\gamma} \|<111>_{\alpha^{\prime}}$. Importantly, however, both processes were characterized by very-strong variant selection. This resulted in a restoration of the crystallographic orientation of the coarse parent austenite grains during the $\gamma \rightarrow \alpha^{\prime} \rightarrow \gamma$ transformation sequence. This effect was most pronounced during relatively low-temperature reversion (i.e. $600-650^{\circ} \mathrm{C}$ ), and therefore the present approach is not feasible for grain refinement.

A very important characteristic of the strain-induced martensite was its almost exclusive activation within deformation bands. This naturally restricted the volume fraction of the martensitic phase developed during rolling. Accordingly, even relaxation of variant selection during reversion at high temperature (i.e. $700^{\circ} \mathrm{C}$ ) resulted only in a bimodal grain structure consisting of transformed ultrafine-grain domains and untransformed coarse-grain remnants of the original grains. 
The refinement of untransformed coarse grains was achieved by recrystallization which follows reversion at $800^{\circ} \mathrm{C}$. However, grains with crystallographic orientations close to Brass $\{110\}<112>$ do not readily recrystallized, and thus the resulting microstructure was noticeably heterogeneous.

At present, therefore, thermomechanical processing utilizing cryogenic deformation is not totally suitable for the formation of an ultrafine-grain microstructure in type 321 metastable austenitic steel. Annealing of the cryorolled material between $700^{\circ} \mathrm{C}$ and $800^{\circ} \mathrm{C}$ was suggested to be a possible pathway for the technology optimization. Such treatment may promote extensive variant selection during the martensite reversion but avoid an excessive growth of recrystallized grains and thus produce the desirable ultrafine-grained structure. To eliminate the recrystallization-resistant grains with nearly-Brass orientation (and thereby provide microstructure uniformity), a relatively long-term anneal may be required, however.

\section{Acknowledgements}

The present work was partially supported by the Russian Fund for Fundamental Research (project No.17-42-020426). The authors would also like to thank P. Klassman for technical assistance during cryogenic rolling.

\section{References}

[1] R. Valiev: Nature Mater., 2004, vol. 8, pp. 511-516, doi:10.1038/nmat1180

[2] R. Song, D. Ponge, D. Raabe, J.G. Speer, D.K. Matlock: Mater. Sci. Eng. A, 2006, vol. 441, pp. 1-17, https://doi.org/10.1016/j.msea.2006.08.095

[3] K.H. Lo, C.H. Shek, J.K.L. Lai: Mater. Sci. Eng. R, 2009, vol. 65, pp. 39-104, https://doi.org/10.1016/j.mser.2009.03.001

[4] J.W. Brooks, M.H. Loretto, R.E. Smallman: Acta Metall., 1979, vol. 27, pp. 1839-1847, https://doi.org/10.1016/0001-6160(79)90074-9

[5] A.K. De, D.C. Murdock, M.C. Mataya, J.G. Speer, D.K. Matlock: Scripta Mater., 2004, vol. 50, pp. 1445-1449, https://doi.org/10.1016/j.scriptamat.2004.03.011

[6] T. Suzuki, J. Kojima, K. Suzuki, T. Hashimito, M. Ichihara: Acta Metall., 1977, vol. 25, pp. 1151-1162, https://doi.org/10.1016/0001-6160 (77)90202-4

[7] Y.F. Shen, X.X. Li, X. Sun, Y.D. Wang, L. Zuo: Mater. Sci. Eng. A, 2012, vol. 552, pp. 514-522, https://doi.org/10.1016/j.msea.2012.05.080

[8] P. Mallick, N.K. Tewary, S.K. Ghosh, P.P. Chattopadhyay: Mater. Character., in press, https://doi.org/10.1016/j.matchar.2017.09.027

[9] T. Suzuki, J. Kojima, K. Suzuki, T. Hashimito, M. Ichihara: Acta Metall., 1977, vol. 25, pp. 1151-1162, https://doi.org/10.1016/0001-6160(77)90202-4

[10] N. Nakada, H. Ito, Y. Matsuoka, T. Tsuchiyama, S. Takaki: Acta Materialia, 2010, vol. 58, pp. 895-903, https://doi.org/10.1016/j.actamat.2009.10.004

[11] I. Shakhova, V. Dudko, A. Belyakov, K. Tsuzaki, R. Kaibyshev: Mater. Sci. Eng. A, 2012, vol. 545, pp. 176-186, https://doi.org/10.1016/j.msea.2012.02.101 
[12] S. Sabooni, F. Karimzadeh, M.H. Enayati, A.H.W. Ngan: Mater. Sci. Eng. A, 2015, vol. 636, pp. 221-230, https://doi.org/10.1016/j.msea.2015.03.101

[13] G.B. Olson, M. Cohen: Metall. Trans. A, 1975, vol. 6, pp. 791-795, https://doi.org/10.1007/BF02672301

[14] A. Das, S. Sivaprasad, P.C. Chakraborti, S. Tarafder: Mater. Sci. Eng. A, 2011, vol. 528, pp. 7909-7914, https://doi.org/10.1016/j.msea.2011.07.011

[15] K. Tomimura, S. Takaki, S. Tanimoto, Y. Tokunaga: ISIJ International, 1991, vol. 31, pp. 721-727

[16] B. Ravi Kumar, A.K. Singh, B. Mahato, P.K. De, N.R. Bandyopadhyay, D.K. Bhattacharya: Mater. Sci. Eng. A, 2006, vol. 429, pp. 205-211, dx.doi.org/10.1016/j.msea.2006.05.107

[17] T.-H. Lee, E. Shin, C.-S. Oh, H.-Y. Ha, S.-J. Kim: Acta Mater., 2010, vol. 58, pp. 3173-3186, https://doi.org/10.1016/j.actamat.2010.01.056

[18] L. Bracke, K. Verbeken, L. Kestens, J. Penning: Acta Mater., 2009, vol. 57, pp. 1512-1524, https://doi.org/10.1016/j.actamat.2008.11.036

[19] B. Roy, R. Kumar, J. Das: Mater. Sci. Eng. A, 2015, vol. 631, pp. 241-247, https://doi.org/10.1016/j.msea.2015.02.050

[20] T.S. Wang, J.P. Peng, Y.W. Gao, F.C. Zhang, T.F. Jing: Mater. Sci. Eng. A, 2005, vol. 407, pp. 84-88, https://doi.org/10.1016/j.msea.2005.06.022

[21] M. Eskandari, A. Kermanpur, and A. Najafizadeh: Metall. Mater. Trans. A, 2009, vol. 40, pp. 2241-2249, https://doi.org/10.1007/s11661-009-9916-Z

[22] T.-H. Lee, C.-S. Oh, S.J. Kim, S. Takaki: Acta Mater., 2007, vol. 55, pp. 3649-3662, https://doi.org/10.1016/j.actamat.2007.02.023

[23] H. Shirazi, G. Miyamoto, S. Hossein Nedjad, T. Chiba, M. Nili Ahmadabadi, T. Furuhara: Acta Mater., 2018, vol. 144, pp. 269-280, https://doi.org/10.1016/j.actamat.2017.10.068

[24] K. Tomimura, S. Takaki, Y. Tokunaga: ISIJ International, 1991, vol. 31, pp. 1431-1437

[25] D-S. Leem, Y-D. Lee, J-H. Jun, C-S. Choi: Scripta Mater., 2001, vol. 45, pp. 767-472, https://doi.org/10.1016/S1359-6462(01)01093-4

[26] A. Kisko, A.S. Hamada, J. Talonen, D. Porter, L.P. Karjalainen: Mater. Sci. Eng. A, 2016, vol. 657, pp. 359-370, http://dx.doi.org/10.1016/j.msea.2016.01.093

[27] X. Zhang, G. Miyamoto, Y. Toji, S. Nambu, T. Koseki, T. Furuhara: Acta Mater., 2018, vol. 144, pp. 601-612, https://doi.org/10.1016/j.actamat.2017.11.003

[28] N. Nakada, Mater. Letter., 2017, vol. 187, pp. 166-169, http://dx.doi.org/10.1016/j.matlet.2016.10.056

[29] J. Jelenkowski: J. Mater. Proc. Technol., 1997, vol. 64, pp. 207-217

[30] A. Wirth: Micron, 1973, vol. 4, pp. 230-242

[31] A.A. Tiamiyu, A.G. Odeshi, J.A. Szpunar: JMEPEG, 2018, vol. 27, pp. 889-904, https://doi.org/10.1007/s11665-018-3180-6

[32] N. Nakada, T. Tsuchiyama, S. Takaki, S. Hashizume: ISIJ International, 2007, vol. 47, pp. 1527-1532

[33] R.D.K. Misra, Z. Zhang, P.K.C. Venkatasurya, M.C. Somani, L.P. Karjalainen: Mater. Sci. Eng. A, 2010, vol. 527, pp. 7779-7792, dx.doi.org/10.1016/j.msea.2010.08.051

[34] V.V. Sagaradze, V.E. Danilchenko, Ph. L'Heritier, V.A. Shabashov: Mater. Sci. Eng. A, 2002, vol. 337, pp. 146-159

[35] M.C. Somani, P. Juntunen, L.P. Karjalainen, R.D.K. Misra, A. Kyrolainen: Metall. Mater. Trans. A, 2009, vol. 40, pp. $729-744$ 
[36] V.V. Sagaradze: NanoStructured Mater., 1997, vol. 9, pp. 201-204

[37] S. Rajasekhara, L.P. Karjalainen, A. Kyröläinen, P.J. Ferreira: Mater. Sci. Eng. A, 2010, vol. 527, pp. 1986-1996, dx.doi.org/10.1016/j.msea.2009.11.037

[38] Y. Lu, B. Hutchinson, D.A. Molodov, G. Gottstein: Acta Mater., 2010, vol. 58, pp. 3079-3090, https://doi.org/10.1016/j.actamat.2010.01.045

[39] M. Klimova, S. Zherebtsov, N. Stepanov, G. Salishchev, D.A. Molodov: Mater. Character., 2017, vol. 132, pp. 20-30, https://doi.org/10.1016/j.matchar.2017.07.043

[40] A.A. Tiamiyu, J.A. Szpunar, A.G. Odeshi, I. Oguocha, M. Eskandari: Metall. Mater. Trans. A, 2017, vol. 48, pp. 5990-6012, https://doi.org/10.1007/s11661-017-4361-x

[41] H.A. Rezzei, M.S. Ghazani, B. Eghbali, Effect of post deformation annealing on the microstructure and mechanical properties of cold rolled AISI 321 austenitic stainless steel, Mater. Sci. Eng. A, 2018, vol. 736, pp. 364-374, https://doi.org/10.1016/j.msea.2018.09.012

[42] M.G. Shahri, S.R. Hosseini, M. Salehi, Formation of nano/ultrafine grains in AlSI 321 stainless steel using advanced thermo-mechanical process, Acta Metall. Sin. (Engl. Lett.), 2015, vol. 28, pp. 499-504, https://doi.org/10.1007/s40195-015-0225-9

[43] V.M.A. Silva, C.G. Camerini, J.M. Pardal, J.C.G. de Blas, G.R. Perera, Eddy current characterization of cold-worked AISI 321 stainless steel, J. Mater. Res. Technol., 2018, vol. 7, pp. 395-401, https://doi.org/10.1016/j.jmrt.2018.07.002

[44] G. Korznikova, S. Mironov, T. Konkova, A. Aletdinov, R. Zaripova, M. Myshlyaev, S.L. Semiatin: Metall. Mater. Trans. A, 2018, vol. 49, pp. 6325-6336, https://doi.org/10.1007/s11661-018-4919-2

[45] A. Stormvinter, G. Miyamoto, T. Furuhara, P. Hedstrom, A. Borgenstam: Acta Mater., 2012, vol. 60, pp. 7265-7274, http://dx.doi.org/10.1016/j.actamat.2012.09.046

[46] Y. Tomota, Y. Morioka, W. Nakagawara: Acta Mater., 1998, vol. 46, pp. 1419-1426

[47] K.B. Guy, E.P. Butler, D.R.F. West: Met. Sci., 1983, vol. 17, pp. 167-176, dpi: 10.1179/030634583790420961

[48] G.S. Sun, L.X. Du, J. Hu, R.D.K. Misra: Mater. Sci. Eng. A, 2018, vol. 709, pp. 254-264, http://dx.doi.org/10.1016/j.msea.2017.10.054

[49] M. Odnobokova, A. Belyakov, N. Enikeev, D.A. Molodov, R. Kaibyshev: Mater. Sci. Eng. A, 2017, vol. 689, pp. 370-383, http://dx.doi.org/10.1016/j.msea.2017.02.073

[50] M. Nezakat, H. Akhiani, S.M. Sabet, J. Szpunar: Mater. Character., 2017, vol. 123, pp. 115-127, http://dx.doi.org/10.1016/j.matchar.2016.11.019

[51] M. Nezakat, H. Akhiani, M. Hoseini, J. Szpunar: Mater. Character., 2014, vol. 98, pp. 10-17, http://dx.doi.org/10.1016/j.matchar.2014.10.006

[52] T. Konkova, S. Mironov, A. Korznikov, S.L. Semiatin: Mater. Sci. Eng. A, 2011, vol. 528, pp. 7432- 7443, https://doi.org/10.1016/j.msea.2011.06.047

[53] J. Hirsch, K. Lucke: Acta Metall., 1988, vol. 36, pp. 2863-2882, https://doi.org/10.1016/0001-6160(88)90172-1

[54] F.J. Humphreys, M. Hatherly: Recrystallization and related phenomena, 2nd ed., Elsevier, Oxford, 2000

[55] D.P. Field: Ultramicroscopy, 1997, vol. 67, pp. 1-9, https://doi.org/10.1016/S0304-3991(96)00104-0 
Figure 1. Effect of annealing temperature on microhardness. In all cases, the annealing time was 1 h. Note: Error bars show the standard deviation.

Figure 2. ThermoCalc predictions of the temperature dependence of the volume fraction of (a) $\mathrm{CrC}$ and (b) $\mathrm{Ni}_{3}$ Ti particles

Figure 3. Selected portions of low-resolution EBSD phase maps showing microstructure (a) after cryogenic rolling, and after subsequent annealing at (b) $400^{\circ} \mathrm{C}$, (c) $600^{\circ} \mathrm{C}$, and (d) $800^{\circ} \mathrm{C}$; in all cases, the annealing time was $1 \mathrm{~h}$. The phase color code is shown in the bottom right corner of (a); black lines depict HABs. RD, ND, and TD denote the rolling direction, normal direction, and transverse direction, respectively.

Figure 4. Selected portions of low-resolution EBSD orientation maps showing austenite microstructure (a) after cryogenic rolling and after subsequent annealing at (b) $600^{\circ} \mathrm{C}$, (c) $650^{\circ} \mathrm{C}$, and (d) $700^{\circ} \mathrm{C}$; in all cases, the annealing time was $1 \mathrm{~h}$. In the maps, individual grains are colored according to their crystallographic orientation relative to the ND; the color code triangle is shown in the bottom right corner of (a). HABs are depicted as black lines. Note: black clusters show the martensitic phase.

Figure 5. Orientation distribution functions showing texture in the austenitic phase after (a) cryogenic rolling or (b) subsequent annealing at $600^{\circ} \mathrm{C}$ for $1 \mathrm{~h}$. For simplicity, the approximate positions of several ideal rolling orientations are indicated in (a).

Figure 6. High-resolution EBSD maps taken from the as-cryogenically-rolled material: (a) Kikuchi-band contrast map, (b) phase map, and (c) orientation map. In (b) and (c), LABs and HABs are depicted as bright and dark lines, respectively. In (c), individual grains are colored according to their crystallographic orientation relative to the ND.

Figure 7. High-resolution EBSD maps taken from material annealed at $600^{\circ} \mathrm{C}$ for $1 \mathrm{~h}$ : (a) Kikuchi-band-contrast map, (b) austenite orientation map, and (c) orientation map of the reverted austenite. In (b) and (c), the austenite grains are colored according to their crystallographic orientation relative to the ND. LABs and HABs are depicted as bright and dark lines, respectively. In (b), black areas represent martensitic phase, and the arrow indicates a new orientation produced during martensite-to austenite reversion.

Figure 8. High-resolution EBSD maps taken from material annealed at $700^{\circ} \mathrm{C}$ for $1 \mathrm{~h}$ : (a) Kikuchi-band-contrast map, (b) austenite orientation map, and (c) orientation map of the reverted austenite. In (a) and (b), arrows indicate recrystallization nuclei. In (b), black clusters show the martensitic phase. In (b) and (c), grains are colored according to their crystallographic orientation relative to the ND. LABs and HABs are depicted as bright and dark lines, respectively.

Figure 9. Typical crystallographic relationship between (a) austenite and strain-induced $\alpha^{\prime}$ martensite in the cryo-rolled material, and (b) the retained $\alpha^{\prime}$ martensite and the reverted 
austenite in the annealed material. The closest related directions in the martensitic and the austenitic phases are circled. In (b), the pole figures were obtained from the material annealed at $700^{\circ} \mathrm{C}$ for $1 \mathrm{~h}$.

Figure 10. Effect of reversion temperature on (a) misorientation distribution in the reverted austenite, and (b) the density of HABs in the reverted austenite. The typical misorientation-axis distribution in the reverted austenite is shown in the top right corner of (a).

Figure 11. EBSD austenite orientation maps taken from material annealed at $800^{\circ} \mathrm{C}$ for $1 \mathrm{~h}$ : (a) low-magnification (overview) map, and (b) high-resolution map taken from a recrystallized area. In the maps, individual grains are colored according to their crystallographic orientations relative to the ND. LABs and HABs are depicted as bright and black lines, respectively. The retained $\alpha^{\prime}$ martensite appears black.

Figure 12. Orientation distribution functions (ODFs) showing the crystallographic texture in austenite in the material annealed at $800^{\circ} \mathrm{C}$ for $1 \mathrm{~h}$ : (a) unrecrystallized material and (b) recrystallized material. For simplicity, several ideal rolling orientations are superimposed on the ODFs.

Figure 13. (a) Misorientation distribution and (b) grain-size distributions in the recrystallized austenite developed in material annealed at $800^{\circ} \mathrm{C}$ for $1 \mathrm{~h}$. In (a), the misorientation-axis distribution is shown in the upper portion of the figure.

\section{Supplementary Figure Captions}

Fig. S-1. Effect of annealing at $600^{\circ} \mathrm{C}$ for $1 \mathrm{~h}$ on grain orientation spread in $\alpha^{\prime}$ martensite

Fig. S-2. Partitioning of the austenite microstructure in the material annealed at $800^{\circ} \mathrm{C}$ for $1 \mathrm{~h}$ : (a) Unrecrystallized material and (b) recrystallized material. In the maps, individual grains are colored according to their crystallographic orientations relative to the ND. LABs and HABs are depicted as bright and black lines, respectively. 
Table 1. Nominal chemical composition of program material (wt\%) according to Russian industrial standard

\begin{tabular}{|cccccccccc|}
\hline $\mathrm{Fe}$ & $\mathrm{C}$ & $\mathrm{Cr}$ & $\mathrm{Ni}$ & $\mathrm{Mn}$ & $\mathrm{Ti}$ & $\mathrm{Si}$ & $\mathrm{Cu}$ & $\mathrm{S}$ & $\mathrm{P}$ \\
\hline Balance & $\leq 0.12$ & $17-19$ & $9-10$ & $\leq 2.0$ & $0.4-1.0$ & $\leq 0.8$ & $\leq 0.3$ & $\leq 0.02$ & $\leq 0.035$ \\
\hline
\end{tabular}




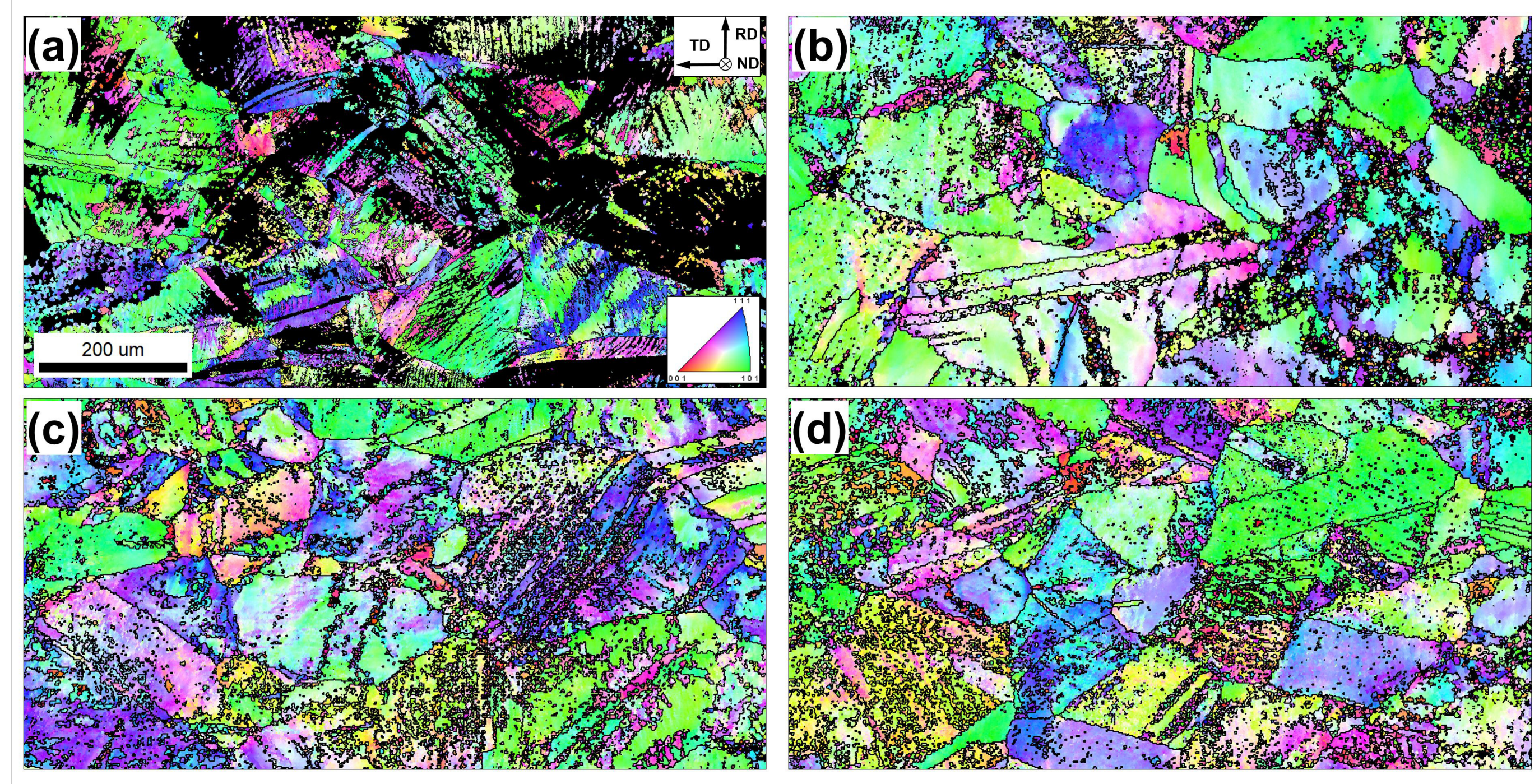


(a) G B

$0^{\circ}$
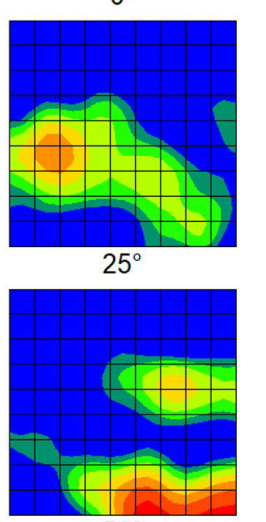

$50^{\circ}$

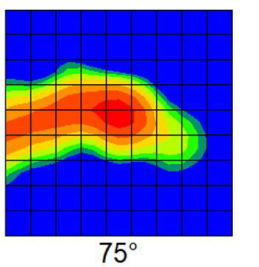

Texture Name: Harmonic: $L=16, H W=5.0$

Texture Name: Harmonic: $L=16, H W=5.0$
Calculation Method: Harmonic Series Expansion Series Rank (I): 16

Gaussian Smoothing: $50^{\circ}$

Sample Symmetry: Orthotropic

Representation: Euler Angles (Bunge)
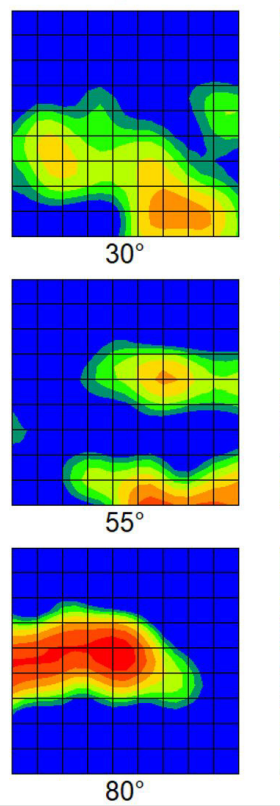
(

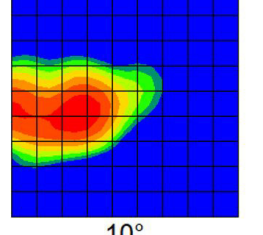

10
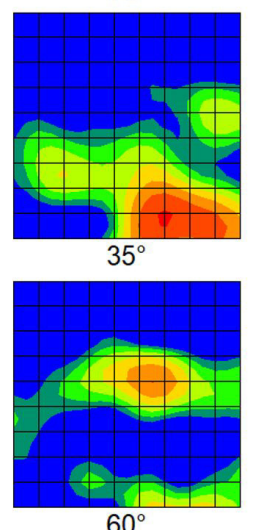

$60^{\circ}$

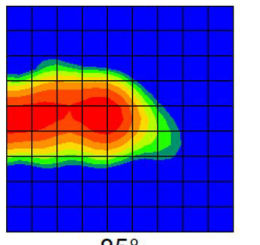

Constant Angle: $\varphi 2$

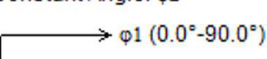

$\downarrow$
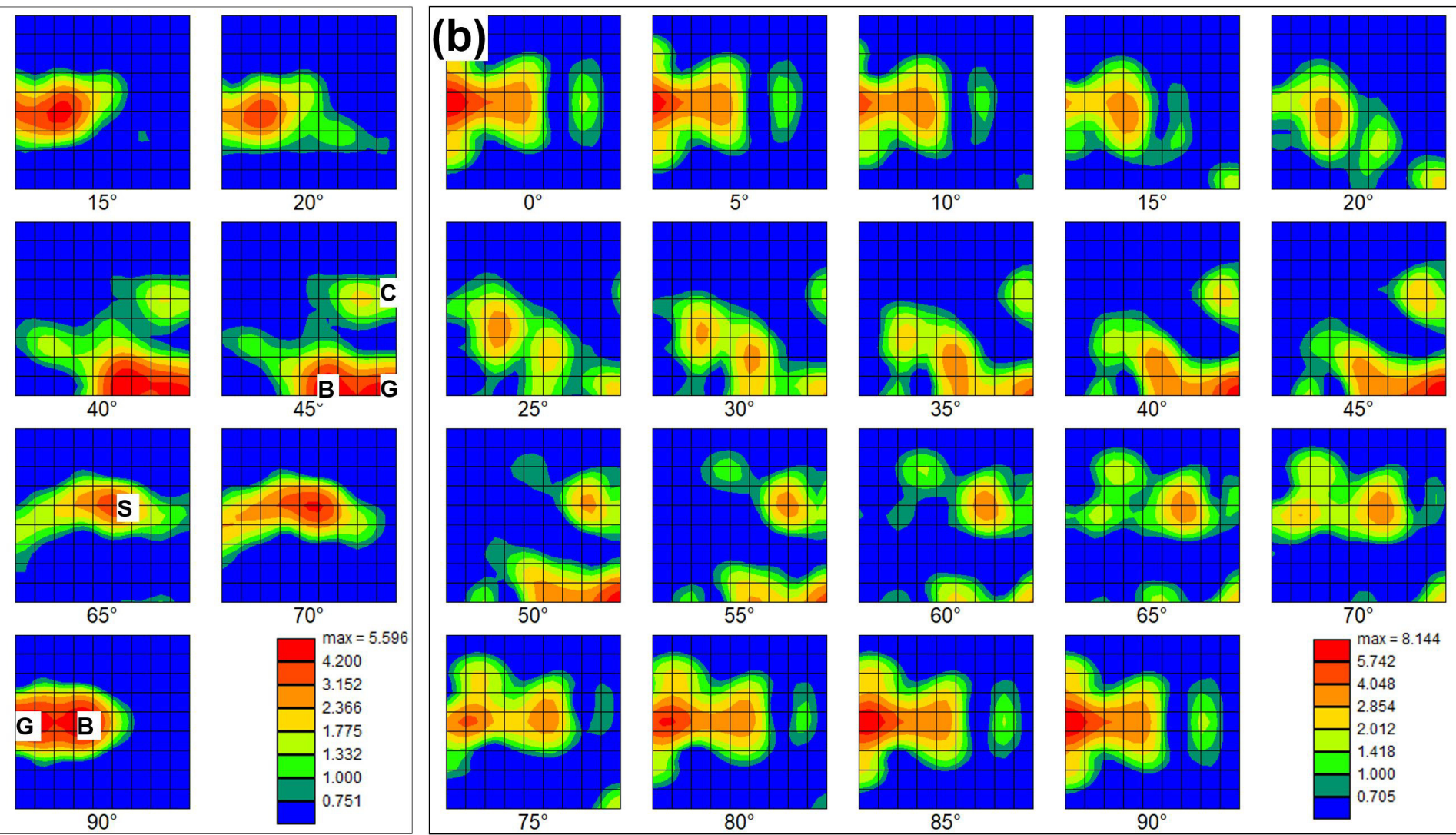

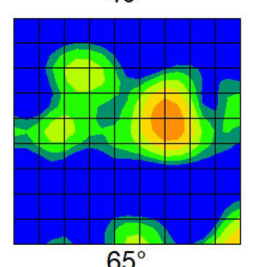

$65^{\circ}$

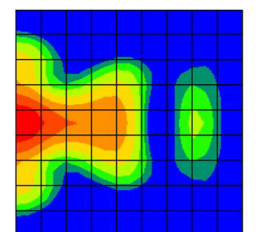

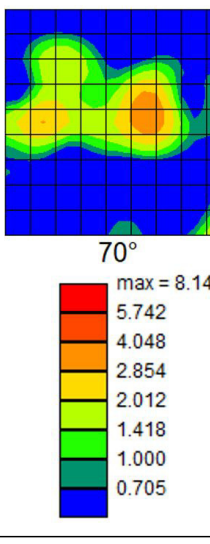

\begin{abstract}
$B=\{110\}<112>$ Brass
\end{abstract}
$G=\{110\}<100>$ Goss

$$
\begin{aligned}
& C=\{112\}<111>\text { Copper } \\
& S=\{123\}<634>S
\end{aligned}
$$




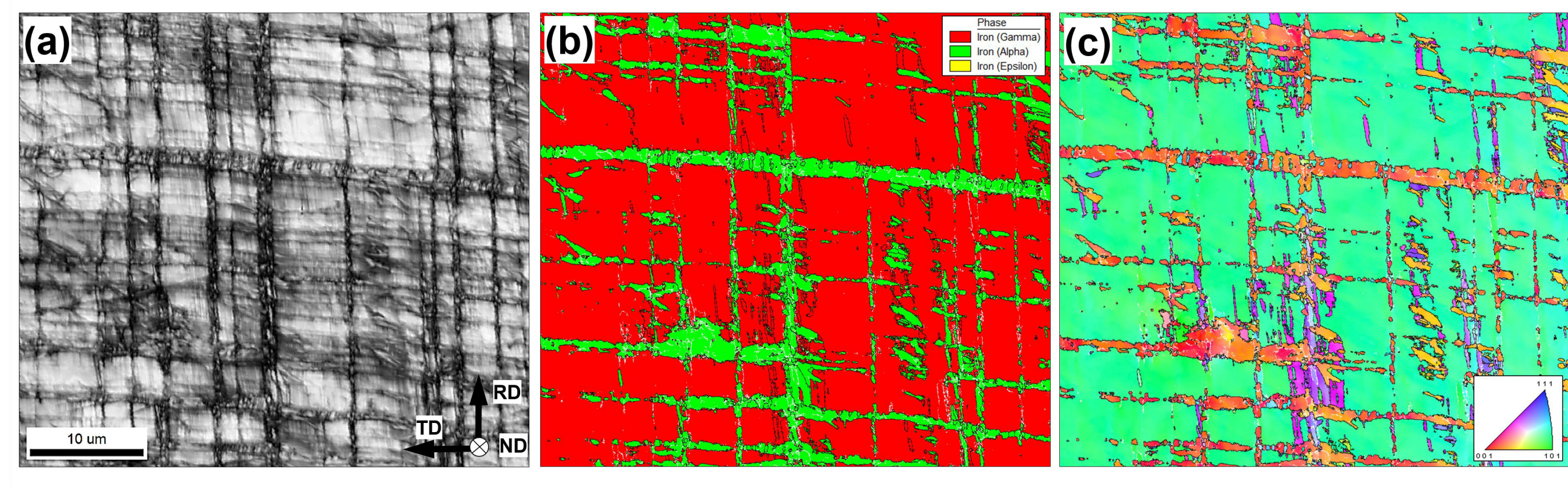




\section{(a) \\ Austenite}

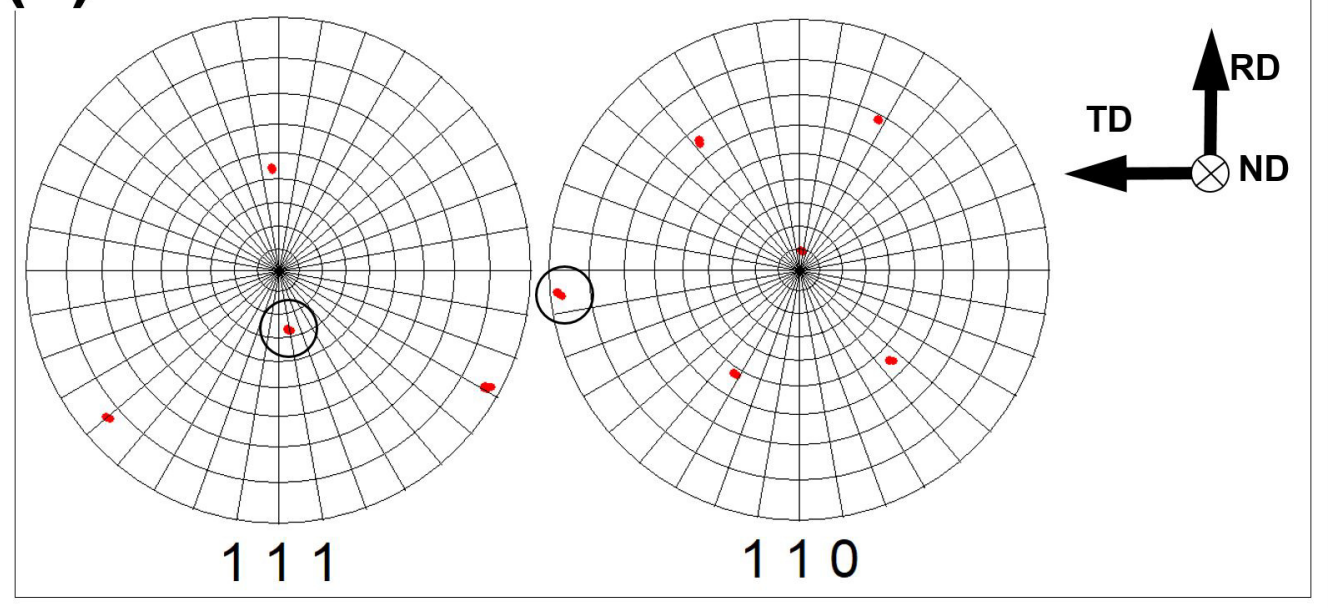

$\alpha^{\prime}$-martensite

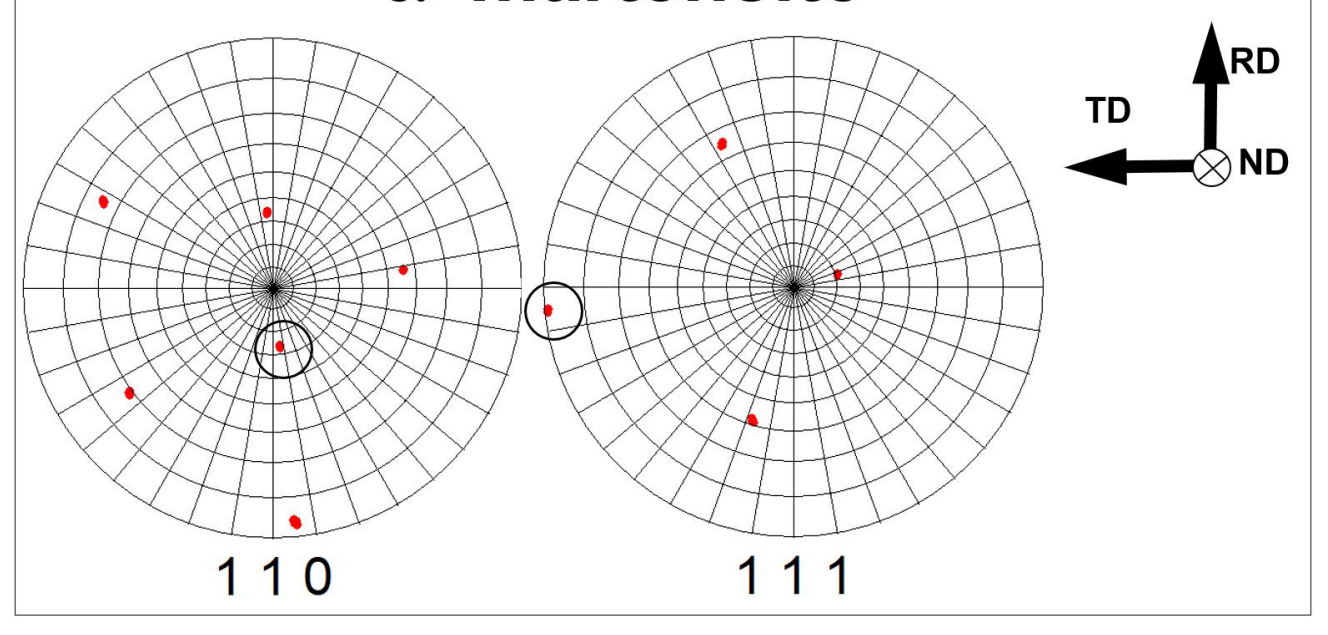

(b) $\quad \alpha^{\prime}$-martensite

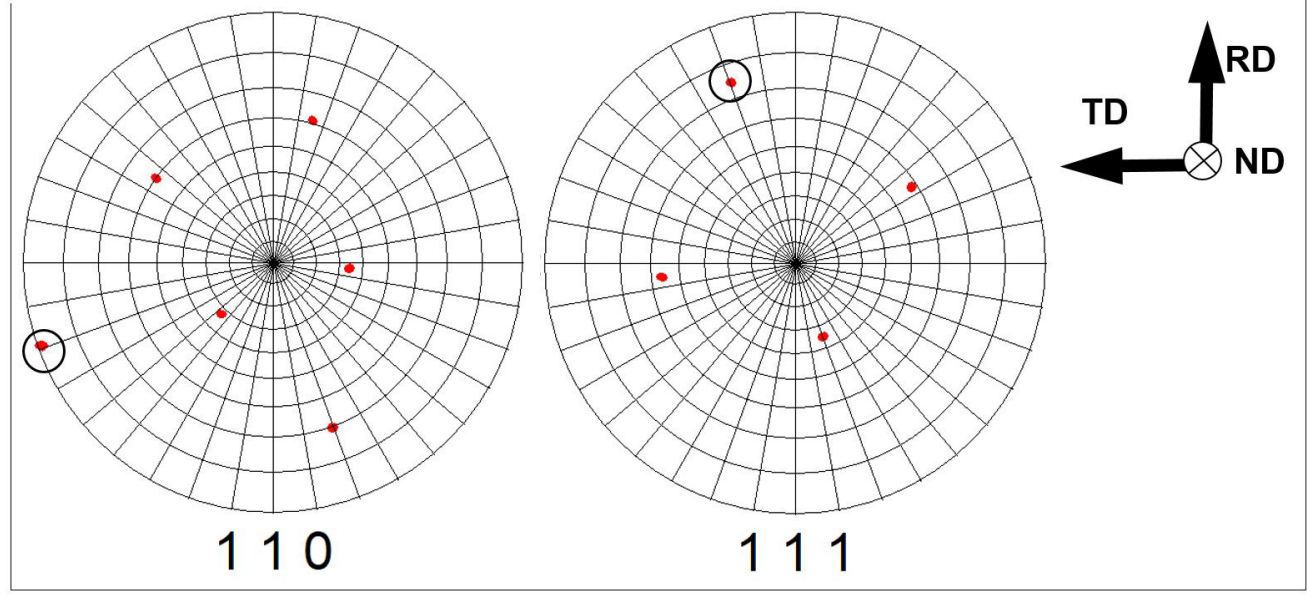

Austenite

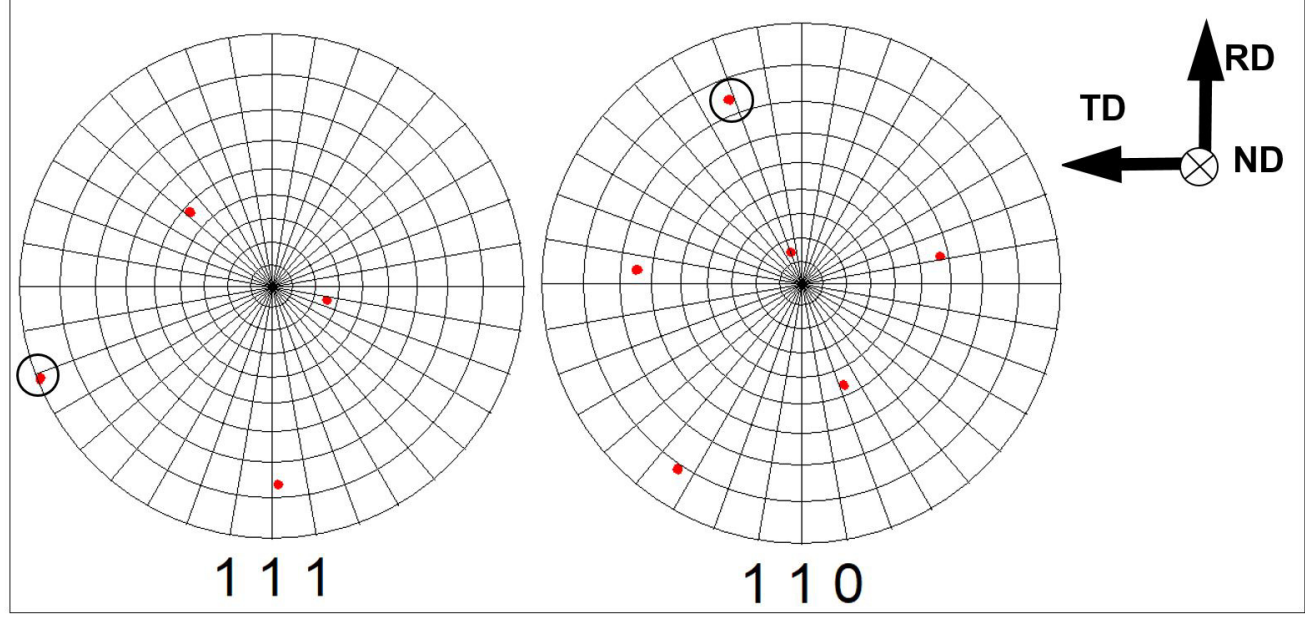



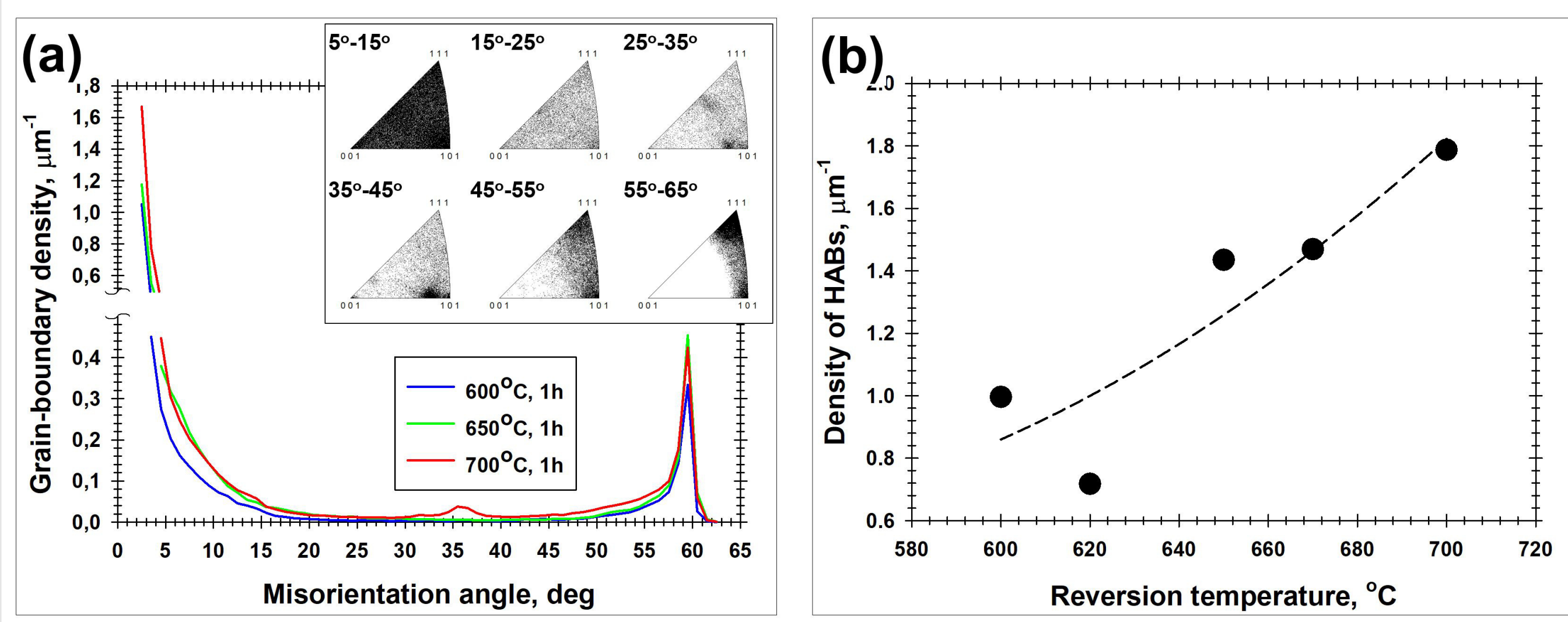


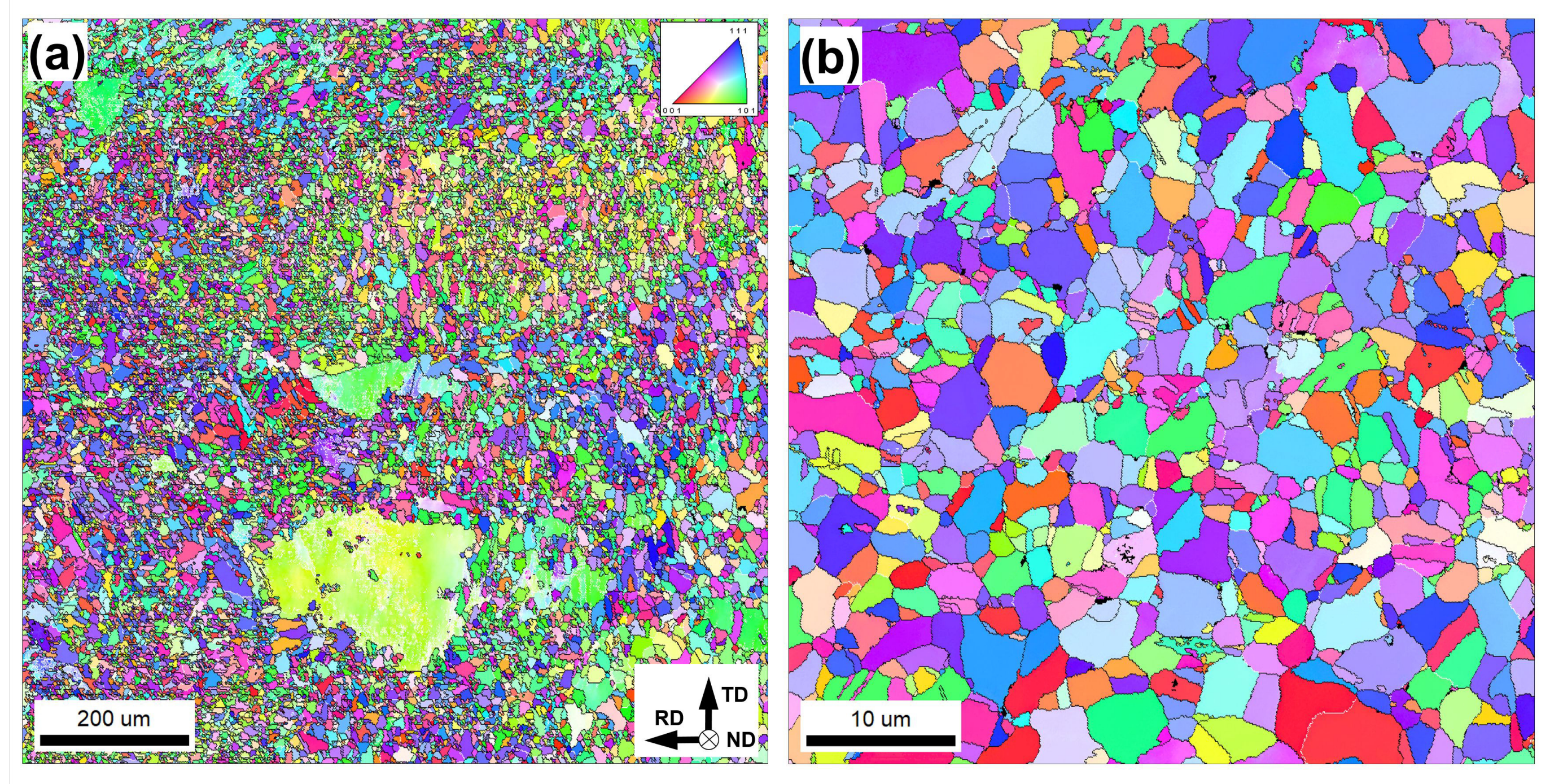




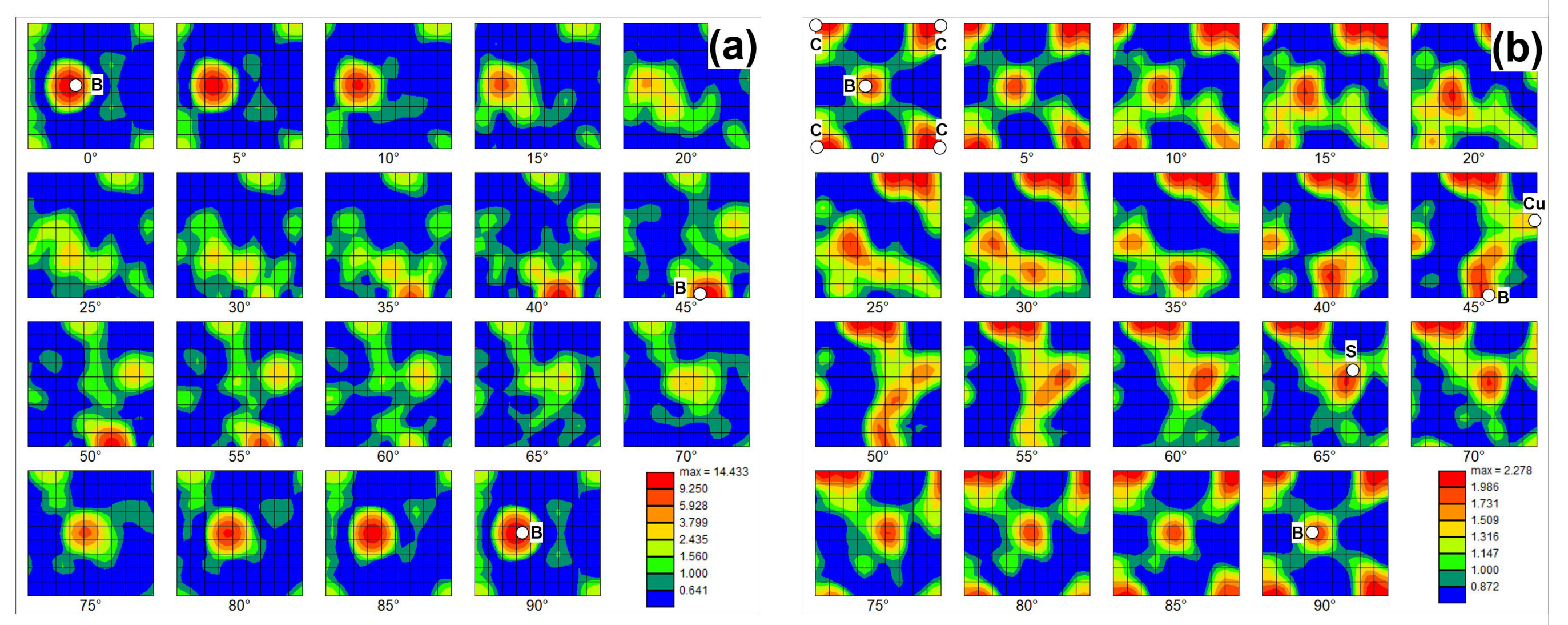

B - Brass $\{110\}<112>$ orientation, Cu - Copper $\{112\}<111>$ orientation, C - Cube $\{100\}<001>$ orientation, $\mathbf{S}-\mathbf{S}\{123\}<634>$ orientation

Constant Angle: $\varphi 2 \quad$ Texture Name: Harmonic: $L=16, \mathrm{HW}=5.0$

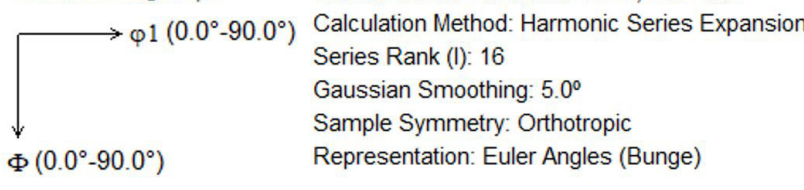



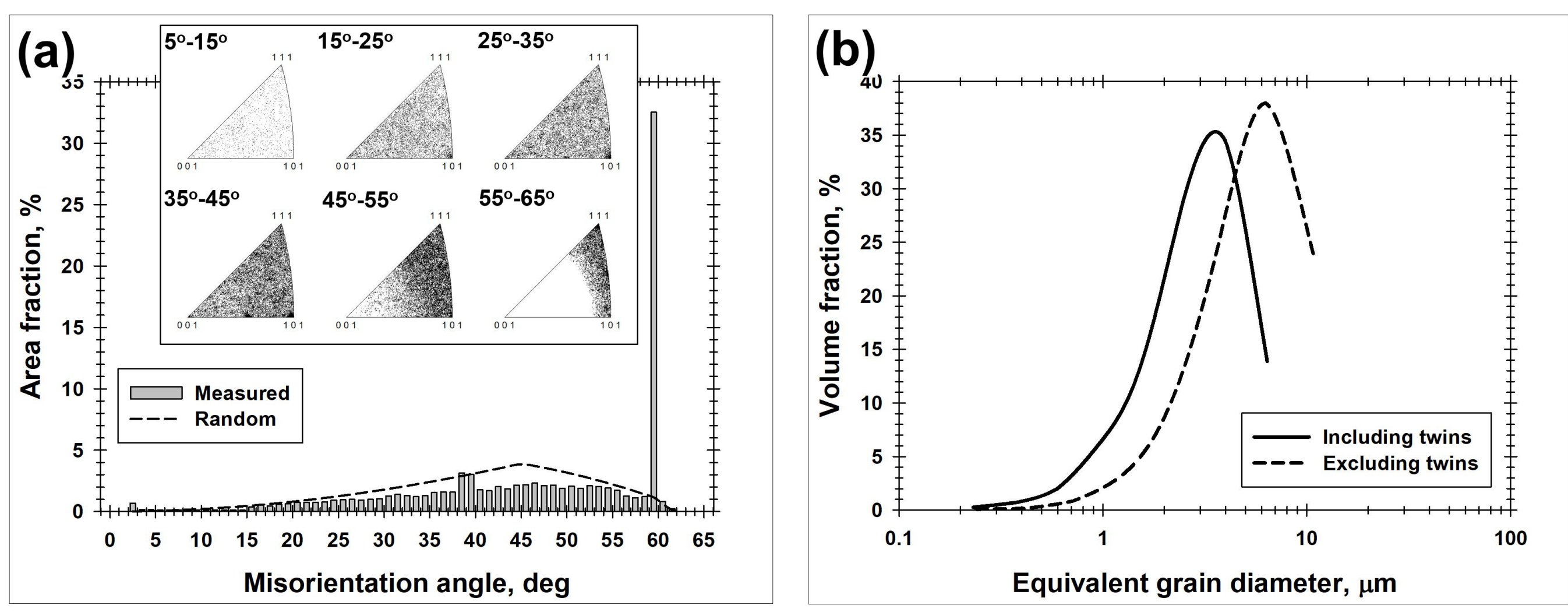